University of Rhode Island

DigitalCommons@URI

Open Access Dissertations

2014

\title{
Horizontal Violence Among Nurses: Experiences, Responses and Job Performance
}

Elizabeth M. Bloom

University of Rhode Island, bbloom1066@aol.com

Follow this and additional works at: https://digitalcommons.uri.edu/oa_diss

\section{Recommended Citation}

Bloom, Elizabeth M., "Horizontal Violence Among Nurses: Experiences, Responses and Job Performance" (2014). Open Access Dissertations. Paper 247.

https://digitalcommons.uri.edu/oa_diss/247

This Dissertation is brought to you for free and open access by DigitalCommons@URI. It has been accepted for inclusion in Open Access Dissertations by an authorized administrator of DigitalCommons@URI. For more information, please contact digitalcommons-group@uri.edu. 
HORIZONTAL VIOLENCE AMONG NURSES: EXPERIENCES, RESPONSES AND JOB PERFORMANCE

BY

ELIZABETH M. BLOOM

A DISSERTATION SUBMITTED IN PARTIAL FULFILLMENT OF THE

REQUIREMENTS FOR THE DEGREE OF

DOCTOR OF PHILOSOPHY

IN

NURSING

UNIVERSITY OF RHODE ISLAND

2014 


\section{DOCTOR OF PHILOSOPHY DISSERTATION}

\section{$\mathrm{OF}$}

ELIZABETH M. BLOOM

\section{APPROVED:}

Dissertation Committee:

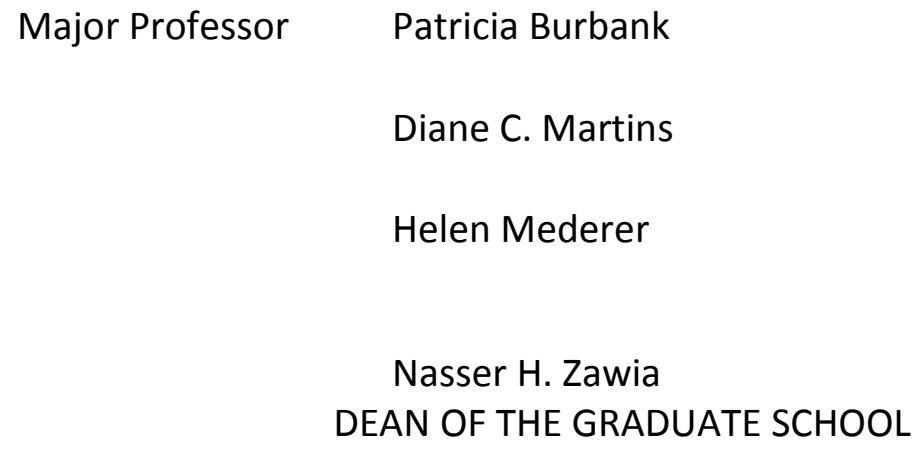

UNIVERSITY OF RHODE ISLAND 2014 


\begin{abstract}
Horizontal violence (HV), or non-physical intergroup conflict that is expressed in overt and covert behaviors of hostility, is pervasive in nursing and has been discussed in the literature for more than two decades. It is costly and has potentially devastating effects including high nurse turnover rates, increased illness, decreased productivity, and decreased quality of patient care. Recognizing how these behaviors are established and sustained is necessary if nurses are to overcome these types of behaviors. This mixed methods study used an online survey to examine 78 hospital nurse's experiences and responses to episodes of HV as well as its effect on job performance. Seven of these nurses answered more in-depth questions during a follow-up interview. Critical Social Theory provided the framework for this study as this phenomenon is thought to be the result of oppression within the nursing profession. Nurses reported that manager and staff support and workplace education were the most helpful in reducing horizontal violence. Increased workload and stress and HV being accepted practice on the unit were factors listed as most important in promoting HV. Nurses also cited reasons why they continue on in their jobs after episodes of HV and behaviors that were successful in addressing HV. Intervention studies are needed to test effective ways of reducing this very difficult behavior among nurses in the workplace.
\end{abstract}




\section{ACKNOWLEDGEMENTS}

I would like to thank my family and friends for their encouragement and support throughout this long process. To my major professor, Dr. Patricia Burbank, for her guidance and patience, they were invaluable. To my dissertation committee, Dr. Diane Martins, Dr. Helen Mederer, Dr. Ginette Ferszt and Dr. Clay Sink for their enthusiasm and willingness to sit on my committee. To my friends and colleagues at St. Joseph School of Nursing, I absolutely, positively could not have done this without your support. I feel honored to work with such terrific people. And last but not least, to the students who I have had the privilege of teaching over the years. You inspired me daily. 


\section{DEDICATION}

To my beloved parents Herbert "Bud" and Katherine "Kate" Creighton who stressed the importance of education to me at a very young age. I miss you every day. 


\section{TABLE OF CONTENTS}

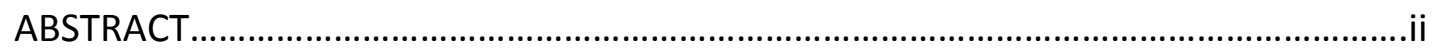

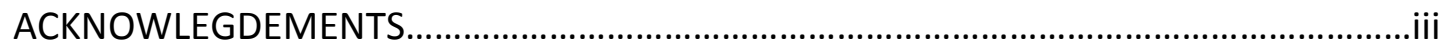

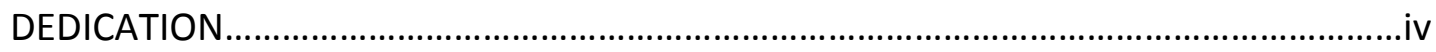

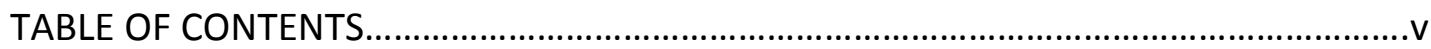

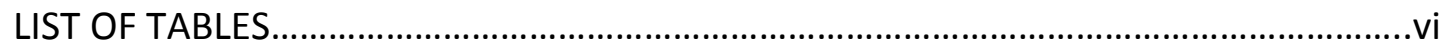

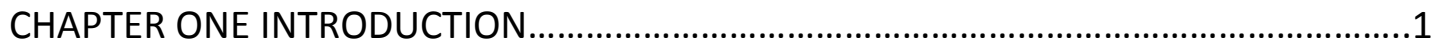

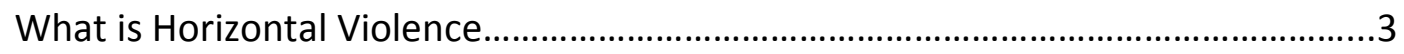

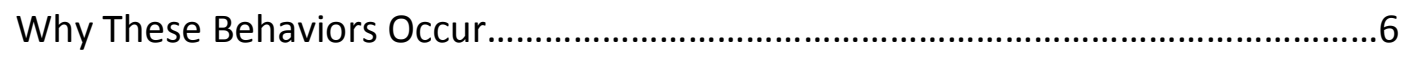

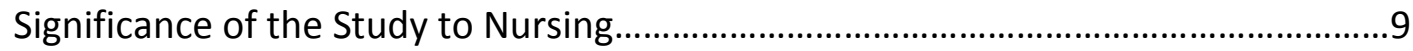

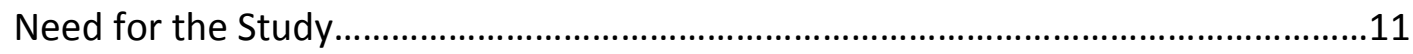

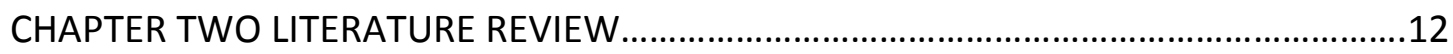

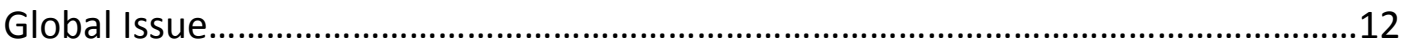

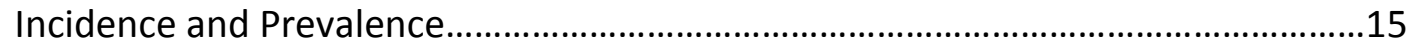

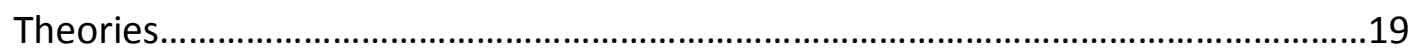

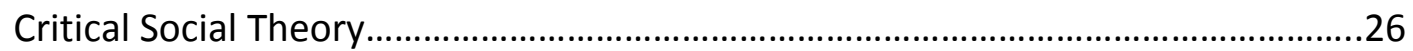

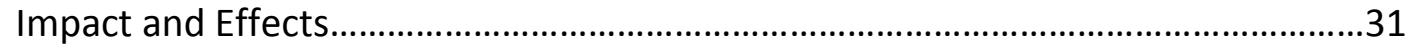

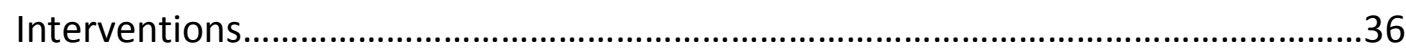

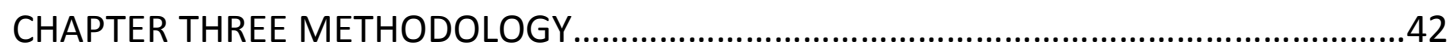

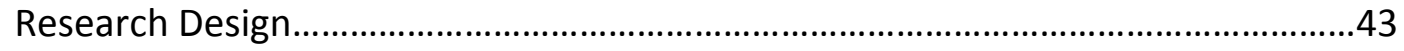

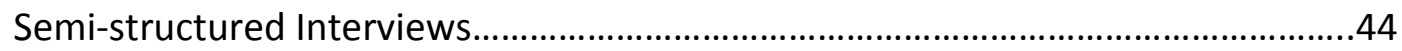




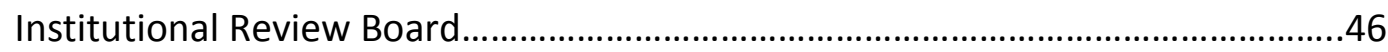

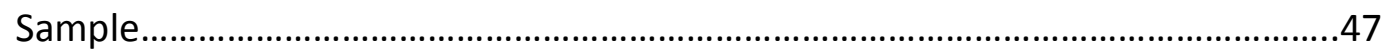

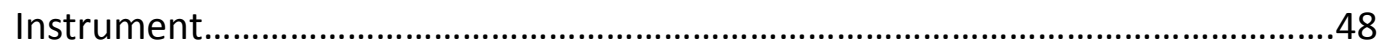

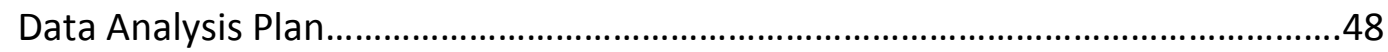

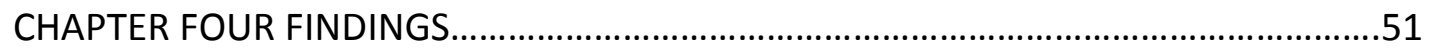

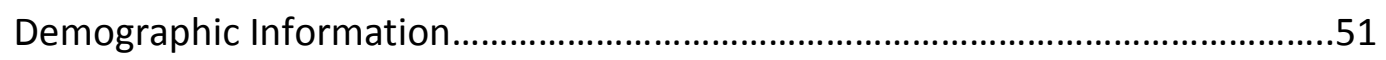

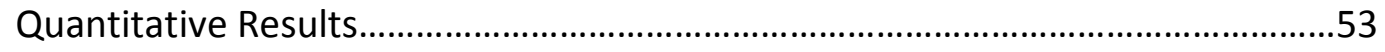

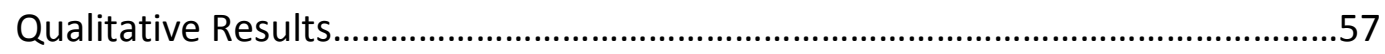

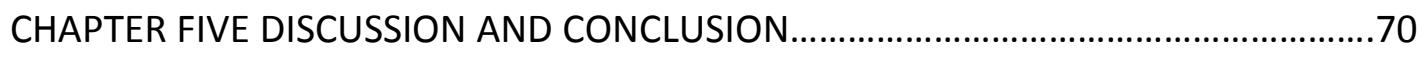

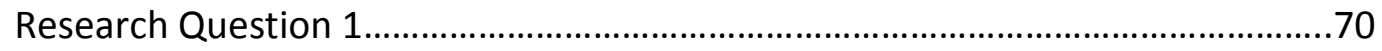

Research Question 2 .....................................................................................

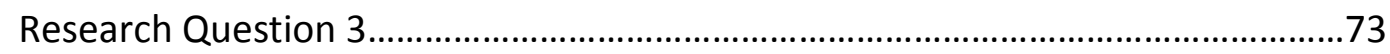

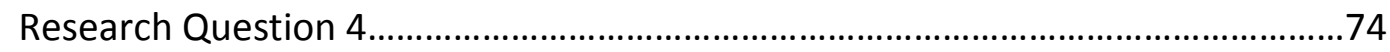

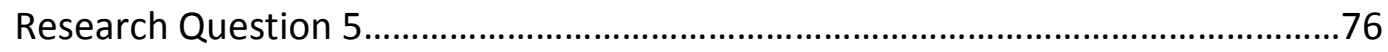

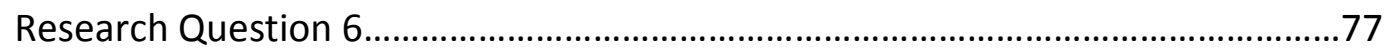

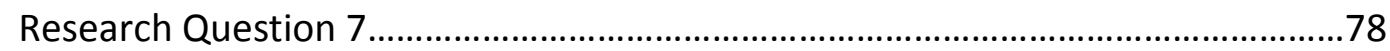

Interpretation of Findings Related to Critical Social Theory..................................79

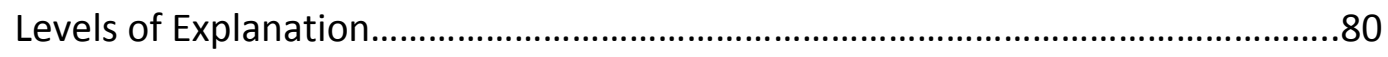

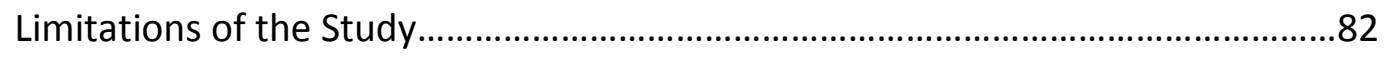

Implications for Nursing Research, Practice and Education....................................84

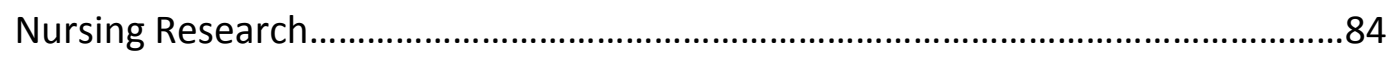


Questions That Need To Be Addressed. .85

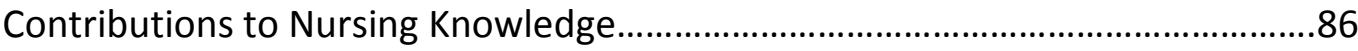

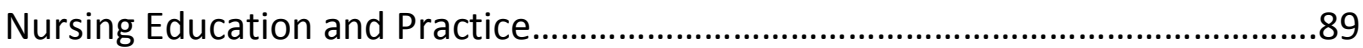

Summary

Appendix A IRB Approval CharterCARE.................................................................91

Appendix B IRB Approval University of Rhode Island..............................................93

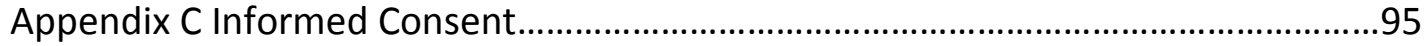

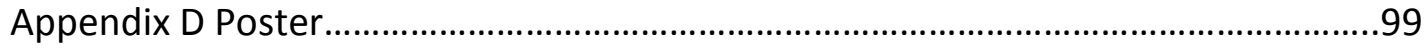

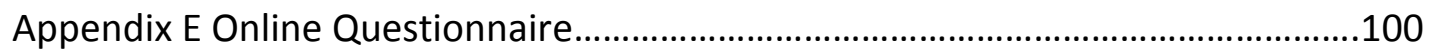

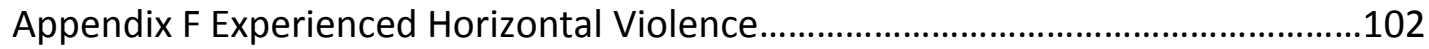

Appendix G Witnessed Horizontal Violence................................................................104

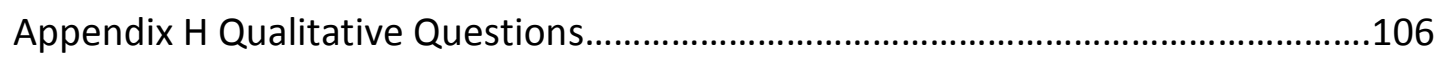

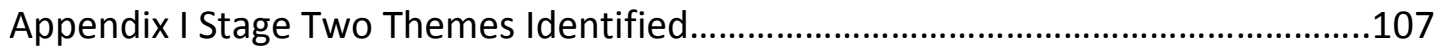

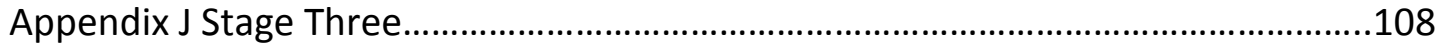

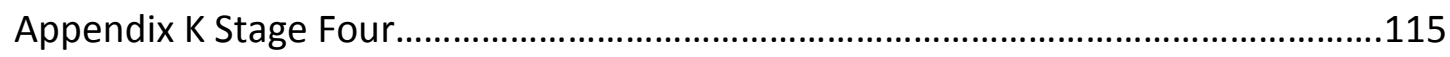

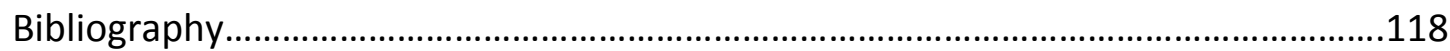




\section{LIST OF TABLES}

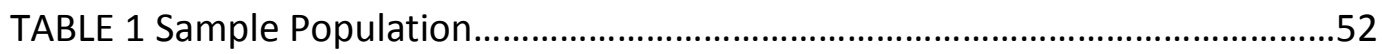

TABLE 2 Person Exhibiting Negative Behavior...........................................................55

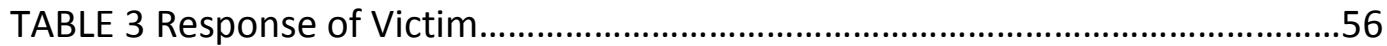

TABLE 4 Factors Increasing Horizontal Violence.................................................56

TABLE 5 Actions Helpful in Reducing Horizontal Violence......................................57 


\section{CHAPTER ONE}

\section{INTRODUCTION}

It has been thirty years since Roberts (1983) first wrote about nurses being an oppressed group, who in their frustration with lack of power and autonomy, act aggressively toward one another. Since then much more research has been conducted that has broadened the descriptors and understanding of the phenomenon of horizontal violence. Horizontal violence in the workplace is an ever increasing concern to the American worker and although horizontal violence is reported in many professional fields, researchers report high instances in the healthcare arenas, specifically among nurses (Craig, 2008; Sofield \& Salmond, 2003). This type of behavior typically has been associated with oppressed groups and usually occurs where there are unequal power relations (Freire, 1968). It is a form of harassment and acts to socialize those who are different into the status quo (Hastie, 2007). Horizontal violence in the workplace is a result of history and politics in western society and is a symptom of an oppressive environment (Hastie, 2007).

Horizontal violence tends to be covert, hard to discern and thus the victim has difficulty in seeking assistance within the job setting (Becher \& Visovsky, 2012). Further, Becher and Visovsky (2012) state that the actual incidence and prevalence of horizontal violence in nursing is hard to know as horizontal violence is often unrecognized and underreported. However, recent research has found that horizontal violence is fairly widespread at $65 \%$ - $80 \%$ of nurses surveyed stating they have either experienced it or witnessed it (Stagg, Sheridan, Jones \& Speroni, 2011; 
Stanley, Martin, Michel, Welton \& Nemeth, 2007; Vessey, Gaffney \& Budin, 2009; Wilson, Diedrich, Phelps \& Choi, 2011).

Hostile interactions directed at nurses in the workplace come from a variety of sources including patients and their families (Farrell, 1999; Farrell, Bobrowski \& Bobrowski, 2006), physicians and other hospital staff (Farrell, 1999; Farrell, Bobrowski \& Bobrowski, 2006; Healthcare Risk Control, 2009; Rosenstein \& O’Daniel, 2005; Rosenstein \& O’Daniel, 2006), and between nursing colleagues (Budin, Brewer, Chao \& Kovner, 2013; Farrell, 1999; Farrell, Bobrowski \& Bobrowski, 2006; Rowel, 2006). These negative behaviors pose a threat to patient safety (McNamara, 2010; McNamara, 2012; Walrafen, Brewer \& Mulvenon, 2012; Sellers, Millenbach, Kovach \& Yingling, 2010), and can result in increased stress levels, frustration, loss of concentration and breakdown in communication (Rosenstein \& O’Daniel, 2005; Sheridan-Leos, 2008; Simons \& Mawn, 2010; Yildirim, 2009). Nurses report that aggression between nurse colleagues or horizontal violence is the most emotionally devastating of all the forms of workplace aggression (Farrell, 1999). The term horizontal violence will be used in this paper because it is derived from oppression theory. Oppression theory, which has its origins in critical social theory, is the most widely cited theory when researching horizontal violence.

A number of different terms have been used in the literature to describe this phenomenon. These include lateral violence (Embree \& White, 2010; Griffin, 2004; Stanley, Martin, Michel, Welton \& Nemeth, 2007); horizontal violence (Duffy, 1995; Lee \& Saeed, 2001; McKenna, Smith, Poole \& Coverdale, 2003; Purpora \& Blegen, 
2012; Thobaben, 2007); workplace aggression (Anderson, 2011; Farrell, 1997, 1999;

Farrell, Bobrowski \& Bobrowski, 2006); bullying (Hutchinson, Vickers, Jackson \& Wilkes, 2005, 2006; Hutchinson, Vickers, Wilks \& Jackson, 2010; Johnson \& Rea, 2009; Randle, 2003; Yildirim, 2009); horizontal hostility (Thomas, 2003); workplace violence (Holmes, 2006; Speedy, 2006); disruptive behavior (Martin, 2008); relational aggression (Dellasega, 2009); disrespect (Parse, 2010); and incivility (Vickers, 2006). Whatever one chooses to call this behavior, one thing is clear; it is a serious issue for nursing.

\section{What is Horizontal Violence?}

Horizontal violence and behaviors that constitute horizontal violence have been described in the literature for many years by various authors and researchers. Duffy (1995) described horizontal violence as non-physical inter-group conflict that is expressed in overt and covert behaviors of hostility. Bartholomew (2006) defined horizontal violence as a consistent hidden pattern of behavior designed to control, diminish or devalue another peer. Stanley, Martin, Michel, Welton and Nemeth (2007) defined this type of behavior as any unwanted abuse or hostility within the workplace. Thobaben (2007) defined horizontal violence as "hostile, aggressive, and harmful behavior by a nurse or group of nurses toward a coworker or group of nurses via attitudes, actions, words and/or behaviors" (p. 82). Purpora \& Blegen (2012) described horizontal violence as behavior that is directed by one peer toward another that harms, disrespects, and devalues the worth of the recipient while denying their basic human rights. According to Tunajek (2007) horizontal violence 
includes "all acts of unkindness, discourtesy, sabotage, divisiveness, infighting, lack of cohesiveness, and unconstructive criticism" (p. 31). It may be overt or covert and can have devastating long-term effects on the recipients. Horizontal violence is a behavior that goes beyond simple rudeness and incivility. It frequently involves subtle or covert acts, rather than direct violence (Hutchinson, 2009). When horizontal violence is covert, it is often very hard to discern, thus the victim has difficulty in seeking assistance in the workplace (Becher \& Visovsky, 2012).

Although there are slight variations in the definitions above, the researchers are in agreement that horizontal violence is violence in the form of action, words, and other behaviors that is directed towards one's peers. It controls, humiliates, denigrates or injures the dignity of another. Horizontal violence reflects a lack of respect for the individual.

This phenomenon in nursing is characterized by such behaviors as "gossiping, criticism, innuendo, scapegoating, undermining, intimidation, passive aggression, withholding information, insubordination, bullying, and verbal and physical aggression" (Baltimore, 2006, p.30). Other behaviors associated with horizontal violence include criticizing, intimidation, blaming, refusing to lend assistance, public humiliation and undermining (Center for American Nurses, 2008; Edwards \& O'Connell, 2007; Vessey, DeMarco \& DiFazio, 2011). It is also characterized by the presence of a series of undermining incidents over time as opposed to one isolated incident (Jackson, Firtko \& Endenborough, 2007). 
Repeated incidents of horizontal violence are overwhelming to the recipient and causes symptoms of depression (Becher \& Visovsky, 2012; McKenna, Smith, Poole \& Coverdale, 2003; Rowell, 2006; Thobaben, 2007), reduction in confidence or selfesteem (Bartholomew, 2006; McKenna, Smith, Poole \& Coverdale, 2003; SheridanLeos, 2008; Thobaben, 2007), anxiety, and sleeping disorders (Rowell, 2006; Sheridan-Leos, 2008; Thobaben, 2007). Hastie (2002) reported that acts of horizontal violence results in the subjects feeling of low morale, apathy and disconnectedness. Nurses can also experience physical symptoms, such as weight gain or loss, hypertension and irritable bowel syndrome (Rowell, 2006). Thomas (2003) found that continued exposure to these behaviors drains nurses of their enthusiasm for the profession and these nurses report the highest rate of burnout. Further, Woelfe and McCaffrey (2007) stated that this type of behavior can lead to high stress conditions, resulting in nurses not being able to perform at their optimal level and the result can be poor patient care.

One of the most difficult consequences of horizontal violence is leaving one's job. According to Embree and White (2010), approximately 60\% of new nurses leave their first place of employment within the first 6 months because of horizontal violence. This would suggest that $40 \%$ of new nurses who experience this type of behavior stay in their current positions. Questions about why a nurse stays with an organization after having experienced this type of behavior remain unanswered. A clear understanding of this phenomenon may lead to interventional studies that could lead to improved work environments and improved retention. 
The literature suggests that horizontal violence is being recognized and named as a phenomenon in nursing which gives permission to nurses to talk about their own experiences of nurse-on-nurse aggression (Freshwater, 2000). What is not clear in the literature, however, is what nurses have found to be helpful to combat episodes of horizontal violence and what might contribute to this behavior. While several studies state that horizontal violence affects job performance (Bowles \& Candela, 2005; Craig, 2008; Stanley, Dulaney \& Martin, 2007; Townsend, 2012), they stop short of explaining how this occurs. Although many nurses leave their positions after experiencing horizontal violence, why do some nurses continue on in their position instead of leaving? In order to identify better interventions these gaps in the literature must be filled. Careful attention must be given to implementing effective strategies to empower nurses to confront, diffuse and resist adopting these negative behaviors.

\section{Why These Behaviors Occur}

The profession of nursing can at times be considered a paradox. Nurses provide care to the sick or injured. They educate, nurture and lead and are frequently rated as the most trustworthy of all the professions by the American public (Moye, 2012). How is it, then, that nurses are also known for exhibiting hostile behavior towards one another?

Nurse against nurse aggression has historically been attributed to oppressed group behavior (Cox, 2001; Duffy, 1995; Fletcher, 2006; Roberts, 1983). Researchers assert that nurses, as a group, are oppressed by more powerful groups such as physicians or 
hospital administration (Croft \& Cash, 2012; Farrell, 1999; Weinard, 2010). Nursing is described in the literature as a profession that is exploited for the benefit of organized medicine (Duffy, 1995; Fletcher, 2006; Longo \& Smith, 2011; Roberts, 1983). Oppression of nurses as a group is believed to result in nurses disliking themselves and their colleagues. A lack of regard for self and other nurses is believed to ultimately result in horizontal violence. Several researchers (Alspach, 2007; Hutchinson, Jackson, Vickers \& Wilkes, 2006) have argued that while oppressed group behavior has provided some understanding of horizontal violence between nurses at work, the theory does not recognize other environmental issues found in the nursing workplace that may contribute to the phenomenon.

Farrell (2001) discussed three perspectives through which horizontal violence can be considered. A micro perspective looks at horizontal violence at the individual level. For example, we can choose to act negatively or positively toward one another. A meso perspective looks at the structure of the organization including workplace practices. Lastly, a macro perspective looks at a nurse's position within the organization and the marginalization and disempowerment that may occur. He believes that by combining these three perspectives, a more complete understanding of horizontal violence will emerge.

Gaddis (2007) also spoke to levels within the workplace focusing on macro cultures, mini cultures, and micro cultures. Macro cultures refer to the organizations overall culture and are the behaviors that are accepted and supported in the workplace environment. Within the greater macro culture there exists numerous 
mini cultures. These mini cultures consist of different groups whose behaviors are supported and accepted within that group. Micro cultures then, are at the individual level.

Freshwater (2000) argued that the cultural narrative in nursing is to be subordinate. Going against these narratives requires energy and when nurses are tired and over worked, it is difficult to harness the energy to challenge the cultural narrative. Further, the author suggested that the educational system in nursing may have contributed to the felt oppression by going along with the cultural narratives regarding nurses traditionally being seen as subordinate.

The demands of today's healthcare system often create a stressful environment that may lead to unprofessional behavior (Vessey, DeMarco, Gaffney \& Budin, 2007). Healthcare is much more complex today and requires interactions of a larger number of caregivers and support personnel than in the past (Porto \& Lauve, 2006). These changes in the work climate have had an adverse effect on the work environment, and as a result of increased stress levels, incidents of unprofessional behavior occur much too often.

The literature about horizontal violence in the nursing workplace reveals that individuals tend to emulate the behaviors of the group members they most closely work with as a way to be accepted by them. When maltreatment of a nurse is occurring, other nurses on the unit may model the behavior of the offending individual as a way to be accepted (Walrafen, Brewer \& Mulvenon, 2012). 
Nurses as healthcare professionals are in a position to identify when horizontal violence occurs. With increased awareness and sensitivity, nurses may better be able to monitor themselves, as well as to assist their peers to recognize when they are participating in negative behaviors (Walrafen, Brewer \& Mulvenon, 2012).

\section{Significance of the Study to Nursing}

Nursing students entering their first clinical experience are excited and enthusiastic. They should be nurtured and supported as they learn what it is to become a nurse. At times they can be treated poorly by the very nurses they emulate. This was the impetus that generated interest in this topic. How is it that people in a caring profession fail to care for each other? What is it about the profession that causes these behaviors to occur? Also, what is it about a particular nurse who, having experienced horizontal violence continues to thrive in the profession?

Studies have shown that horizontal violence has detrimental effects on workplace satisfaction and workforce retention (Cox, 2001; Becher \& Visovsky, 2012;

Maddelena, Kearney \& Adams, 2012; Simons, 2008; Simons \& Mawn, 2010; Sofield \& Salmond, 2003), on the psychological and physical health of nurses (Corney, 2008; Farrell, 1997; Farrell, Bobrowski \& Bobrowski, 2006; McKenna, Smith, Poole \& Coverdale, 2003; Yildirim, 2009), and on the quality of patient care health outcomes (Joint Commission, 2008; Purpora \& Blegen, 2012; Vessey, DeMarco \& DiFazio, 2011; Woelfe \& McCaffrey, 2007). Most of these studies to date focus on the prevalence, causes, and effects of horizontal violence using quantitative methods without 
exploring the actual experiences of nurses during episodes of horizontal violence, or on their short and long term responses to these incidents. It is because of the consequences of this destructive behavior that horizontal violence must be further studied and understood. The experience of this behavior is psychologically distressing, threatens patient safety, nurse moral, and nurse retention (Joint Commission, 2008; McKenna, Smith, Poole \& Coverdale, 2003; Simons, 2008). While there has been evidence that this type of behavior exists across all health care professional groups, studies have shown that this problem is greatest within the nursing profession, both in its prevalence and in the level of distress it causes (Farrell, 1997, 1999; Randle, 2003; Woelfe \& McCaffrey, 2007).

The first several years of practice have been identified in the literature as being important confidence building years for nurses; however, several studies indicate that newly licensed nurses are subjected to a variety of unprofessional behavior that diminish confidence and self-esteem. Programs must be developed which effectively reduce horizontal violence, and emphasis should be placed on preventing this occurrence. Prevention begins with education and training of staff. The literature suggests that the majority of newly registered nurses have little to no undergraduate education regarding horizontal violence and did not receive any training once employed to help them cope with this unprofessional behavior.

The literature has been clear regarding horizontal violence as an identified threat to the quality of patient care and nurse well-being. What is not clear, however, is what nurses have found to be helpful to combat episodes of horizontal violence and 
what might contribute to this behavior. While several studies state that horizontal violence affects job performance (Bowles \& Candela, 2005; Craig 2008; Stanley, Dulaney \& Martin, 2007; Townsend, 2012), they stop short of explaining how this occurs. And, why after experiencing horizontal violence do some nurses continue in their position? In order to identify better interventions these gaps in the research must be filled. Careful attention must be given to implementing effective strategies to empower nurses to confront, diffuse, and resist adopting these negative behaviors.

\section{Need for the Study}

The concept of horizontal violence has been discussed for two decades. It is costly and has potentially devastating effects. It has been linked to high nursing turnover rates, increased illness, decreased productivity, and lower quality of patient care. As a result, there is recognition that horizontal violence is a pervasive and harmful feature which exists in most workplaces. Recognizing how these behaviors are established and sustained is a must if nurses are to overcome these types of behaviors. This study will contribute to the understanding of horizontal violence and ways to combat this behavior. Reasons why a nurse stays with an organization after experiencing this type of behavior will contribute to nursing's knowledge about this sensitive topic. This study will enhance the understanding of negative nurse-to-nurse interactions through the interviews with nurses who have experience with this phenomenon. 


\section{CHAPTER TWO \\ LITERATURE REVIEW}

The nursing work environment involves complex interpersonal relationships within a social and political context (Vessey, DeMarco \& DiFazio, 2011). Nurses balance a multitude of tasks and are accountable to many people. Most agree on the hectic nature of nursing practice and the constraints nurses face every day in delivering quality care (Taylor, 2001). As a result of the demands of the healthcare system, the practice environment can be quite stressful. This in turn may lead to unprofessional behavior or horizontal violence. This chapter will explore the literature related to this type of behavior and its incidence and prevalence. Theories that have been used by researchers to explain this behavior will be discussed. Critical social theory will be presented, including what this theory can offer a researcher when studying this phenomenon. Finally, the impacts and effects of this behavior will be presented followed by interventions that have been utilized to address this behavior.

\section{Global Issue}

A review of the literature reveals that conflict among nurses has been identified as a significant issue within healthcare settings around the world (Almost, 2006).

Studies conducted in Australia and Canada have shown that the frequency of conflict in nursing is cause for concern (Almost, 2006; Corney, 2008; Croft \& Cash, 2012; Laschinger, Grau, Finegan \& Wilk, 2010; Laschinger, Leiter, Day \& Gilin, 2009; Smith, Andrusyszyn \& Laschinger, 2010). Lambert, Lambert and Ito (2004) reported on nurses in Japan who experience conflict with other nurses and their intent to leave 
their current nursing position. McKenna, Smith, Poole and Coverdale (2003) found high levels of interpersonal conflict within one year after graduation in New Zealand's new nurse population. Indeed, there have been countless studies conducted in the United States with regards to this type of behavior and its impact on the nursing profession.

A study conducted by Croft and Cash (2012) used a postcolonial feminist lens to study contributing factors to bullying and lateral violence in nursing in British Columbia. The authors found that bullying and lateral violence is deeply institutionalized and that nurse managers and organizations need to create a civil workplace.

As part of his doctoral research, Lewis (2006) examined bullying within nursing from a "micro-sociological perspective" with the intent of identifying factors contributing to its causes and continuation within the nursing profession. The author stated that the growth and continuation of workplace abuse in the United Kingdom within healthcare, and in nursing in particular presents a worrying problem. Further, evidence from the United Kingdom healthcare system suggests that up to $85 \%$ of nurses were witnesses or have been targets of bullying. The overall findings from the research point strongly to bullying activity being a learned behavior within the workplace.

Corney (2008) conducted a study in the United Kingdom to look at horizontal violence utilizing a Heideggerian hermeneutic phenomenology to illuminate the phenomenon of bullying and answer the question "How does it feel to be bullied?" 
Results showed that despite the physical and psychological repercussions, victims were afraid to speak out which resulted in feelings of shame and inadequacy thus preventing them from seeking support.

Canadian researchers have identified incivility and bullying behaviors as a concern with regard to recruitment and retention issues. Laschinger, Leiter, Day and Gilin (2009) conducted a study of nurses employed in 5 different Canadian hospitals the aim of which was to examine the influence of empowering work conditions and workplace incivility on nurses' experiences of burnout and important nurse retention factors identified in the literature. The authors stated that a major cause of turnover among nurses is related to unsatisfying workplaces and that incidents of incivility are on the rise. The authors found that nurses' perceptions of empowerment, supervisor incivility, and cynicism were strongly related to job satisfaction, organizational commitment, and turnover intentions.

Farrell, Bobrowski and Bobrowski (2006) conducted a study the aim of which was to identify the occurrence of workplace aggression experienced by nurses in Tasmania, Australia. A specially designed questionnaire was sent to all nurses registered with the Nursing Board of Tasmania. The authors had a response rate of $38 \%$ the results of which indicated that nurses were subjected to considerable amounts of aggression at work. Among those identified as perpetrators were nursing colleagues. This abuse influenced nurses' desire to stay in nursing, productivity and potential to make errors. Despite this, the authors found that they were reluctant to 
report this behavior. In addition, nurses were distressed because they could not provide the appropriate care to meet patient needs.

From this review, it can be seen that horizontal violence is a global issue; the preponderance of the literature supports that this type of behavior is a great problem intra-professionally within nursing; both in its prevalence and level of distress it causes (Farrell, 1997, 1999; Randle, 2003; Vessey, DeMarco \& DiFazio, 2011; Woelfle \& McCaffrey, 2007).

\section{Incidence and Prevalence}

The actual incidence and prevalence of horizontal violence in nursing is relatively difficult to know with certainty. The reasons for this is that horizontal violence often is unrecognized and underreported (Beecher \& Visovsky, 2012), and there is difficulty tracking events secondary to definitional inconsistencies and measurement problems (Vessey, DeMarco \& DiFazio, 2011). Recent research, however, suggest that horizontal violence is widespread with $65 \%-80 \%$ of those nurse surveyed either experiencing it or witnessing it (Stagg, Sheridan, Jones \& Speroni, 2011; Vessey, DeMarco, Gaffney \& Budin, 2009; Wilson, Diedrich, Phelps \& Choi 2011).

This type of behavior is not limited to practicing nurses. Nursing students have reported acts of horizontal violence during their clinical practicum. A study conducted in Australia reported that $50 \%$ of nursing students experienced horizontal violence during their clinical rotation (Curtis, Bowen \& Reid, 2007). Students also reported feelings of powerlessness and feeling humiliated by seasoned nurses. Thomas and Burk (2009) conducted a study of junior level students the results of 
which showed that horizontal violence occurs as early as the first interaction with professional nurses in a clinical setting.

Farrell (1997) utilized a qualitative approach in an initial study to describe nurses' views regarding the nature and extent of aggression in the clinical setting. Finding indicated that nurses are most concerned about their colleagues' aggression towards them. Colleague abuse ranged from non-verbal innuendo to physical assault. Nurse Managers were criticized for failing to implement supportive measures when aggression did happen, or take appropriate action to prevent its recurrence. The author stated that much of the aggression reported could be seen as a breakdown in "relationship rules" such as failure to respect privacy, unwillingness to help out, and failure to keep confidences.

McKenna, Smith, Poole and Coverdale (2003) conducted a descriptive study which explored the prevalence of lateral violence experienced by 1,169 nurses residing in New Zealand in their first year of practice. One hundred percent of the respondents had been involved in lateral violence in some way. The first year of practice is important to nurses in order to build confidence, making horizontal violence at this time especially damaging.

Newly registered nurses are at a high risk for experiencing lateral violence. Sheridan-Leos (2008) reported a study of 551 newly registered nurses who had experienced lateral violence. The nurses were subjected to rude, abusive or humiliating comments. Over a third of the participants reported blocked learning 
experiences and neglect, and felt that they were given too much responsibility for their level of nursing.

Walrafen, Brewer and Mulvenon (2012) conducted a study utilizing a mixed method descriptive design to fully describe the participant's experiences with horizontal violence and to achieve a thorough understanding of the phenomenon. The results of the questionnaire revealed that as many as $77 \%$ of nurses personally witnessed a peer as a victim of negative behavior as well as experienced the behavior themselves. Behaviors included backstabbing, failure to respect the privacy of others, nonverbal negative innuendo, and bickering among peers. The qualitative portion of the study revealed the following themes; sadly caught up in the moment, overt and covert maltreatment, and commitment to positive change in the workforce. Individual responses to the qualitative questions provided rich descriptions of the nurses as observers and victims.

Stanley, Martin, Michel, Welton and Nemeth (2007) undertook a study to measure perceived incidence and severity of lateral violence in response of attendees to a presentation on lateral violence given within the institution they worked for. The researchers developed a questionnaire, the Lateral Violence in Nursing Survey, which was designed to measure perceived incidence and severity of lateral violence. The participants in the study were not acquainted with the term lateral violence although they were familiar with the types of behavior that define it. The authors reported that of the approximately 1850 persons contacted, 663 responses were received generating a response rate of $36 \%$. The majority of the respondents indicated that 
they were often treated with courtesy and respect by coworkers. However, $46 \%$ of the respondents reported lateral violence behaviors were very serious in their work areas. Lateral violence was identified as a major cause of stress and tension and $65 \%$ reported more frequent use of lateral violence behaviors by their coworkers. This study brought to attention the critical role of management in establishing an appropriate tone and culture on nursing units.

Morrow (2008) conducted a study to explore the lived experience of the transition of new nursing graduates in their first year of practice. The author wanted to identify the implications to nursing and actions required to support new graduates in their transition to practice. The author conducted a literature search to uncover what is known about the transition of new graduates, identify gaps in knowledge, and reveal data and implications for nurse managers. It is well known that the first few months of nursing can be very challenging and stressful for new nursing graduates and it is an important confidence building phase. Other themes that emerged from the literature review with regards to what is known about new graduate transitions include role stress and role ambiguity, differing expectations and values and moral integrity. The author goes on to state that despite the large amount of literature over the past three decades, the experience of graduate nurses has not improved. They continue to be marginalized and disenfranchised. The author concludes that the exploration of the experience of new graduate transitions in their first year of practice reveals ongoing challenges and historical inaction. Further, nurse managers 
must take action to resolve the discourse of new graduate transition in the workplace.

Yildirim (2009) conducted a cross-sectional and descriptive study for the purpose of determining the rate and nature of workplace bullying experienced by nurses who work in healthcare facilities and the effects on nurses' practice and depression status. The sample for this research study included a total of 286 registered nurses employed in a teaching hospital. A five section survey form was used for the collection of research data. The results showed that $21 \%$ of the participants had been directly exposed to bullying. The most common type of bullying behaviors was attacks on professional status, followed by attacks on personality. Further, the authors found that $45 \%$ of the nurses participating in this research study had symptoms of moderate or severe depression. The authors concluded that psychologically violent behaviors in the nursing profession occur frequently and even intensely at times.

These authors and studies clearly indicate that, regardless of what the behavior is called workplace bullying is clearly a measurable problem. Studies consistently support that it negatively affects the psychological, social, and physical status and job performance of nurses.

\section{Theories}

The theory of Oppression has been widely used by researchers when studying horizontal violence in nursing. Oppressed groups are those that are controlled and exploited by others possessing greater power, prestige, and status (Simons, 2008). 
When researchers attempt to explain horizontal violence in nursing, they most often turn to Freire's (1968) oppressed group behavior model. In Freire's model, oppression is characterized by assimilation, marginalization, self-hatred, low selfesteem, submissive behaviors and horizontal violence. The values of the oppressors are internalized by the oppressed. The oppressed group then attempts to assimilate themselves into the powerful group by adopting the group's values. With successful assimilation of the powerful group's values, the oppressed become marginalized (Mendez, 2011). Oppression theory helps to explain that the behaviors of horizontal violence aren't necessarily directed at the individual but are rather a response to the situation in which the nurse finds her/himself.

The high incidence of nurse on nurse aggression is often attributed to the fact that nursing is historically a female profession and, thus, evidences characteristics of an oppressed group. These characteristics comprise low self-esteem, self-hatred, passive-aggressive behaviors, and in-fighting among group members. The oppressed group typically develops aggression and anger toward the oppressor but does not express these emotions for fear of retaliation. Rather, they displace this aggression within the oppressed group with subsequent infighting (Dunn, 2003).

Paolo Freire (1968) is credited as first describing oppressed group behavior in his observations of colonized Africans, South Americans, African Americans, Jews and American feminists (Roberts, 1983). Freire found that subordinate groups learn to dislike themselves and their attributes because the dominant group sets the norms for what is valued. He theorized that oppressed people internalize their situation by 
adopting the dominant group's beliefs and values while minimizing their own. Oppressed people begin to act like those who oppress them while remaining submissive to them. This in turn leads to dissatisfaction for their own group and results in the oppressed becoming the oppressors. Building on this work, Roberts (1983) proposed that nurses have worked in a situation of oppression since the early 1900s when they began caring for patients in hospitals controlled by male physicians and administrators.

Roberts (1983) described how nurses exhibited oppressed group behaviors because of the frustration and powerlessness that they experienced as a result of actions from those higher positions. Not daring to retaliate towards management, the nurses lash out against each other and those of lesser status. Roberts further maintained that nursing leaders in management tended to side with hospital administrators and physicians against their own colleagues. Nurses traditionally are educated in teams; however, physicians have traditionally been educated to believe that they are in charge. This according to Rowell (2007) is a basis for stress between physicians and nurses. Oppressive behavior related to the perception of being subordinate to a more powerful group affects nurse-physician relationships as well as, and perhaps most distressing, nursing peer relationships. In one particular study conducted on horizontal violence in nursing, nurse on nurse aggression was seen as the most distressing form of horizontal violence (Farrell, 1997).

Farrell (2001) conducted a critical analysis of an extended literature review to develop a conceptual framework to account for interpersonal conflict in nursing. 
Nursing as an oppressed discipline was addressed and the author suggests that intrastaff conflict in nursing is characteristic of nurses' oppressed status. He stated that while this perspective is widely used, it is only one consideration in understanding horizontal violence.

Although many authors have utilized oppression theory when conducting research on horizontal violence, some state that while oppression perspectives can be insightful, it may be limiting in that it omits a deeper analysis necessary for a fuller understanding and offers little with regards to resolution of the problem.

Symbolic Interactionism is a sociological perspective that has been utilized by researchers when studying lateral violence. It is derived from American pragmatism and particularly from the work of George Herbert Mead. Symbolic Interactionism posits that people's selves are social products, but that these selves are purposive and creative. People act towards things based on the meaning those things have for them. These meanings are derived from social interaction and modified through interpretation (Blumer, 1969).

Herbert Blumer (1969) is credited with coining the term symbolic interactionism. He identified three basic principles of the theory. First is that of meaning. The principle of meaning states that humans act towards people and things based upon the meaning that they have given those people or things. The second principle is language. Language gives people a means by which to negotiate meaning. The third principle is that of thought where thought modifies each person's interpretation of symbols. Thought requires imagining different points of view (Nelson, 1998). 
Symbolic Interactionist researchers investigate how people create meaning during social interactions. One of the central ideas in symbolic interactionism is that people act as they do because of how they define situations. Lewis (2006) was particularly interested in exploring how the meaning of bullying was connected to situations of bullying. Symbolic interactionism guided this study because the approach, according to Lewis, seemed suitable in investigating a nurse's world and in particular relationships. This in turn could lead to an understanding of bullying's social construction.

The Person Environment Congruence Theory was used in a study which looked at nurses work environments and the potential for work place violence (Dendas, 2004). This theory argues that people either fit in their environment of they do not. The environment is seen as exerting multiple demands upon individuals and has been recognized as one of the factors that lead to acts of violence. When the individual and the environment fit well together, or are congruent, satisfaction and fulfillment results. A lack of fit or congruence leads to a negative outcome which could result in horizontal violence.

Clegg's Circuits of Power Model was used by Hutchinson, Jackson, Vickers and Wilkes (2006) to explain how bullying can become so normalized within an organizational culture that it is almost invisible. The authors of this study stress that in order to understand bullying one must give consideration to the concept of power and the working environment itself. In an attempt to understand the relationship between power and bullying in nursing, the authors consider Foucault's conceptions 
of power and Clegg's Circuits of Power Theory. According to the authors, when applying both Foucault's and Clegg's approaches to conceptualizing bullying in nursing, nurses seek to establish ways of critically exploring their workplace experiences. The circuits of power model highlight the complex flow of power that operates within organizations. This can be illuminating and allow closer scrutiny of the ways in which individual nurses are recruited to incorporate views about themselves that are in line with powerful organizational interest.

In yet another study, Walrafen, Brewer and Mulvenon (2012) used Bandura's Social Learning Theory in an attempt to explore horizontal violence. Bandura's Social Learning Theory emphasizes the importance of observing and modeling behaviors, attitudes, and emotional reactions of others as a way to assimilate into a particular group. Bandura states that much of our learning to navigate interpersonal situations is a result of emulating the behaviors we observe in the group to which we want to be accepted as a member. The literature about horizontal violence in the workplace reveals that individuals tend to emulate the behaviors of the group members as a way to be accepted. Walrafen, Brewer and Mulvenon (2012) conducted a mixed method study to fully describe the participants' experiences with horizontal violence. Bandura's Social Learning theory guided this study and the authors found that the results of the study validated the appropriateness of the theory. They found that some of the nurses were surprised they were maltreating their peers by simply "going along with the crowd." The authors reported that many of the nurses stated 
that "it's the culture" when this was pointed out saying that they adopted the negative behavior as a result of watching fellow nurses.

Theories provide frameworks to assist in understanding the factors and processes implicated in a complex phenomenon such as horizontal violence. While some of the above studies looked at bullying, which can be considered somewhat different from horizontal violence, the antecedents and consequences remain similar. The use of different names for these unprofessional acts continues to be somewhat problematic; however, many studies focus on acts themselves and the consequences to the nurse, the patient, and the organization. Interventions identified to assist the nurse in curtailing horizontal violence would be applicable to bullying behaviors, incivility, lateral violence and horizontal violence.

Critical Social Theory has been utilized by many researchers when studying the phenomenon of horizontal violence. Critical Social Theory is a theory oriented toward critiquing and changing society. Therefore, the duty of the theory is practical, not just theoretical. The goal is to bring about a correct understanding leading to a positive change within society. In other words, the goal of the theory was not just to determine what was wrong with a society, but identify ways to help change the society for the better. In nursing, within a framework of Critical Social Theory, horizontal violence can be explored with regards to empowering nurses to overcome feelings of oppression and identify means to overcome it. 


\section{Critical Social Theory}

One of the most important intellectual thoughts of the last century was Marxistbased social theory. Based on ideas of Karl Marx and Freidrich Engels, this movement is made up of a number of loosely related theories which oppose the dominant order of society. Marx and Engels argued that the means of production determines the very nature of society and profit drives production and thus dominates labor. Working class groups are oppressed by the group in power who benefit from the profit. Marxist based critical theory has been studied and expanded on by a number of scholars including Antonio Gramsci, Louis Althusser and members of the Frankfurt School.

The term "critical theory" was first established by Max Horkheimer of the Frankfurt School in 1937. The Frankfurt School consisted of a group of philosophers, sociologists and psychologists who worked in the period before and after the Second World War. They were a group of thinkers who shared the same philosophical assumptions and perspectives and were influenced by G.W.F. Hegel and Karl Marx (Finlayson, 2004). The Frankfurt School sought to break away from the Hegel/Marx philosophy, the tradition of logical empiricism, and approach questions of the day from a variety of perspectives and disciplines. They challenged the assumption that the empirical approach of the natural sciences was the only valid one. Horkheimer first described Critical Social Theory as a social theory oriented toward critiquing and changing society. He maintained that the duty of the theory was practical, not just theoretical. The theory should not only aim to bring about correct understanding, 
but also to create a positive change within society. In other words, the goal of the theory was not just to determine what was wrong within society, but to identify ways to help change the society for the better (Finlayson, 2004). With the rise of Nazism, the Frankfurt School was first relocated to Geneva, and then to the United States. While in the United States, the group was struck by the way in which culture had been industrialized. The group saw firsthand how giant corporations applied coercive techniques which made people accept what was happening in society when really behind their backs the corporations were working in their own best interests. The theorists of the Frankfurt School analyzed this occurrence and gained insight into the ways that people could be manipulated. By the time Horkheimer returned to Frankfurt, he had become very pessimistic about the goal of Critical Social Theory. In the late 1960's Jurgen Habermas, a German philosopher and sociologist, revisited Critical Social Theory. While not directly a member of the Frankfurt School, he is included in the school of thought because his work critiques the work of the founding members. While Habermas remains true to many concepts brought forth by the original founders of Critical Social Theory, he believes in the notion of enlightenment which the original thinkers of the Frankfurt School critized as unrealistic. Enlightenment is a process that theoretically liberates man and leads to human freedom. The members of the Frankfurt School believed that members of society were subjected to a powerful economic system which sought to imprison them rather than liberate them. Habermas did believe that society was not meeting the people's needs and that institutions within society were manipulating individuals, 
however, he believed that people could be empowered to interact and respond to this manipulation. This is where the notion of communicative action arose. The concept and theory of communicative action is based in the belief that people have the capacity to communicate reasonably and rationally. It is Habermas's belief that communicative action advances the goals of emancipation and that all speech acts have an inherent goal, one of mutual understanding.

Communicative action, in Habermas's view, uses all ways of thinking and language that allows people to understand and agree with one another. This coming together and agreeing is the impetus for change. Critical Social Theory aims to explore various features of human life with the intention of providing a critique of their fairness or unfairness. It raises questions of whether situations are being distorted by power imbalances. Habermas also attempts to provide guidelines that would characterize ideal situations where these distortions could be avoided and describe mechanisms for change.

Critical Social Theory has as its main goal the improvement of the human condition. With this in mind, there are four basic assumptions with the theory. The first assumption of the theory is that people can change their world. They can find alternatives to existing social conditions and also challenge taken-for-granted conditions. A second assumption is that all social knowledge is value laden and that all scientific knowledge is a social construction. The third assumption is that reason and critique are inseparable and are reflexive. Finally, an important premise of Critical Social Theory is that theory and practice must be interconnected. As critical 
social theorists seek to improve human's conditions, they should not limit themselves to critiquing but rather to become involved with real life situations where power is manifested.

Propositions within Critical Social Theory are clear in that there are certain criteria that must be met in order for the theory to be considered a critical theory. First and foremost is that critical theory opposes positivism. Critical Social Theory would argue that knowledge is not simply a reflection of an inert world but is an active construction by scientists and theorists who make assumptions about what to study and thus not strictly value free. Critical Social Theory also opposes positivist's notion that science should describe natural laws of society believing on the contrary that society is characterized by domination, exploitation, and oppression and looks to a future where this no longer exists. Critical Social Theory argues that domination is structural; that people's everyday lives are affected by larger social institutions. Critical Social Theory illuminates this so that society can understand the roots of their oppression.

Critical Social Theory is action oriented. It aims to integrate theory and practice such that people become aware of disparities and become inspired to change them. Critical researchers reject the idea of an objective disinterested inquirer and are oriented toward a transformation process. An important feature of critical social theory is that it calls for inquires that foster enlightenment (Polit \& Beck, 2008). Research that follows this theoretical paradigm emphasizes the importance of discovering and rectifying societal problems. Rather than advocating neutrality, 
critical researchers emphasize action research, arguing that research should address past oppression, bring problems to light and act to change society for the better.

Critical research is a means of empowering the oppressed. Critical researchers generally take sides by studying "underdog" groups, those facing oppression and powerlessness in order to give them a voice. The researcher examines situations in which certain groups are oppressed or ignored and try to learn how and why this occurs. Research should lead to action to reduce the problems caused by oppression.

Critical Social Theory is an approach that involves theory, practice and research with the aim of transforming society rather than maintaining the status quo. It can orient research that relates to prevailing social conditions posed in ways that potentially are linked to practical interventions with practical insights into ways to achieve change. Using a Critical Social Theory perspective when studying horizontal violence in nursing has the potential to empower and inspire positive change.

As the literature portrays, horizontal violence is a global issue. It is detrimental to nurses' well-being and organizational culture. It results in nursing dissatisfaction and intent to leave. It also interrupts intra-professional communication, and is a crucial component in errors and patient outcomes (Vessey, DeMarco \& Difazio, 2011). Although much research has been done to explain and describe horizontal violence, additional research is needed to develop effective interventions to ultimately eliminate these behaviors. 


\section{Impact and Effects}

The harmful effects of continued exposure to horizontal violence are multiple. Victims report an overall decreased sense of well-being, physical health complaints, and depressive symptoms (Dehue, Bolman, Vollink \& Pouwelse, 2012). Other effects can include sleep disturbances, anxiety and symptoms consistent with post-traumatic stress disorders (Quine, 2001; Randle, 2003; Vessey, DeMarco \& DiFazio, 2011). Nurses who experience horizontal violence report less trust in their organization and significantly lower job satisfaction. They are also more likely to leave, thus contributing to decreased productivity and poor communication on their units (Becher \& Visovsky, 2012; Johnson \& Rea, 2009; Quine, 2001).

The first several years of practice have been identified in the literature as being important confidence building years for nurses; however, several studies indicate that newly licensed nurses are subjected to a variety of unprofessional behaviors that diminish confidence and self-esteem. While most nurses would state that their careers are rewarding, many would also agree that they work in a profession that not only is physically and psychologically challenging, but is also not always a nurturing as one would expect (McAllister \& Lowe, 2011).

This form of violence is very costly to an organization. Studies of the cost of nurse turnover have reported results ranging from about $\$ 22,000$ to over $\$ 64,000$ per nurse turnover (Jones, 2005; O’Brien-Pallas, Griffin, Shamian, Buchan, Duffield \& Hughes, 2006; Waldman, Kelly, Sanjeev \& Smith, 2004). 
In a study conducted by Simons and Mawn (2010), four themes describing different aspects of bullying were identified using a qualitative descriptive design. The study examined the stories of bullying among newly licensed nurses based on actual or witnessed experiences. The themes that emerged were structural bullying, nurses eating their young, feeling out of the clique and leaving their job. The authors stated that workplace bullying must be further explored to develop effective strategies to eliminate it.

Corney (2008) utilized a Heideggarian Methodology to illuminate the phenomenon of bullying and answer the question "How does it feel to be bullied?" Results showed that despite the physical and psychological repercussions, victims were unaware that they were being bullied until it was pointed out to them. The bullying actions resulted in the victims blaming themselves and reporting low self-esteem. The victims were afraid to speak out which resulted in feelings of shame and inadequacy, thus preventing them from seeking support.

Vessey, DeMarco and DiFazio, (2011) reported that this type of behavior interrupts critical components of teamwork; communication, the exchange of essential health information, and collaborative decision-making, all of which are associated with increased medical errors and poorer patient outcomes.

Several studies have reported that disruptive or bullying behaviors were found to increase nurses' stress and frustration (Becher \& Visovsky, 2012; Rosenstein \& O’Daniel, 2006; Sheridan-Leos, 2008).). Rosenstein and O'Daniel (2006) surveyed 244 participants at one hospital and asked the question "Are you aware of specific 
adverse events that did occur as a result of disruptive behavior?" The authors stated that the most disturbing outcomes of the study were the impact of this behavior on staff relationships, teamwork, and clinical outcomes of care. The participants linked disruptive behavior to the occurrence of adverse events, medical errors, compromises in patient safety, impaired quality of care and patient mortality.

McNamara (2010) explored the effects of workplace violence and the effects on patient safety. The author found that abusive work situations can lead health care professionals to make mistakes, the consequences of which patients must suffer. Further, McNamara (2012) reported that in a Veterans Administration study, $17 \%$ of the 1,500 respondents reported patients experiencing pain or prolonged pain, delays in treatment, misdiagnosis, mistreatment, and death as a result of disruptive behavior in their facility. This certainly has implications for nurses as their primary commitment is to the patient.

In McKenna, Smith, Poole and Coverdale's (2003) research study, the authors described the most distressing incidents experienced by nurses in their first year of practice. More than half of the respondents reported being undervalued by other nurses. Most distressing incident descriptions involved rude, abusive or humiliating comments which resulted in feelings of reduced confidence and low self-esteem. The respondents also stated psychological consequences such as anxiety, depression, frustration and nervousness.

In a study conducted by Simon and Mawn (2010), four themes describing different aspects of bullying were identified using a qualitative descriptive design. The study 
examined the stories of bullying among newly licensed nurses based on actual or witnessed experiences. The themes that emerged were structural bullying, nurses eating their young, feeling out of the clique, and leaving the job.

Sheridan-Leos (2008) reported a study of 551 newly registered nurses who had experienced lateral violence. The nurses were subjected to rude, abusive or humiliating comments. Over a third of the participants reported blocked learning experiences and neglect, and felt that they were given too much responsibility for their level of nursing. A large percentage of new nurses left their first new graduate position within the first year.

Additionally, there have been several other studies conducted on horizontal violence and intent to leave an organization. Sofield and Salmond (2003) conducted a study to describe the experience of verbal abuse in a large multihospital system to determine the relationship of verbal abuse with the intent to leave the organization. The nurses' responses to verbal abuse were most frequently identified as anger, followed by feelings of powerlessness, harassment and embarrassment. Nurses clearly believed that verbally abusive incidents caused an increased turnover in staff and that verbal abuse contributes to an increased shortage of nurses.

Similarly, Simons (2008) conducted a descriptive study to examine bullying behavior among nurses and looked at the relationship between bullying and nurses' intention to leave their organization. The author found that bullying had a great impact on intent to leave. As bullying behavior increased, so did the nurses intention 
to leave. Another finding of note in this study is that many nurses seem to be unaware of being bullied and surmise that these behaviors are typically female.

Wilson, Diedrich, Phelps and Choi (2011) conducted a study to determine the degree of horizontal hostility in the workplace and the extent that the perception of horizontal hostility affected ill calls and the likelihood of a nurse leaving their current position. The authors cited that the cost of nursing turnover was estimated in excess of $\$ 300,000$ per year in nurse turnover cost. In an effort to understand the potential relationship between horizontal hostility and intent to leave, the respondents were asked if they were considering leaving their position specifically because of horizontal hostility. Of the participants who responded to this question, $39.6 \%$ were either definitely going to leave their current position or, $19 \%$ were considering leaving their current position because of horizontal hostility. The authors concluded that horizontal hostility has a profound influence in the hospital setting on nurse job satisfaction and well-being, contributing to sick call and high turnover rates.

Maddalena, Kearney and Adams (2012) conducted a study which examined the quality of work life of novice nurses. The authors stated that novice nurses face unique challenges as they transition from student nurse to registered nurse. According to the authors, the participants expressed the view that the novice period is both an exciting and stressful period. One aspect that they found particularly stressful and anxiety provoking was managing working relationships with professional peers. Older more experienced nurses were often a source of fear and anxiety as the novices felt the nurses were intimidating and not helpful. The 
experience of either witnessing or experiencing horizontal violence was not

uncommon among the novice nurses who were interviewed. The novices indicated that ongoing support for them during the novice period was a critical factor for their success.

\section{Interventions}

Several different interventions have been proposed in the literature to prevent, reduce, or eliminate horizontal violence. Griffin (2004) conducted a study using cognitive rehearsal as a means for newly licensed nurses to combat lateral violence. Cognitive rehearsal is a strategy where a person imagines a difficult situation and a "therapist" guides him/her through the step-by-step process of facing and successfully dealing with it. The person then works on practicing, or rehearsing these steps mentally.

The author wanted to better understand lateral violence and ascertain whether it could be controlled. This study was particularly interested in newly graduated nurses as this group was identified by the author as being vulnerable to lateral violence during their socialization to nursing practice.

During hospital orientation the newly registered nurses received an hour long lecture on the constructs of lateral violence and its impact on nursing practice followed by a second hour of interactive instruction on cognitive rehearsal. During the interactive sessions the newly registered nurses were taught appropriate responses to the ten most frequent forms of lateral violence. They were then given 
two laminated cards which included behaviors that professionals should exhibit and responses to the ten most frequent forms of lateral violence.

After one year the participants of the study were asked six questions regarding their experiences with lateral violence. It was clear that by the end of their first year they had either witnessed lateral violence of been a target. When asked about cueing cards, $100 \%$ of the participants stated that they did not specifically look at the card when dealing with lateral violence but rather knew what was on them and used that knowledge.

While cognitive rehearsal as a response to lateral violence may help raise awareness of the issue in the nursing staff, it is often difficult to compose oneself and draw on this strategy "in the moment." As Griffin (2004) pointed out in the study, the newly registered nurses who had experienced lateral violence expressed that the encounter was very difficult; often times resulting in very emotional reactions. The literature does state that the behavior should be addressed "in the moment" but it is often very hard to think of a response when faced with such behavior. Despite this, education about horizontal violence with newly registered nurses is needed so that the behavior will not be interpreted as something every new nurse goes through.

Griffin (2004) concluded that it is unclear whether cognitive rehearsal or just knowledge of what lateral violence is, that made a difference. However, Griffin did state, that learning about lateral violence appeared to have been helpful. Further, in a study conducted by Stagg, Sheridan and Sperone (2011) cognitive rehearsal was used in a training program to evaluate the effectiveness of this intervention on 
bullying behaviors. Similar to Griffin, the researchers found that staff nurses attendance at a cognitive rehearsal training program increased awareness and knowledge of workplace bullying.

Taylor (2001) undertook a study the purpose of which was to investigate reflective practice and action research as a means to identify and transform dysfunctional nurse-nurse relationships. According to Taylor, nursing in hospitals involves complex interpersonal relationships within an organization of constraints while attending to multiple tasks and roles. The researcher utilized the tenets of reflective practice and action research with experienced nurses in order to identify practice problems faced daily. The purpose of this was to improve nursing care and educate nurses in a process that they can use for any clinical problem that may emerge. In this particular study nurses chose to identify and begin to transform dysfunctional nurse-nurse relationships. Convenience sampling was used to intentionally target participants who were interested in reflecting on their practice in order to improve it. The nurses kept journals and met once a week for one hour to discuss clinical problems that were raised in the journals. The researcher acted as a facilitator and as a guide and commented when appropriate. The nurses received information and were able to become familiar with reflective practice and action research. This research involved three action research cycles. The first cycle involved the development of group processes, becoming familiar with the aims of the research study, reflective practice and action research. The second cycle involved using reflective processes to identify individual and collective practice issues. Problems with nurse-nurse relationships 
was identified with particular behaviors identified as bullying and horizontal violence. The third cycle involved working together to generate and act, and reflect on the action plan. The researcher reported that after the action plan was put into place there were varying degrees of success reported in attempting to improve nursenurse relationships. She further suggested that dysfunctional nurse-nurse relationships have a complex pathology and they might be difficult to eradicate. The author concluded that the study confirmed the need for reflective practice and continued research to bring about cultural change in nursing regarding this behavior.

In nursing, reflective practice is used quite often as a means of identifying how a particular problem was handled and how it might have been handled better. It is a very useful tool and as Griffin (2004) found in her study, nurses had difficulty "in the moment." Reflective practice is useful in identifying what could be said if this occurred again.

Jackson, Firtko and Edenborough (2007) conducted a literature review on personal resilience as a strategy for responding to workplace adversity and to identify strategies to enhance personal resilience in nurses. The authors stated that resilience is the ability of an individual to adjust to adversity in a positive manner. In nursing it can be applied to building personal resilience through different strategies. These strategies include building positive and nurturing relationships; maintaining a sense of optimism and positivity; achieving life balance and spirituality; and, becoming more reflective. The authors further state that it is important to assist nurses to develop skills that will aid them in being more resilient and better able to 
cope with and protect themselves from the effects of workplace adversity.

Workplace adversity for nurses may involve interpersonal difficulties such as feeling bullied or oppressed, blamed and scapegoated or devalued in some way. Specific self-development strategies are proposed by the authors. These include, building positive nurturing professional relationships and networks; maintaining positivity; developing emotional insight; achieving life balance and spirituality and becoming more reflective. The authors concluded that it is important to identify ways of nurturing and supporting nurses so that they are better able to thrive and sustain satisfying careers in the context of organizational difficulty and workplace adversity. Further, nurses can actively participate in the development and strengthening of their own personal resilience to reduce their vulnerability.

Gerardi (2004) stated that advances in the scientific aspects of patient care have expanded rather rapidly while healthcare organizations have not evolved as quickly. This has resulted in a healthcare organization that is filled with poor communication, unclear policies, role confusion, turf battles and stressful interpersonal conflicts. The author suggested the use of mediation techniques as a way to manage conflict and create healthy work environments. Mediation is a conflict resolution process, in which a neutral person facilitates communication, the development of understanding, and the generation of options for creative dispute resolution. A mediator's role is to help participant's surface issues that may be emotionally or psychologically difficult, and to foster agreement as participants seek options that could move them forward towards workable solutions. Mediation allows the 
participants in the dispute to remain in control of the process and to contribute to the outcomes. Through facilitated dialogue, the participants are able to identify what is important to them and what they need to reach a solution. By integrating the four different mediation techniques, listening for understanding, reframing, elevating the definition of the problem and making clear agreements, the clinical environment can effectively reduce the level of conflict and prevent a unit from becoming dysfunctional. Collaborative working relationships are essential in a healthy working environment. Integrating the techniques used by mediators can foster better working environments, improve patient outcomes, improve retention and recruitment of staff, and improve patient satisfaction.

The evidence indicates that the majority of working nurses will experience horizontal violence at work sometime during their career (Aiken, Clarke, Sloane, Sochaliski, Busse, Clarke \& Shamian, 2001; Rosenstein \& O’Daniel, 2005; Sofield \& Salmond, 2003; Young, 2011). Current scholarly discussion of horizontal violence in nursing demonstrates continuing interest in constructively managing this negative phenomenon in the nursing work environment. 


\section{CHAPTER THREE}

\section{METHODOLOGY}

Horizontal violence or non-physical conflict among nurses has been a persistent problem in nursing for many years (Griffin, 2004). Quantitative research has provided a foundation describing the frequencies, trends and relationships associated with horizontal violence in the nursing workplace (Mendez, 2011). These studies have provided a great deal of evidence that these negative behaviors occur, are longstanding in the workplace (Cox, 1987; Curtis, Bowen \& Reid, 2007; Dunn, 2003; Embree \& White, 2010; Stanley, Martin, Mitchel, Welton \& Nemeth, 2007) and that those responding to surveys perceive that this behavior is a threat to patient safety (Rosenstein \& O'Daniel, 2005). The evidence clearly supports the existence of these negative interactions between nurses in the workplace. While this is well documented in the literature for over 20 years with much quantitative research, there is a paucity of research on how nurses describe their experiences with horizontal violence or their long and short term responses to these incidences. The meaning that people ascribe to negative social interactions and their explanations for why they respond in different ways can be difficult to capture using quantitative methods. The qualitative design is well suited to examine phenomenon by hearing from individuals involved and allowing them to share their perspectives (Bitsch, 2005).

Horizontal violence continues to be a problem despite the research and interventions aimed at reducing it. If horizontal violence is to be reduced, a deeper 
understanding of this phenomenon is necessary. Research using mixed methods is needed to gain understanding of nurses' experiences and responses to incidents of horizontal violence.

\section{Research Design}

The purpose of this study was to examine the characteristics of horizontal violence experienced by registered nurses in two city hospitals, explore nurses' responses to horizontal violence incidents, and identify factors that helped them to successfully respond to these incidents. The research questions are:

1. What is the prevalence of horizontal violence (HV) experienced by registered nurses (RNs) during their career?

2. Who are most likely to be the perpetrators reported by RNs?

3. What are the characteristics of the victims reported by RNs?

4. What factors do nurses describe as fostering the occurrence of $\mathrm{HV}$ in the workplace?

5. What factors do nurses describe as helpful in reducing the occurrence of HV in the workplace?

6. In what way is job performance affected by experiences with HV?

7. What protective factors do nurses identify as the reason for remaining in their jobs after experiencing $\mathrm{HV}$ ?

The research questions were answered using a mixed methods study beginning with an online anonymous survey of nurses and followed by a qualitative study of a 
sub-sample of nurses who volunteered to participate in post survey interviews to describe the incidents of horizontal violence and their responses to them.

A mixed method descriptive design was utilized to fully understand the participants experiences with horizontal violence and to achieve a more thorough and explicit understanding of the complexities surrounding this phenomenon. Initially, a short questionnaire revised from questions used by Stanley, Martin, Michel, Welton and Nemeth (2007) and based on the seminal work of Griffin (2004), was administered to registered nurses via online survey to elicit information regarding experiences with horizontal violence and who would agree to be interviewed. The second exploratory qualitative stage of the study consisted of semistructured interviews to further investigate incidences of horizontal violence as the participants experienced it.

\section{Semi-structured Interviews}

Semi-structured interviews, according to Polit and Beck (2008), are a style of interview in which the researcher asks participants of the study questions without having a predetermined plan regarding the content or flow of information to be gathered. Researchers establish what is to be studied but participants are given considerable control over the course of the interview.

In Rubin and Rubin's (2012) model, interviews are viewed as conversations and participants are viewed in a collegial manner and thus called conversational partners, who share their experiences to increase understanding. They utilize an interpretive 
constructionist research approach in order to elicit the interviewee's perception on the phenomenon.

Researchers using semi-structured interviews begin informally by asking a broad question. For this study, initially, all participants were asked the same three questions: (1)"Have you personally experienced horizontal violence?" if yes (2) "Can you describe the two most distressing incidents that you remember?" and (3) "Are there any other incidents that you would like to tell me about?" Subsequent questions were more focused and guided by the responses made to the first two questions. Probes such as, "What was your response to these incidents?" and "What happened as a result of your response?" were utilized to help manage the conversation, clarify unclear statements and keep the conversation on topic (Rubin \& Rubin, 2012). This type of interview can be considered a conversation in which the researcher guides the respondent in an extended discussion. This is done with the hope of eliciting depth and detail about the research topic. This researcher followed up on answers given by the respondent during the discussion. Other questions that were asked to help answer the main research questions were:

Did the behavior continue or were you successful in stopping it? What, if any, were the responses that were successful in stopping the behavior?

How did these incidents affect your job performance? 
According to the literature, semi-structured interviews typically are much more like conversations than formal interviews (Patton, 1987; Rubin \& Rubin, 2012, Wolf, 2007). Initially the researcher opens the conversation with a predetermined topic to help uncover the participant's perspective on the phenomenon of interest should "unfold" as the participant views it, not as the researcher views it (Rubin \& Rubin, 2012). A very important aspect of this methodology is for the researcher to convey to the participants that their views are valuable and useful.

One must keep in mind that interviewing is a skill and this skill does need experience to develop. A good interviewer must be able to establish rapport and trust, gather information without controlling the flow of information and record it accurately (Rubin \& Rubin, 2012). Interviews must be adapted to the needs of the respondents.

Interviews involve personal interactions; cooperation is essential. Participants may be unwilling or may feel uncomfortable sharing all that the interviewer hopes to explore. Rubin and Rubin (2012) stated that the researcher has to realize that she or he is the instrument, the "tool of discovery". The researcher has to be able to hear what is said and change direction if needed while at the same time be cautious not to impose his or her views on the participant.

\section{Institutional Review Board Approval and Confidentiality Measures}

Institutional Review Board Approval (IRB) was obtained from CharterCARE (see Appendix A) and the University of Rhode Island (see Appendix B). Participation was voluntary and the initial online survey was anonymous. Those agreeing to be 
interviewed signed a written consent (see Appendix C). This researcher explained that participation could be terminated at any time and that the study would not identify specific nurses or their employers. Participants were identified by an assigned number. The workplace is identified only as an acute care environment as this term can be used to describe a unit in either institution utilized for this study.

Transcripts were identified only by number assigned to them and no names were included. All records relating to this project were handled and safeguarded according to standard policy. The data is kept on paper, digital and audio tapes. The data is stored in a locked filing cabinet. Data which is electronically communicated is password protected.

\section{Sample}

The study used a convenience sample of nurses employed at two city hospitals. The general demographic characteristics of the study population were identified through the questions asked on the online questionnaire. Data such as gender, age, number of years as an RN, number of years worked in the institution, type of unit currently working on and level of education was elicited.

This researcher visited the nursing units in the two hospitals to explain and promote the study to the nurses. Assistance was also sought from the Chief Nursing Officers of the two institutions as well as the nurse managers.

The initial data collection phase of the study took place at two city hospitals via an electronic survey. Data collection began in October of 2013 and ended mid December, 2013. The survey identified registered nurses who agreed to be 
interviewed. The location of the interviews was determined by the interviewer and participant.

\section{Instrument}

Initial data was collected via an online survey modified from the Lateral Violence in Nursing survey developed by Stanley, Martin, Michel, Welton and Nemeth (2007) and the seminal work of Griffin (2004) with some additional researcher-constructed questions. The resultant questionnaire reflected what the study questions addressed and was brief enough to promote participation. The questionnaire identified those who had experiences with horizontal violence and would agree to be interviewed. Rubin and Rubin's (2012) Method of Qualitative Interviewing guided the data collection and analysis. The semi-structured interviews were audio-taped and transcribed verbatim.

\section{Data Analysis Plan}

Quantitative data was analyzed using REDCap. REDCap is a secure, web-based application for building and managing online surveys and databases. Descriptive statistics were used to summarize the demographic characteristics and the responses to the Likert scaled items.

The qualitative data interviews were audio-taped, transcribed verbatim and analyzed using conversational analysis. According to Rubin and Rubin (2012) analysis in this interviewing model proceeds in two phases. In the first phase the interviewer prepares the transcripts; finds and elaborates themes; and then codes the interview to be able to retrieve what the participants have said about the identified themes. 
Once the data was coded, it was grouped and linkages between the themes were identified.

Rubin and Rubin's (2012) model guided the analysis of the qualitative data. The analysis of the responsive interviews involved five steps. The first step in the analysis was to transcribe the audio-taped interviews, which was completed by this researcher. This allowed for full immersion into the data and proved to be very valuable when analyzing the transcribed interviews. By doing this, the researcher had the exact responses given by the participants.

The next step in Rubin and Rubin's model is coding. Coding involves defining, finding and marking in the text excerpts that have relevant themes, events, examples, names, places or dates. Coding enabled this researcher to bring together all information on a similar topic, look at the information and either modify original ideas or indicate when and how ideas might be true or not true. Coding allowed this researcher to choose the codes that provided a better understanding of the research topic.

Finding and labeling events and themes helped this researcher to describe and explain the phenomenon under study. Rubin and Rubin (2012) stated that events are occurrences such as an episode of horizontal violence or disruptive behavior. These were labeled as such in the data. Themes identified were placed in groups according to causes, characteristics, when, who, consequences and responses. They helped this researcher identify meaning that was relevant to the research topic. 
When the events and themes were identified, each was assigned a letter. The excerpts marked with the same letter across interviews were sorted into data files. The contents of each file, was then summarized. As themes were formulated and tentative conclusions were drawn, this researcher tested them against the data making sure there was sufficient, convincing evidence. In figuring out how themes go together, a theory that explains the phenomenon may be generated.

This analysis took this researcher step by step form the data obtained in the interview to clear answers to the research questions. This allowed this researcher to prepare a report based on what the participants said. The following chapter will present the results of both the qualitative and quantitative data. 


\section{CHAPTER FOUR}

\section{FINDINGS}

This chapter summarizes the findings of the online survey as well as semistructured interviews. The quantitative results are presented according to the research questions and organized by the questions on the initial online survey. The qualitative results will be presented with regards to identified themes.

After obtaining Hospital and University IRB approval, an online survey entitled Nursing Horizontal Violence Survey was placed on the CharterCARE intranet. Posters were placed on the nursing units of the two CharterCARE hospitals (see appendix D). The investigator also visited the units to promote the study. REDCap, a secure, webbased application for building and managing online surveys and database, provided the means to place the survey online. REDCap displays all project data in aggregate graphical format and as descriptive statistics, and is designed to assist in data cleaning and evaluation.

\section{Demographic Information}

The sample for the study was drawn from registered nurses employed at two city hospitals. There were a total of 78 respondents to the online survey. Not all numbers in each category added up to 78 as some nurses responding to the questionnaire left some questions unanswered. The number of RNs agreeing to be interviewed totaled 11 , however, only 8 provided contact information and 1 , when contacted, stated that she did not have the time. As a result, 7 semi-structured interviews were conducted. Table 1 displays the sample demographic information. 
Table 1

Sample Population

\begin{tabular}{|c|c|c|}
\hline \multicolumn{3}{|l|}{ Gender } \\
\hline Female & 68 & $89.5 \%$ \\
\hline Male & 8 & $10.5 \%$ \\
\hline \multicolumn{3}{|l|}{ Highest Level of Education Completed } \\
\hline Associate Degree & 19 & $25 \%$ \\
\hline Diploma & 11 & $14.5 \%$ \\
\hline Baccalaureate Degree in Nursing & 19 & $25 \%$ \\
\hline Baccalaureate Degree (non-nursing) & 10 & $13.2 \%$ \\
\hline Masters Degree in Nursing & 17 & $22.4 \%$ \\
\hline Doctor of Nursing Practice & 0 & \\
\hline $\mathrm{PhD}$ & 0 & \\
\hline \multicolumn{3}{|l|}{ Number of Years as an $R N$} \\
\hline Less than 2 years & 9 & $13 \%$ \\
\hline $2-4$ years & 3 & $4.3 \%$ \\
\hline $5-9$ years & 8 & $11.6 \%$ \\
\hline $10-19$ years & 7 & $10.1 \%$ \\
\hline $20-29$ years & 18 & $26.1 \%$ \\
\hline $30+$ years & 24 & $34.8 \%$ \\
\hline \multicolumn{3}{|c|}{ Number of Years Worked at This Institution } \\
\hline Less than 1 year & 9 & $13 \%$ \\
\hline $1-2$ years & 6 & $8 \%$ \\
\hline $3-4$ years & 8 & $10.7 \%$ \\
\hline $5-9$ years & 13 & $17.3 \%$ \\
\hline $10-19$ years & 17 & $22.7 \%$ \\
\hline $20-29$ years & 12 & $16 \%$ \\
\hline $30+$ years & 9 & $12 \%$ \\
\hline \multicolumn{3}{|l|}{ Type of Unit Currently Employed On } \\
\hline Primarily medical & 12 & $16.2 \%$ \\
\hline Primarily surgical & 16 & $21.6 \%$ \\
\hline Oncology & 2 & $2.7 \%$ \\
\hline Geriatric & 1 & $1.4 \%$ \\
\hline Psych/Geri psych & 4 & $5.4 \%$ \\
\hline $\mathrm{ICU} / \mathrm{CCU}$ & 3 & $4.1 \%$ \\
\hline Rehabilitation & 2 & $2.7 \%$ \\
\hline Emergency Department & 3 & $4.1 \%$ \\
\hline Operating Room/Recovery Room & 6 & $8.1 \%$ \\
\hline Outpatient Services & 0 & \\
\hline Float & 5 & $6.8 \%$ \\
\hline Other & 20 & $27 \%$ \\
\hline
\end{tabular}


The majority of the respondents to the online questionnaire were female $(89.5 \%)$ The highest level of education completed was Associate Degree in Nursing (25\%) and Baccalaureate Degree in Nursing (25\%) followed by Masters Degree in Nursing (22.4\%). A smaller percentage (14.5\%) had attained a Diploma with $13.2 \%$ having a Baccalaureate Degree (non-nursing).

The majority of respondents (60.9\%) have worked as registered nurses for $20+$ years. A smaller percentage of nurses (21.7\%) have work between 5 to 19 years, with $17.3 \%$ working anywhere from less than 2 years to 4 years as a registered nurse.

Many of the nurses (28\%) work in one of the two organizations for $20+$ years while $22.7 \%$ have worked between 10 and 19 years. Several nurses (36\%) have worked in one of the two institutions from 1 to 9 years with $13 \%$ responding that they have worked within one of the institutions for less than one year. Respondents were located throughout the hospital with the majority of nurses (22\%) on primarily surgical or primarily medical (16\%) floors.

\section{Quantitative Results}

There were a total of fifteen questions on the online questionnaire including 5 demographic questions and 8 questions related to horizontal violence (see Appendix E).

The survey provided the following definition: "Horizontal violence/lateral violence is the persistent demeaning and downgrading of another through vicious words and cruel acts (Randle, 2003). It is manifested through overt and covert behaviors such as withholding pertinent information, criticism and failure to respect confidences, and 
covert behaviors such as eyebrow raising, snide remarks and turning away (Griffin, 2004).

To answer research question one the respondent was asked whether she/he had experienced this type of behavior using the definition provided. The majority of the respondents (67.9\%) indicated that they had experienced horizontal violence. Many of the nurses (23) responded that they had experienced it recently with 18 experiencing horizontal violence in the past and 3 early in their careers. Some nurse's listed specific instances where they experienced horizontal violence such as "getting and giving report" or in the recovery room (see Appendix F).

When asked "have you seen others subjected to this type of behavior?" $72 \%$ responded yes. Appendix $\mathrm{G}$ describes when the behavior was witnessed and how frequently it was witnessed. Several of the nurses (14) reported that horizontal violence was witnessed recently with 13 nurses reporting that they had witnessed it in the past. Several respondents reported specific incidents where they had witnessed horizontal violence such as "usually after the person walks away", "getting and giving report", "surgeons towards charge nurses and also surgeons towards nurses and techs during surgery", and "during conversations with superior."

To answer research question number two the respondent was asked "If you have experienced horizontal violence or have seen others who have been treated poorly, who is most likely to exhibit this negative behavior?" the majority of the respondents (85.5\%) reported a peer or fellow nurse. Physicians $(55.1 \%)$ and manager/administrators (37.7\%) were also identified as exhibiting this type of 
behavior. Other health care workers (36.2\%) and patient's family $(36.2 \%)$ also were seen as exhibiting this type of behavior. Patients were found (29\%) to display these behaviors and a small percentage (7.2\%) reported that others were responsible.

Table 2 summarizes these findings.

Table 2

\begin{tabular}{|l|l|}
\hline \multicolumn{1}{|c|}{ PERSON EXHIBITING NEGATIVE BEHAVIOR } & \multicolumn{1}{|c|}{ PERCENTAGE } \\
\hline Peer or fellow nurse & $85.5 \%$ \\
\hline Physician & $55.1 \%$ \\
\hline Manager/Administrator & $37.7 \%$ \\
\hline Patients family & $36.2 \%$ \\
\hline Other health care worker & $36.2 \%$ \\
\hline Patient & $29 \%$ \\
\hline $\begin{array}{l}\text { Other } \\
\text { - Secretary }\end{array}$ & $7.2 \%$ \\
- Chysician's Assistant & \\
- Case manager M.H. & \\
\hline
\end{tabular}

To answer research question number three the respondents were asked "If you have witnessed this type of behavior, what was the response of the victim?" The greatest response (67.2\%) was that the victim walked away followed by the victim remained silent (58.6\%). Responding to the perpetrator in a very emotional way was reported by $43.5 \%$ of the respondents and $29.3 \%$ witnessed the victim crying. Several respondents (20.7\%) reported witnessing other types of behaviors such as talking about the episode and voicing concern and worry that the situation will continue to make them feel awkward and would question if they should switch jobs. Table 3 summarizes these findings. 
Table 3

\begin{tabular}{|l|l|}
\hline \multicolumn{1}{|c|}{ RESPONSE } & \multicolumn{1}{|c|}{ PERCENTAGE } \\
\hline Walk away & $76.2 \%$ \\
\hline Silence & $58.6 \%$ \\
\hline Responded to perpetrator in a very emotional way & $34.5 \%$ \\
\hline Crying & $29.3 \%$ \\
\hline Other & $20.7 \%$ \\
- Confided to me about it and talked it out & \\
- Discussion/disclosure of the impact & \\
- Comment made back & \\
- They were unaware & \\
- Delling, throwing charts & \\
- Ignores at times, calls out at times & \\
\hline
\end{tabular}

To answer research question number 4, the respondents were asked "What factors do you view as increasing horizontal violence in the workplace?" Table 4 summarizes what the respondents reported as increasing horizontal violence in the workplace. Increase in workload/stress (73\%) was reported as the number one cause. Accepted practice on the unit (62.2\%) followed by manager attitude $(50 \%)$ were also reported as factors that increase horizontal violence. Two other factors, lack of implementation of policies (47.3\%) and patient acuity $(45.9 \%)$ were also identified as factors that increase horizontal violence in the workplace.

Table 4

\begin{tabular}{|l|l|}
\hline \multicolumn{1}{|c|}{$\begin{array}{c}\text { FACTORS INCREASING HORIZONTAL } \\
\text { VIOLENCE }\end{array}$} & \multicolumn{1}{c|}{ PERCENTAGE } \\
\hline Increase in workload/stress & $72 \%$ \\
\hline Accepted practice on the unit & $62.7 \%$ \\
\hline Manager attitude & $49.3 \%$ \\
\hline Lack of implementation of policies & $46.7 \%$ \\
\hline Patient acuity & $45.3 \%$ \\
\hline
\end{tabular}


Table 5 summarizes what the respondents viewed as helpful in reducing horizontal violence. This answered research question number 5 . Manager awareness and support $(77.3 \%)$ and staff support $(74.7 \%)$ were identified by the respondents as being most helpful. Education in the workplace (69.3\%), workplace policy (57.3\%) and education in nursing programs (53.3\%) were also identified as being helpful. A small percentage, (9.3\%) responded that nothing helps. Some of the respondents viewed other behaviors (8\%) such as taking disciplinary action and using deescalation techniques and awareness.

Table 5

\begin{tabular}{|l|l|}
\hline $\begin{array}{l}\text { HELPFUL IN REDUCING HORIZONTAL } \\
\text { VIOLENCE }\end{array}$ & \multicolumn{1}{|c|}{ PERCENTAGE } \\
\hline Manager awareness and support & $77.3 \%$ \\
\hline Staff support & $74.7 \%$ \\
\hline Education in the workplace & $69.3 \%$ \\
\hline Workplace policy & $57.3 \%$ \\
\hline Education in nursing programs & $53.3 \%$ \\
\hline Nothing helps & $9.5 \%$ \\
\hline $\begin{array}{l}\text { Other } \quad \text { Disciplinary action } \\
\text { - De-escalation techniques }\end{array}$ & $8.1 \%$ \\
$\quad$ Teaching staff how to deal effectively & \\
- Treat others as you would want to be & \\
treated & \\
\hline
\end{tabular}

\section{Qualitative Results}

Seven semi-structured interviews were conducted over a four week period at a place and time convenient to the participants. Upon ensuring that the participants understood the nature of the research, informed consent was obtained. The investigator, participant and a witness signed the document and a copy was given to 
the participant with the original being place in the investigators file. The interviews lasted an average of 40 minutes. The interviews were audio-taped and transcribed verbatim by this researcher and analyzed using Rubin and Rubin's (2012) approach to analysis. This type of analysis has seven steps and proceeds in two phases. In the first phase the interviewer prepares the transcripts; finds and elaborates themes; and then codes the interview to be able to retrieve what the participants have said about themes identified. The second phase involves studying the themes to generate theory. Since the purpose of this dissertation was not to generate theory, the analysis stopped at the descriptive stage, step 5.

There were a total of seven scripted questions for the semi-structured interview (see Appendix $\mathrm{H}$ ); however, follow up questions depended on the response to the initial question. Each interview began with the same question "Have you ever experienced an episode of horizontal violence?" Each of the seven participants responded yes to this question and they were then asked to describe the experience. During the time that the participant was describing the incident questions were asked about how the participant responded to the incident and what happened as a result of the response. Respondents were also asked "Have you ever witnessed an episode of horizontal violence?" Each of the seven participants responded yes to this question and they were asked to describe the incident. As the participants were describing what they had witnessed they were asked if they had tried to stop the behavior and if they found anything helpful in stopping the behavior. They were also asked if they felt that this type of behavior affected job performance and whether or 
not it had an impact on patients. Once again, all seven participants responded yes to this question. At the end of the interview the participants were asked despite having experienced this behavior, what are the reasons they chose to stay in their position. The results to these questions will be described in detail.

The analysis of the responsive interviews took place in stages described by Rubin and Rubin (2012). The first stage involved transcribing and summarizing each interview. The interviews were transcribed verbatim and read several times to get a sense of what was said and to look for commonalities. In the second stage of the analysis 14 themes emerged (see Appendix I). Stage three involved further breaking down the categories into causes, characteristics, when, who, consequences and responses which are described in Appendix J. Stage four involved sorting and resorting to compare the excerpts between the participants. In stage five, the final stage, the descriptions from the different interviews were integrated to create a complete picture (see Appendix K).

What follows are excerpts from the interviews in the participants own words. They offer compelling evidence that despite the many years that this phenomenon has been studied, horizontal violence continues to be a problem within the profession. The number that follows each excerpt, was the number given to the participant during analysis of the interviews.

Research question two looks at the perpetrators of horizontal violence and who is most likely to exhibit this behavior. 
Six out of the seven respondents stated that nurse managers were the

perpetrators and five respondents stated that physicians exhibited this type of behavior.

"Early in my career I had an episode with a nurse manager. I was working in pediatrics at the time and I had a patient who had chicken pox who arrested and I ran into the room and resuscitated him and the head nurse blasted me for not using isolation precautions so instead of saying you saved a child's life, I actually got yelled at and written up. I was so distraught I actually drove home thinking I can't do this anymore." (2)

"I feel like we generally run very short staffed all the time and on this particular day we had students so they floated the CNAs to another floor. I was the resource nurse so when the students left I asked the secretary to call the staffing office to see if we were going to get our CNAs back. Well, the manager came flying onto the floor screaming who made the distress call to staffing? When I said that I asked the secretary to call to see if we were getting our CNAs back she just started screaming at me, yelling at me right there at the desk." (3)

"I remember my first job. There was a charge nurse that I will never forget because she was really angry, you know what I mean? She used to push everyone around and I was really uncomfortable with that because I was a new nurse just starting out. It wasn't a very positive experience." (5)

"I've seen physicians in the OR who can be very, well, let's just say not nice to the nurses and it causes a trickledown effect, you know, physician's to nurses, nurses to OR techs and so forth." (6)

"Um well being a staff nurse, you know physicians are very prone to talk down to nurses, even now in 2014." (7)

Two of the participants identified preceptors as perpetrators, with one person

witnessing an encounter with a Physician's Assistant.

"And if you've got that strong nurse preceptor that is going to come in and barrel all over them; just beat them down until they realize that they are going to move on because this isn't going to work, they feel that they are never going to move forward and we've had that issue where you try to tell a preceptor look you have to teach them, you can't intimidate them and you 
have to get them to want to learn and you gotta get them to stay." (6)

"We had a physician's assistant going after a nurse and the nurse standing her ground, it was getting really rough and I stepped up and told the nurse you need to back away before something happens." (1)

All seven respondents stated that fellow nurses or peers were found to be the perpetrators and that this type of behavior was experienced or witnessed as a new nurse.
"It happened more during my orientation. I think as a young nurse your insecurities make you more of a target because you're not confident." (1)
"Well I think that as a new nurse it is easy prey for the senior nurses, they are not looked at as much higher than a CNA. They pawn off duties to new nurses and have it said as being a learning experience." (4)
“Nurses eat their young, we aren't kind to each other, we take care of everyone else, we support other people but we are the first to throw each other under the bus." (7)
"It really didn't happen to me per se as a new nurse because I heard that Nurses eat their young and I was a bit nervous about that so I decided you have to go in and be like really humble and be like I'm learning, that probably is the best advice you can give a new nurse. Do not walk on the floor and think you know everything because you know zero. It's ok to be scared; it's ok to be nervous, and it's ok to ask a million questions even if they're stupid. I think that helps because I've seen new nurses who go out and think they know everything and I'm thinking oh God, They're screwed. They're in trouble." (3)

All of the respondents described actions or characteristics of the perpetrators with several describing the same actions. Disrespectful communication was identified by all of the interviewees, with several stating that nurses tended to "snap" at them.

"You know you are doing all you can and they just snap at you." (1)

"I've seen a lot of snapping between nurses and spying. Like li feel like we're always being watched and reported back too." (3) 
"So if you're at that stress level and someone comes to you and you're usually not gonna react with oh let's sit down and talk about it, you're usually going to snap." (7)

Several of the nurses interviewed felt that personality and personal issues accounted for the disrespectful behavior.

“People aren't always aware of how they are coming across." (2)

"I think most of it is just the way they do stuff and I don't think they are aware that sometimes they have a blow out of they cause a problem because it's just the way they work. They may not realize that they're causing that kind of an issue." (1)

"Usually my experience is that most people aren't even aware of how they are coming across." (7)

"Some people don't even realize they came across that way and when you tell them they become remorseful and teary eyed, they're almost apologetic." (6)

During the interview, the nurses were asked how they responded to the incidents that they either experienced or witnessed. This addressed research question number three. Interestingly, several respondents stated that they stepped in when it was happening to someone else but remained silent or walked away when they were experiencing it.

"I find it difficult to approach the nurse who's been that way to me but if I see it happening too someone else, yes, l'll talk to that nurse." (1)

"When it happened to me I let it stew but I have stepped in when it was happening in a room and said let's take it outside." (6)

Several of the nurses stated that they became angry or upset.

"I would get frustrated, really upset. It makes you feel bad." (3)

"I was upset because the secretary said that it's going throughout the hospital, everyone's talking about it." (3) 
"It made me feel angry, frustrated, you know?" (5)

Difficulty in addressing this type of behavior was evident in that several of the participants were reluctant to report the incident related to fear of retaliation.

"I was very close to writing a GMERS (complaint) but the incident was so specific that I know that they follow up on every GMERS and it would have gotten back to her. You know, she's my boss, and then what?" (3)

Well the problem is that the person who l've has a bit of a problem with is a friend of the nurse manager, so I can't go to her and complain." (5)

Several of the nurses stated that you learn who to go to for help.

"I just find people who I work with, some people who are helpful and some people who are not and I just find the helpful person and we just help each other out." (5)

"I just let them do their own thing and I would end up going to another nurse for help." (1)

With regards to research question 4, when the participants were asked what they thought the cause of horizontal violence was, many of them again, identified the same issues. The most frequently cited was stress; in fact, all 7 participants felt that high stress levels lead to unprofessional behaviors on the unit.

"I think horizontal violence may be hard to discern because it's hard to tell what's horizontal violence and what's stress related because it's changing so much on the floor, and it's getting more difficult to do what we're supposed to do I think so there is a lot higher stress levels and I think you're gonna see more tempers blown." (1)

"I think we work in very stressful environments and they get stressed about what's going on." (2)

"The stress, I think the stress, the hurrying, I've got to get this done all these tasks and how am I going to do this and now he wants me to do that and now you're cutting staff and just a lot of pressure." (7) 
"So if you're at a stress level and somebody comes to you with one more thing you're usually going to snap." (7)

"I think everyone is too stressed because of short staffing." (3)

High patient acuity was also cited as causing unprofessional behaviors.

"I think the acuity of the patients we have and the demands of the patients." (4)

"The acuity is way up there, the nurses are stressed." (7)

"Stress and patient acuity are big issues and the equipment and technology has changed and that creates a whole other issue." (6)

Another cause of horizontal violence identified by the nurses interviewed was

older nurses and younger nurses working together - generational differences.

"As a new nurse some of the more experienced nurses would question my ability To do something and then they would override it and go do it themselves." (1)

"Younger nurses are really being taught to be confident and to come forward and that creates another conflict with that seasoned nurse because now she's saying what does this new one think, she knows everything?" (6)

"And it's very difficult generationally so you have us baby boomers who were all about no matter what they told you to do, you did it, it was all about work. The younger generation seem much better than us at um having a like a work/life balance and the baby boomers kind of resent that. It's gotten better but there is still a perception that you know I went through it and you need to go through it. A lot of us got beaten up and they can't separate that now and say yes that was the wrong thing to do, I think it's tough." (2)

Five of the nurses interviewed felt that this type of behavior was "accepted practice" on the unit or "the culture" of the unit.

"I think that this just might be accepted on the floor, you know, the culture of the unit. I was the manager of a unit that was particularly toxic, horrifically toxic to their peers." (2)

"It's accepted practice on the unit or it usually falls under well, that's just how 
that person usually is." (4)

"It happens on the floor and nobody does anything, you learn who you can count on and who you can't." (1)

"Some people will confront, others will roll their own eyes and then they become um passive about it, well it's just so and so being so and so and that's how they sort of roll with the punch." (6)

Consequences of the behavior were discussed particularly as it affected job performance and patient outcomes. All seven of the participants felt that horizontal violence affected both job performance and patient outcomes. This addressed research question number 6 .

“Patient's are affected, when I am given the worst assignment and I can't answer the call lights in a timely manner." (1)

"It does affect patients because they can sense you are having a bad day and they don't want to bother you even though they might need something." (1)

"I think the patient's are so attuned to what's going on that the nurses don't even realize it." (6)

"Patients are affected because they can sense that the nurse is upset they can see body language, they can hear the tone of the nurse's voice." (1)

"Patients should never have to worry about the mental state of the nurse caring for them." (2)

"I see patients suffering because of this type of behavior." (3)

"It affects the nurse and job performance especially when they are going to do their best not to show something in front of others." (1)

"I think it affects patients in an indirect way, they see you are not quite as attentive, they can sense the tension." (6)

"It does affect patients because sometimes you get yelled at and you feel rotten all morning and the patient can sense that, it come right through." (7)

"It definitely affected my job performance, it made me on edge, it made me 
scared, it made me afraid to ask questions; it made me afraid to make decisions because I might get yelled at; it kept me from growing." (2)

Behaviors such as avoiding, ignoring and not helping out were identified by several of the nurses.

"You come out and ask for a little bit of help and they just totally avoid you, that's the silent abuse." (1)

"Um, I've seen nurses snap in general, not really being willing to help each other out." (5)

"There's this one nurse who will ask if you need help and when you say yes she never helps out, she says oh I have such and such to do." (4)

"I work with one right now who sits behind the desk most of the time, sometimes on the phone, sometimes just talking and um admissions come up and she says ok you're getting the next one and l've already got four very difficult patients and she's been sitting there for like 2 hours not doing anything and I get frustrated." (5)

"There are times when you ask for help from somebody and they say yea ok and then they just walk away." (1)

Nurses exhibiting this type of behavior were identified by three of the participants when floating to units other than the one they generally worked on.

"They come up and give me those facial expressions like oh, you're here type attitude." (1)

"If I get pulled from my floor and floated to another unit you can bet your life I'm gonna get the first admission, the isolation patients, I'm gonna be spread all over the floor." (4)

"When I've floated to another floor and have experienced that bad end of that where you get the worst assignment on the floor and no matter how many times you ask for help, you don't get it. You're on your own." (1)

With regards to research question number 7 , discussion took place with each of the participants with regards to continuing to work at the organization or on their 
particular floor after experiencing an episode of horizontal violence and what might be done to curb this type of behavior. Several of the nurses stated that the "good" people outweighed the "bad" people.

"I thought about leaving once but there are too many good people who work here." (1)

"I think there are several reasons why I stay; one is the patients, I love the patients and their families. The other is the new nurses, I like to mentor them and I enjoy watching them grow and develop." (2)

"Well there are other people you work with, like there is one nurse who's fantastic, really helpful." (5)

"There are too many people here who make it worthwhile rather than make it disagreeable." (6)

Three of the nurses interviewed had been in nursing for twenty plus years and expressed the feeling that the more experience you have the better able you are to handle it.

"Later in my career I would step right in and say what is the issue; let's talk this out. Communication has to be respectful." (2)

"I've had enough experience with that and I've been through some education if you will and as you get older you learn that people are not always attacking you personally, it comes from other places which I think a young person doesn't have that background." (2)

"I've learned that it really is about setting up communication networks and having almost like a safe zone where it's ok to say what's going on here and do you realize that this is happening, do you realize this is how you are coming across, do you realize that people are shunning away from you because they're sort of afraid of you and a lot of times when you bring that to someone's mind set they go, oh wow, I didn't quite get that." (6)

A couple of nurses interviewed cited personal and economic reasons as to why they continued to work for the organization. 
"I'm comfortable in my job, I have the hours I want and it works out for my family and I need the money." (3)

"I think I've stayed because I really like the unit that I am working on. I mean I've known some ICU nurses who have left because they just couldn't take it, not being with the in crowd." (6)

All if the nurses interviewed felt that managerial support was lacking.

"I think there is a big problem with nurse managers, they don't get dirty anymore. They just make schedules and walk around and go to meetings. I call them the clip board nurses." (3)

"I think management is a factor. I don't think we have the professionalism we need in some of the supervisors." (6)

"No tolerance policies are not enforced." (4)

"Administration, they don't want to hear it, they don't care." (5)

"I think there is a real lacking of managerial support. Sometimes I think the managers would rather look away because if the bully is truly a bully their gonna be bulling their manager as well." (6)

"I think management could be more involved. I don't see a lot of nurse managers being real visible on the floor and I think they need to be." (7)

In an attempt to identify an intervention to assist the victims of horizontal

violence, a question was asked with regards to stopping the behavior. Did they try to stop the behavior, and if so, were they successful? Also, they were asked "Is there something you feel might work to either prevent or stop the behavior? Several of the nurses felt proper communication worked especially in the event that the perpetrator was not aware of his/her actions.

"Communication has to be respectful, keeping your voice calm and emphasizing respectful communication. It's been pretty effective." (2)

"I think it's all about communication it's all about the way you come across." (2) 
"It needs to be communicated to the person immediately and it has to stopped the behavior in the moment, but it has reoccurred." (6)

"Sometimes I think a lot of it is setting up a communication network and having like that safe zone where it's ok to sat what's going on here and do you realize this is happening. Some people will say that they didn't realize that they were coming across that way." (6)

One nurse suggested role modeling as a way to prevent the behavior while another nurse stated that skills must be taught to nurses on how to handle this type of behavior.

Horizontal violence is not an isolated phenomenon that can be separated from the influences of the work environment. Influences include organizational factors, personality factors of both the perpetrators and the targets of horizontal violence, and stress in the workplace related to low staffing, high patient acuity and increased responsibility. This data indicates that there is ongoing concern regarding horizontal violence as an identified threat too quality of patient care and nurse wellbeing. 


\section{CHAPTER FIVE \\ DISCUSSION AND CONCLUSION}

This chapter will discuss the results of the research questions and theoretical application. Implications of the study for nursing practice will be discussed as well as limitations of the study. Finally, implications for nursing research, practice and education will be discussed followed by the conclusion.

\section{Discussion}

Research Question \#1 - What is the prevalence of horizontal violence (HV) experienced by registered nurses (RNs) during their career?

This question was answered by the results form survey questions $1-4$. The answer to the question related to prevalence on the online survey found that $67.9 \%$ of the respondents reported that they had experienced this type of behavior. The majority of the nurses who responded to when they experienced HV reported that this occurred frequently, as much as daily to one month ago. Several of the respondents reported that this occurred early in their careers as a new nurse with several others reporting that they experienced it throughout their careers in nursing. Some of the respondents were very specific as to when they experienced HV as one nurse stated that this occurs when receiving patients from the recovery room. Another nurse stated that it happened when getting and giving report. One nurse reported that it happened sometimes when she/he gave an opinion and yet another reported it happened when "being blamed for actions that others have done." 
Frequency ranged from rarely to daily with most respondents experiencing it frequently.

When the respondents were asked if they witnessed an act of HV against another, $74 \%$ responded yes. When it was witnessed was similar to when it was experienced in that many of the respondents reported that it was witnessed frequently such as every day, daily, yesterday, last week and at various times. Others were more specific stating that they witnessed it after the person walks away, when others ask for help or ask questions, during conversations with supervisors and especially at shift change. Frequency of witnessing HV was different than experiencing it in that almost all of the respondents witnessed it daily or at least once a week.

The respondents reported witnessing HV more frequently than actually experiencing it. This is also the case in the literature in that witnessing unprofessional behavior is more prevalent than experiencing it (Ditmer, 2010; Rocker, 2008; Walrafen, Brewer \& Mulvenon, 2012; Yildirim, 2009). Chipps and McRury (2012) stated that nurses seem to easily recognize when others are bullied but do not easily self-identify as having experienced bullying. One participant did state that he was uncertain if he was experiencing HV or just the nurse's reaction to stress and therefore he did not respond to the behavior.

\section{Research Question 2 - Who are most likely to be perpetrators reported by RNs?}

For purposes of responding to this question, the online survey provided 7 responses; peer or fellow nurse, patient, patient's family, manager/administrator, physician, other health care worker and other. The majority of the respondents 
(85.5) found that peers or fellow nurses were likely to be the perpetrators followed by physicians (55.1\%). Manager/Administrator was identified by $37.7 \%$ of the respondents. Patient's family and other health care workers were also found to be the perpetrators (36.2\%). The patient was found to exhibit this type of behavior by $29 \%$ of eh respondents while $7.2 \%$ identified others, such as a secretary, physician's assistant and CNAs as the perpetrators.

The literature supports these findings and demonstrates that nurses are major perpetrators of some forms of workplace violence towards other nurses (Jackson, Clare \& Mannix, 2002). Farrell (1999) identified this intercollegial aggression as a major source of work-related distress for nurses and stated that it is common in many clinical settings.

Relationships between nurses and doctors continue to be a concern. O'Connell, Young, Brooks, Hutchings and Lofthouse (2000) stated that medical staff was the most frequent cause of nurses feelings of intimidation and lack of confidence in their own abilities as professionals.

Farrell (1999) stated that nurse managers were consistently found to use aggression towards nurses while relatives and friends of patients were found to be a major source of aggression toward nurses (Nabb, 2000; O'Connell, Young, Brooks, Hutching \& Lofthouse, 2000). Patient aggression is also addressed in the literature suggesting that patients were a common source of verbal and physical abuse (Farrell, 1997; Jackson, Clare \& Mannix, 2002). 
The evidence suggests that horizontal violence experienced by nurses is not isolated to any one person or group in particular. For horizontal violence in health care settings to be reduced, organizational processes must change. Nurse Managers and Administrators must not overlook episodes of unprofessional behavior. Nurse Managers must be a presence on their nursing units and offer support to nurses who are incredibly stressed overworked. Administration must look to ways of assisting the nurses in providing an outlet for their stress. No tolerance policies must be enforced.

\section{Research Question 3 - What are the characteristics of the victims reported by RNs?}

This question began with the online survey question related to the response of the victim to this type of behavior. Five different responses were provided, silence, crying, responded to perpetrator in a very emotional way, walk away and other. Walking away (67.2\%) and silence (58.6\%) were most reported as being the response of eh victim. This was followed by responding to the perpetrator in an emotional way $(34.5 \%)$ and crying $(29.3 \%)$. Some respondents $(20.7 \%)$ reported witnessing other behaviors such as confiding in a fellow nurse, talking it out, withdrawal and voicing concern that the situation would continue to make them feel awkward. This question was also raised during the semi-structured interviews. Several of the nurses interviewed stated that it was the newer, timid nurses who were most on the receiving end of this type of behavior while another nurse stated that it is the new "know it all nurse" who is most likely to be the target. This sentiment was alluded to 
by several of the participants in that "new" nurses were perceived as pushy and somewhat disrespectful to the "seasoned" nurses.

The research regarding new nurse's experience with horizontal violence is abundant (Bartholomew, 2006; Bowles \& Candela, 2005; Budin, Brewer, Chao \& Kovner, 2012; Farrell, 2001; Griffin, 2004; Laschinger, Grau, Finegan \& Wilk, 2010). It would appear that newly graduated nurses need skills to be able to address this negative behavior.

The literature also speaks to the findings in this study with regards to the characteristics and responses of the nurses to episodes of horizontal violence. Many nurses will not respond to the negative acts choosing instead to either suffer in silence, confide in a peer, or walk away (Baltimore, 2006; Becher \& Visovsky, 2012; Roberts, DeMarco \& Griffin, 2009). This is in an attempt to maintain the "status quo" and prevent more disruption (Valentine, 1995).

\section{Research Question 4 - What factors do nurses describe as fostering the occurrence of $\mathrm{HV}$ in the workplace?}

The response to this question began with question number 8 on the online survey. The respondents were given five choices and could choose all that applied. The choices were accepted practice on the unit, increase in work load/stress, patient acuity, manager attitude and lack of implementation of policies. Seventy-two percent of the respondents felt that increase in work load/stress led to episodes of horizontal violence. This was followed by accepted practice on the unit (62.7\%). Manager attitude (49.3\%) and lack of implementation of policies (46.7\%) were also 
identified as increasing HV in the workplace as well as patient acuity (45.3\%). This question was also asked of the participants of the semi-structured interviews. All of the participants felt that stress and increased responsibility were a cause of HV. The participants identified short staffing which led to the increase in stress and added responsibilities. Each of the nurses interviewed felt that manager support was lacking with one nurse actually describing an incident that involved the nurse manager. No tolerance policies are in place at the two facilities that the nurses work in but several of the participants felt that the policies were not enforced. While patient acuity was found to be the least factor seen as increasing HV in the workplace on the online survey, each of the nurses interviewed felt that patient acuity did contribute to stress which contributed to unprofessional behavior.

Several of the nurses interviewed stated that this type of behavior was the "norm" on their units or "that's just so and so being so and so". When managers and indeed staff nurses allow horizontal violence to continue, these behaviors can become the behavioral norm for and the culture of the unit. It indirectly promotes the behavior as acceptable. New staff nurses are socialized into this culture and the behaviors continue. Indeed, organizations can perpetuate this problem by not taking action when horizontal violence occurs. Consequently, nurses continue to accept verbal abuse because they believe that they do not have the power to change it.

The literature also speaks to the culture of the nursing unit as fostering the occurrence of horizontal violence. Walrafen, Brewer and Mulvenon (2012) found that incidents of horizontal violence were a result of the culture on the unit and that 
the nurses "were caught up in the drama". Indeed, there have been many studies that have explored nurses work environments and the culture of the unit as a reason for the continuation of these unprofessional behaviors (Almost, 2006; Bally, 2007; Bigony, Lipke, Lundberg, McGraw, Pagac \& Rogers, 2009; Shader, Broome, Broome, West \& Nash, 2001). Thomas, 2010;

\section{Research Question 5 - What factors do nurses describe as helpful in reducing the occurrence of HV in the workplace?}

Several choices were given on the online survey related to what is helpful in reducing the occurrence of $\mathrm{HV}$. Manager awareness was cited by $77.3 \%$ of the respondents. This is in contrast to the nurses interviewed in that all of the nurses interviewed felt that manager support was lacking. This would suggest that while nurse's state managerial support would be helpful in stopping this behavior, they are not getting it. Staff support (74.7\%) was noted as being helpful in reducing HV. This supports the findings in the interview portion of the study. Several of the nurses interviewed stated that they would and did in fact intervene when a colleague was being mistreated. Also of note in the findings were that nurses who experienced this type of behavior "talked it out with a peer," and "discussed/disclosed" the incident with a fellow nurse. The literature also supports this. Farrell, Bobrowski and Bobrowski (2006) found that talking with colleagues was by far the most helpful following an act of aggression. Similarly, Sofield and Salmond (2003) found that the nurses described their colleagues as being a "constant support" when coping with this type of behavior. Education in the workplace (69.3\%) and education in nursing 
programs (53.3\%) were seen as helpful in reducing HV. One nurse who was interviewed stated that this type of behavior was not specifically addressed during nursing orientation. Although several of the nurses interviewed stated that workplace policies were not enforced, $57.3 \%$ of the respondents to this question on the online survey stated that work place policies did help in reducing horizontal violence in the work place. A small percentage (9.3\%) felt that nothing helps while $8 \%$ identified other actions such as de-escalation techniques and holding people accountable that would be helpful reducing horizontal violence in the workplace.

The literature supports that administrative and management support is essential in establishing and enforcing workplace policies. Enforcing policies mandating zero tolerance is a must if this behavior is to be stopped (Sofield \& Salmond, 2003).

In light of the findings, educational seminars that focus on conflict resolution, communication techniques and stress management can be developed to assists nurses in addressing this destructive behavior.

Research Question 6 - In what way is job performance affected by experiences with HV?

Each of the nurses participating in the semi-structured interviews agreed that job performance is affected by episodes of horizontal violence. The nurses overwhelmingly felt that the patient can sense when something is going on with the nurse and refrain from calling on the nurse for anything they might need. One nurse in particular was caring for a patient and was in and out of the room all day. At one point during the day the nurse had an "unpleasant" experience with a colleague. 
When the nurse went into the patient's room to administer a medication the patient immediately asked him if something was wrong. The nurse was very taken aback and asked the patient why he felt that something was wrong. The patient replied that "I just know." The nurse stated that "here I am thinking that I am going into the patients room like I always do and he sensed right away that something was different." The nurse further went on to state that later in the shift when he went in to check the patient, the patient stated that he had wanted something a while ago but didn't want to bother him (the nurse) because he knew he was having a bad day.

The nurses interviewed stated that episodes of unprofessional behavior left them feeling distressed and that their concentration and judgment were impaired. This has definite implications for patient care. Patient care can also be compromised because of the decrease in the communication and decrease in collaboration among the staff nurses. Further, Hughes (2003) stated that episodes of horizontal violence are not limited solely to the two individuals involved staff who are bystanders are also affected and teamwork is undermined.

Research Question 7 - What protective factors do nurses identify as the reason for remaining in their jobs after experiencing HV?

All of the nurses who participated in the semi-structured interviews stated that peer support after an episode of HV was key to their decision to remain in their current position. Several of the nurses stated that "there are too many good nurses I work with." One nurse stated that she remained because it was a good "fit" for her in terms of hours, family responsibilities and money. Indeed, these are difficult times 
for nurses. Jobs are scarce, especially in acute care settings, and many nurses are fearful that they will lose their jobs secondary to downsizing and units closing.

\section{Interpretation of Findings Related to Critical Social Theory}

Critical social theory is action oriented. It aims to integrate theory and practice such that people become aware of disparities and become inspired to change them. It is a perspective that involves theory, practice and research with the aim of transforming rather than maintaining the status quo.

Critical social theory has been described as an approach for critiquing existing conditions for the purpose of enhancing individual autonomy and responsibility (Wilson-Thomas, 1995). Within this framework, the behaviors that constitute horizontal violence have been brought to light. The majority of nurses participating in this study were knowledgeable about horizontal violence and behaviors that constituted horizontal violence, however, actions to decrease these behaviors were much less understood. Habermas contended that critical theory helps to uncover what one ought to do to emancipate themselves from forms of domination. This is accomplished through a process of self-reflection. Self-reflection involves learning by reflecting on actions in the hope of gaining insight from an experience. Without reflection, patterns of communication and socialization are reproduced (Finlayson, 2004). Several nurses in this study spoke of support groups to help deal with the unprofessional behavior. Support groups may help to bring about self-reflection as a means of managing behaviors associated with horizontal violence. 
Critical social theory speaks to oppression; research question 3 speaks to the characteristics of the victims and how the nurse reacted to episodes of horizontal violence. Based on the findings, oppressed group behaviors were demonstrated. Nurses reported silence and walking away in response to horizontal violence and this pattern has been seen repeatedly in the literature in relation to these types of negative acts (Cox, 1991; DeMarco \& Roberts, 2003; Roberts, DeMarco \& Griffin, 2009). Critical social theory seeks to liberate individuals from constraints that interfere with social interactions. This theory has implications for looking at these relationships for the purpose of enhancing individual responsibility and improving the culture on the nursing units.

\section{Levels of Explanation}

Farrell (2001) offered three levels of explanation to account for poor staff relationships; a macro level, a meso level and a micro level. A macro level focuses on nurses' relationships with powerful others and their resultant marginalization. It avoids discussing the details of individual incidents in favor of looking at nursing with respect to medicine and other perceived dominant groups in terms of the denial of

power and control. Accordingly, nurses feel alienated and removed from decisions of control over their working conditions. A meso level focus concentrates on the organizational structures, including workplace practices many of which Farrell contends are controlled by nurses themselves. A micro level focus then is one that acknowledges the individual determinant of aggression. For example, nurses can 
choose to treat each other with respect or stand up for a colleague who is unfairly treated.

Within critical social theory, the macro level looks at the position of nurses with regards to power imbalances within an organization. Nursing work is increasingly driven by managerial imperatives (Hutchinson, Vickers, Jackson \& Wilkes, 2006). Nursing activities are constantly monitored and reported. Nurses are typically not included in the financial and decision making forums and therefore are in constant fear of their jobs. Indeed, these are difficult times economically in healthcare. Acute care hospitals are merging and units are closing in response to lost revenue. This study found that despite experiencing horizontal violence, some nurses continued to work for the organization because they needed the job; they needed the money.

The meso level then would look at the way nursing is practiced within the organization and particularly on the nursing units. Despite having experienced horizontal violence many nurses choose to stay in their current position. The nurses in this study stated that peer support was vital when instances of horizontal violence was either experienced or witnessed. Several nurses did not stop the behavior when it was happening to them but did step in when witnessing it. Those that did not stop the behavior sought the support of a peer after the occurrence. Managerial support was also cited as necessary in stopping these types of behaviors although, the nurses felt that support from managers and administration was lacking.

At the micro level, training must be offered to graduate nurses and nurses new to an organization with regards to combating this behavior. Griffin (2004) taught new 
nurses cognitive rehearsal as a means to handle horizontal violence in the moment. Although the nurses did not rely on this method "in the moment" all of them reported that knowledge of horizontal violence was crucial. In this study, a higher percentage of nurses witnessed this occurrence than experienced it. Several of the nurses stated that they would "step in" when they saw this happening. Interventional studies aimed at the witness are needed. If nurses can learn strategies to effectively step in when witnessing horizontal violence then perhaps this type of behavior would lessen. There is power in numbers and by stepping in and assisting the nurse experiencing horizontal violence, the perpetrator might also benefit.

If horizontal violence is to be halted, all of these levels within an organization need to be scrutinized. The importance of looking at staff conflict with regards to each of these levels acknowledges that there is a connection between the three that helps to explain the occurrence and promote resolution of the phenomenon. Thus, according to Farrell (2001) when attempting to account for conflict, individual characteristics, demographic variable and stressors from within and outside the work situation must be considered. This is especially true as this time when faced with an aging population, increase in chronic illness and economic pressures in healthcare.

\section{Limitations}

This study was based on nurses' perceptions of horizontal violence in the work environment and what they believed caused these negative behaviors. All of the qualitative data was from participants' recollections of past events during tape recorded interviews. Observation of interactions on the clinical unit was not utilized 
as this was not a practical option for this study. The presence of the researcher on the unit could have changed how the staff interacted with each other.

A possible limitation to the study was the sample size for both the quantitative data and qualitative interviews. The sample size for the online interview was small (78 respondents). Data collected reflected the literature however a larger sample may have brought to light information not previously obtained about horizontal violence in the nursing work environment. Although the seven nurses agreeing to be interviewed were able to provide richly detailed data that met the requirement of the study, they may not have been representative of the workforce in nursing as they are employed in two city hospitals. Also, this is not a representative sample of nurses as people self-selected to participate in the survey. This biases the sample and thus the findings are not generalizable. However, the results of this study support the literature on horizontal violence.

Another possible limitation was that the researcher was well known to many of the participants. Although it may have been an advantage in that the interviewees felt comfortable sharing information, there was concern that the participant's responses were influenced by their knowledge of both the researcher and the project. 


\section{Implications for Nursing Research, Practice and Education}

Disruptive behaviors associated with horizontal violence continue to exist, are toxic to the nursing profession, and have a negative impact on retention. Horizontal violence is detrimental to nurses' well-being and organizational culture. It results in nursing dissatisfaction, interrupts communication and has implications related to patient outcomes. This has definite implications for nursing research, practice and education.

\section{Nursing Research}

Both the online survey and the semi-structured interviews revealed that peer support was important after an incident of horizontal violence. However, reluctance to report these incidents, particularly related to fear of retaliation, and belief that this is the way it is, can stymie an organization into identifying ways to combat this behavior. The respondents to the semi-structured interviews related a lack of managerial support indicating that the nurse manager plays a vital role in achieving and maintaining a positive unit culture. Although nursing research directed at methods to increase understanding and awareness of horizontal violence have been conducted, more is needed with regards to the skills necessary to combat this behavior.

Nursing research is needed to identify ways to improve RN work relationships and increase the level of professionalism between nurses. When one particular nurse was asked about how she responded to an episode of unprofessional behavior she replied that she dealt with it on the spot in a "no nonsense manner". When ask if the 
other nurse might potentially see her as the aggressor, she replied "I don't care." Certainly, respondents were able to recognize the behaviors in their coworkers but perhaps, not in themselves. This was also evident when one nurse said that she also addressed the behavior in the moment and hoped that she wasn't seen as the "bully." Nurses are certainly in a position to identify and intervene on the part of their colleague when they see or experience horizontal violence. With increased awareness, nurses may be better able to monitor themselves, as well as assist fellow nurses to recognize when they are exhibiting negative behaviors.

Although there have been several interventional studies conducted to help nurses respond to this type of behavior, further interventional studies are needed to help individual nurses effectively cope with horizontal violence and to describe barriers within the organization that prevent nurses from advocating for themselves and their practice

\section{Questions that need to be addressed}

Although the study addressed protective factors that nurses identified as the reason for remaining in their jobs after experiencing episodes of horizontal violence, this area needs to be explored more thoroughly. The nurses in this study stated that peer support was essential however it would be interesting to see if other protective factors could be identified. Peer support could be studied as a strategy to decrease horizontal violence.

Stress was identified by all of the interviewees as a cause of HV. Overwhelmingly, the literature supports this. However, what factors are protective against stress? 
Nursing research examining different care environments consistently identifies common sources of stress that nurses must manage while at work (Almost, 2006; Becher \& Visovsky, 2012; Kupperschmidt, Kientz, Ward \& Reinholz, 2010; SheridanLeos, 2008 ). With this knowledge, research can be undertaken to identify protective factors which can be employed in the workplace to counteract the stress.

There have been many studies regarding registered nurses' experiences with horizontal violence and new graduate nurse's experiences. Research soliciting the views of student nurses and nurse educators may provide information useful in answering the questions "When does the behavior begin?" and "Is it a learned behavior?"

\section{Contributions to Nursing Knowledge}

The domain of practice as conceptualized by Kim (2010) includes phenomena particular to the nurse who is engaged in delivering nursing care. It includes concepts related to what nurses do "in the name of nursing." Further, Kim stated that within the domain of practice, interest lies in understanding and explaining nursing practice and in improving the way nursing is practiced. Within the practice domain Kim asserted that two kinds of variables should be considered. These are exogenous variable and intrinsic variables. Exogenous variables are those "outside"

of the nurse and include organizational factors; culture of nursing practice including norms and ethics and patient oriented factors such as nursing care requirements. Intrinsic values are those specific to the nurse. These variables include personal characteristics; cognitive style; characteristics developed as a result of previous 
experience and professional characteristics. Horizontal violence situates itself in the practice domain. The literature suggests that the antecedents of horizontal violence exist in both exogenous variables such as the organization and the culture of the nursing unit and intrinsic variables such as personal attributes and previous experience.

Kim speaks to three different structures that compose nursing practice; the philosophies, the dimensions and the processes. Philosophy provides fundamental guidelines for nursing practice to be carried out and includes three orientations; therapy, care, and professional work. The structure of dimension refers to characteristics that make up the nature of nursing practice constituted by scientific, aesthetic and ethical. The structure of process refers to how nursing practice is carried out and is concerned with deliberation and enactment.

The philosophy of therapy provides guidelines for the parts of practice that are goal oriented and aimed at solving or addressing problems. The major tenets are remedy and treatment. This philosophy, according to Kim, guides nurses to select and implement nursing actions that are effective, efficient, timely and appropriate.

The philosophy of care orients nursing practice to involve all of the experiences of the person as a human being. This looks to uphold values of individuality, respectfulness and wholeness. Philosophy of care requires attendance to basic needs and providing care to patients as "human persons." In a profession that is rooted in caring, why at times do nurses not care for each other? The results of this study support that horizontal violence continues to be an issue within the profession. 
The philosophy of work is oriented towards meeting the standards of professional conduct in nursing. It provides guidelines for prioritizing, coordinating one's work with other members of the health care team and searching for the best solutions and approaches while following the established ethical standards for practice.

The major orientation of this philosophy is clinical situations that involve the patient. When a nurse engages in horizontal violence, the profession suffers. When a nurse is exposed to unprofessional behavior by a colleague, patient care suffers. Kim stated that while nursing practice is composed of three sets of structures it also encompasses three dimensions that must exist together. The dimensions are science, professional ethics and aesthetics. The dimension of science refers to making practice decisions guided by science and scientific knowledge. The dimension of professional ethics is reflected in the everyday conduct of nursing practice which relates to and affects the patient. The aesthetic characteristics of nursing practice refers to the way the nurse comports herself/himself in relation to the clinical situation to achieve a positive outcome. Nursing practice then, includes these three characteristics which are integrated to bring about the best possible outcome for the patient. The dimensions of professional ethics and aesthetics are clearly not evident in a nurse who demonstrates behaviors that constitute horizontal violence.

Horizontal violence in nursing is a serious issue in the domain of practice not only to the targeted nurse but also the patient. It interferes with communication among nurses which potentially could be disastrous for the nurses and the patients well being. The fact that some nurses can treat a colleague in such a demeaning manner 
is great cause for concern. The profession has worked hard to establish itself and only if we work to eliminate it will nurses be able to fulfill their professional commitments to patients, families, communities and themselves.

\section{Nursing Education and Practice}

Nurses in this study recognized horizontal violence as a phenomenon that occurred early in their careers as novice nurses. Study participants described incidents that happened very early in their careers that made them question the profession they had chosen. The academic environment is an ideal place to teach the skills necessary to respond appropriately to horizontal violence between nurses at work. The safe environment of the classroom can give students an opportunity to discuss the different behaviors they have witnessed and develop constructive strategies for recognizing and managing these interactions (Mendez, 2011).

Within the hospital setting, one venue for targeting horizontal violence is continuing education programs presented as short educational offerings targeting interpersonal skills and relationships in the workplace. Nurses must also be made aware of policies within their organization which address these types of behaviors.

Nurse leaders are in a position to prevent and eliminate horizontal violence by providing resources in terms of support and education. Providing resources to decrease job stress and anxiety can prepare nurses to care for their patients (Longo \& Sherman, 2007). Providing ample opportunities for education and professional development is important in planning to prevent or eliminate horizontal violence in the workplace (Becher \& Visovsky, 2012). 


\section{Summary}

Horizontal violence or behaviors that constitute horizontal violence in nursing have been present for as long as the profession has existed making it a prominent issue in the field (Privitera, 2010). Throughout the thirty years that the nursing profession has been discussing horizontal violence no definitive resolution to this recognized problem has emerged. Although the terms used to identify the phenomenon have changed over the years, the underlying problem of nurse-to-nurse hostility and aggression have been a constant in the nursing work environment.

The evidence indicates that the majority of working nurses will experience horizontal violence in the workplace. Horizontal violence as a phenomenon includes behaviors such as, verbally abusive communications, workplace sabotage, difficult patient care assignments, social isolation and non-verbal behaviors such as eyerolling or raised eyebrows. Although the literature confirms that nurses recognize that these negative behaviors can put patients at risk, the behaviors continue to occur.

Horizontal violence is not an isolated phenomenon that can be separated from the influences of the work environment. Influences include effects of oppression, organizational factors, personality factors of both the perpetrators and the victims and stress in the workplace. After many years of scholarly discussion and suggestions for change, these negative behaviors continue to occur. An alternate or additional explanation is needed to constructively manage behaviors that are damaging to the patients and nurses involved in these events. 
B25 CHALKSTONE AVENUE 825 CHALCSTONE AVENUE
PROVIDENCE, RI 02908-1735 (401) $458-2000$

July 3,2013

Elizabeth M. Bloom MSN, PhDc, RN

Interim Director

St. Joseph School of Nursing

200 High Service Avenue

North Providence, RI 02904

RE: RWH\# 13-719-99; entitled; "Horizontal Violence Among Nurses: Experiences, Responses and Job Performance"

Dear Ms Bloom:

Thank you for submitting the revised protocol, questionnaire and consent form inclusive of the changes requested by the expedited reviewer on June 25,2013 as vell as the draft recruitment flyer.

This protocol and consent form both dated $6 / 28 / 13$ are approved as submitted, and the study may commence. Please submit your final recruitment flyer for review and approval prior to its use.

Under Federal and Committee regulations, this protocol will automatically be submitted for continuing review in June 2014. Prior to that time, it will be necessary for you to submit a Progress Report regarding the activities of this study.

The Human Research Review Committee is in compliance with the requirements in Part 56 Subchapter D, Part 312 of the 21 Code of Federal Regulations published January 27, 1981.

\section{Sincerely,}

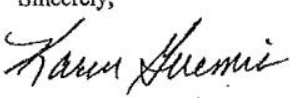

Karen Geremia, Director

Human Research Review Committee

KG:cs 


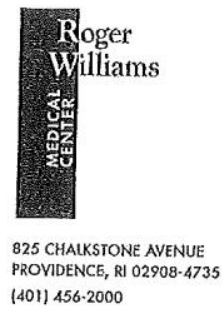

WWW.RWMC,ORG

July 3,2013

Elizabeth M. Bloom MSN, PhDc, RN

Interim Director

St. Joseph School of Nursing

200 High Service Avenue

North Providence, RI 02904

RE: RWH\# 13-719-99; entitled; "Horizontal Violence Among Nurses: Experiences, Responses and Job Performance"

Dear Ms Bloom:

Thank you for submitting the recruitment flyer, for the above mentioned study. The advertisement was submitted for expedited review and approved as written on October 22, 2013.

The Human Research Review Committee is in compliance with the requirements in Part 56, Subchapter D, Patt 312 of the 21 Code of Federal Regulations published January 27, 1981.

Sincerely,

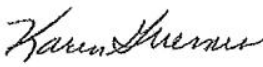

Karen Geremia, Director

Human Research Review Committee

\section{KG:cs}

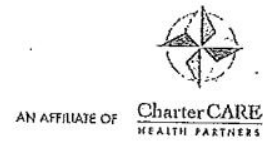




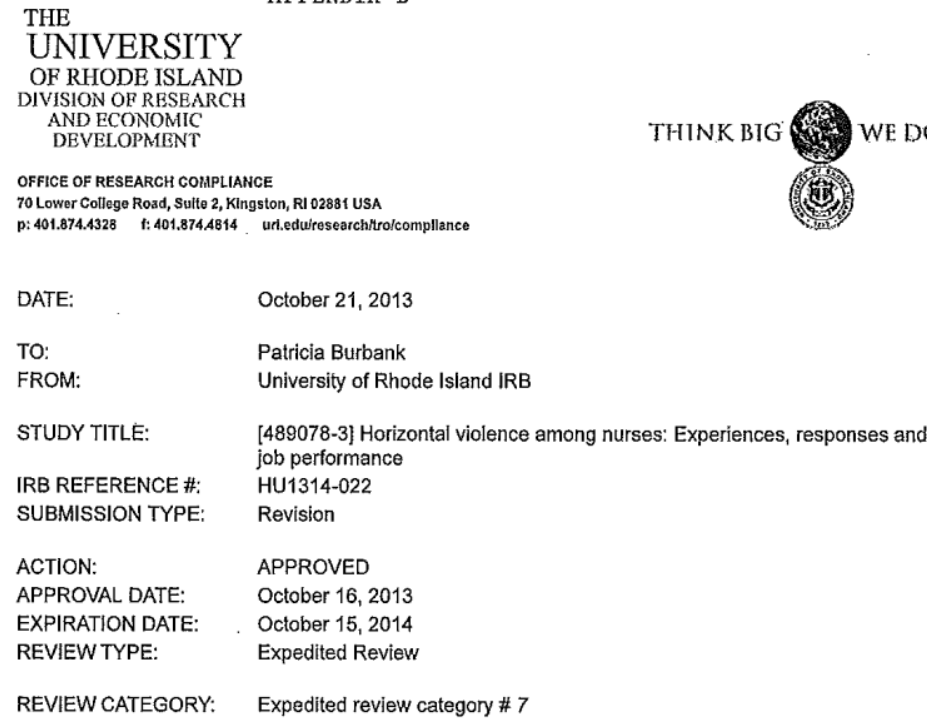

REVIEW CATEGORY: Expedited review category \# 7

Thank you for your submission of Revision materials for this research study. University of Rhode Island IRB has APPROVED your submission. This approval is based on an appropriate risk/benefit ratio and a study design wherein the risks have been minimized. All research must be conducted in accordance with this approved submission.

This submission has received Expedited Review based on the applicable federal regulation.

Please note that any revislon to previously approved materials must be approved by this office prior to initiation. Please use the appropriate revision forms for this procedure.

All SERIOUS and UNEXPECTED adverse events must be reported to this office. Please use the appropriate adverse event forms for this procedure. All FDA and sponsor reporting requirements should also be followed.

Please report all NON-COMPLIANCE issues or COMPLAINTS regarding this study to this office.

Please note that all research records must be retained for a minimum of three years.

Based on the risks, this project requires Continuing Review by this office by October 15, 2014. Please use the appropriate renewal forms for this procedure.

If you have any questions, please contact us by email at compliance@ds.uri.edu. Please include your study title and reference number in all correspondence with this office.

Please remember that informed consent is a process beginning with a description of the study and insurance of participant understanding followed by a signed consent form. Informed consent must continue throughout the study via a dialogue between the researcher and research participant. Federal

$$
-1-
$$


regulations require each participant receive a copy of the signed consent document unless the signature requirement has been waived by the IRB. 


\section{APPENDIX C}

\section{SAINT JOSEPH HEALTH SERVICES}

\section{Providence, Rhode Island}

Principle Investigator: Patricia Burbank

PhD Student Investigator: Elizabeth Bloom

University of Rhode Island

\section{CONSENT FORM}

\section{You are invited to participate in the following study:}

Horizontal violence among nurses: Experiences, responses and job performance.

The purpose of this study is to examine the characteristics of horizontal violence defined as the persistent demeaning and downgrading of another through vicious words and cruel acts (Randle, 2003). You are being asked to participate in this study as the researcher hopes to explore nurses' responses to horizontal violence incidents and identify factors that help successfully respond to these incidents.

\section{If you decide to participate, the procedures to be followed are explained} below:

An interview time and place will be set up at your convenience. Questions about your experiences with horizontal violence will be asked. You will be asked to describe these experiences, how you felt and how you responded. Questions related to how these incidents affected job performance will also be asked. The study will require one interview lasting approximately 60 minutes or until you want to stop. The interview will be taped recorded with your permission. 
3. Those procedures and/or substances, which are investigational, have been described as:

This project, through in-depth interviews, is investigating horizontal violence, its prevalence, consequences and how you react to these types of behavior

4. The following complications or risks have been reported, or are known, or may occur:

You may feel uncomfortable describing your experiences with horizontal violence.

5. The benefits, which can be expected, have been describes as:

You will receive no direct benefit from taking part in the study.

6. The alternative procedures, if any, which would be possibly advantageous to you, have been described as follows:

The alternative is not participating in the study.

7. Financial considerations:

There is no compensation for taking part in this study.

8. Should any problems arise during the study or in the event of a study related injury, Elizabeth Bloom URI PhD candidate may be contacted by calling (401) 456-3054 or (401) 742-2946. Dr. Patricia Burbank, principle investigator, may be contacted by calling (401) 874-5314

9. Your confidentiality will be maintained as follows:

If you give the student investigator permission by signing this document, information that does not identify you by name, may be used. The information will be used for the principle investigators dissertation in partial fulfillment of the PhD program in nursing at the University of Rhode Island. The student investigators dissertation committee may have access to information however; the information will not identify you by name. All records relating to this project will be handled and safeguarded according to standard hospital policy. The data will be kept on paper, digital and audio tapes. The data will be stored in a locked filing cabinet in the student researcher's office at St. Joseph School of Nursing, 200 High Service 
Avenue, North Providence RI for a period of three years. The student investigator, principle investigator and the Dean of URI College of Nursing will have access to the data. The data will be communicated electronically by email. All persons having access to the data have password protected emails.

10. If you have questions about the research you may contact Beth Bloom at (401) 456-3054 or Patricia Burbank at (401) 874-5314. If you have questions about your rights as a research subject or otherwise, please contact: James Melfi at (401) 456-3143.

11. You are making a decision whether or not to participate in this study. Your decision whether or not to participate will not prejudice your future relationship with Saint Joseph Health Services of Rhode Island or Roger Williams Medical Center. If you decide to participate, you are free to withdraw your consent and to discontinue your participation at anytime without prejudice. In addition, if you have any questions about your rights as a research participant, you may contact the office of the Vice President for Research, 70 Lower College Road, Suite 2, University of Rhode Island, Kingston, Rhode Island, telephone: (401) 874-4328.

12. You understand that you do not have to participate in this study. You have read this informed consent and agree to participate in the study. You have received a copy of this consent.

13. You consent to tape recording the interview.

PARTICIPANT DATE TIME

THIS EVIDENCE OF INFORMED CONSENT MUST BE SIGNED BY THE PARTICIPANT

PARTICIPANT DATE TIME

WITNESS DATE TIME

Participants Initials 
I have explained this study to the participants:

PERSON EXPLAINING

THE

STUDY

DATE TIME

WITNESS

DATE TIME

Participants Initials 
APPENDIX D

\section{URI COLLEGE OF NURSING RESEARCH HORIZONTAL VIOLENCE}

- The phenomenon of Horizontal Violence (HV) in nursing, while not new to the profession continues to be of concem.

- It is costly and has been linked to high nursing turn over rates, increased illness, decreased productivity, and lower quality of patient care.

- You are invited to participate In a study on this important topic in nursing.

- The study will consist of an anonymous on -line survey located on the Chartercare intranet on the left of the screen entitled "Horizontal

Violence Survey". This would be followed by an

interview for those consenting to be interviewed.

- This study is voluntary and will contribute to what is known about HV and how to prevent it.

- For more Informatlon contact Elizabeth Bloom at $456 \cdot 3054$

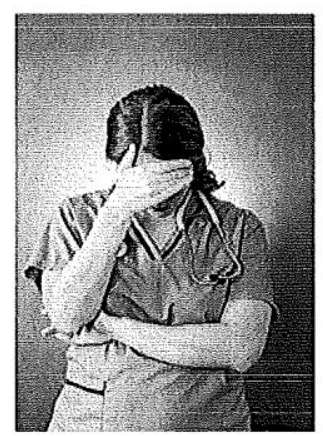




\section{APPENDIX E}

\section{ONLINE QUESTIONNAIRE}

Horizontal violence/lateral violence is the persistent demeaning and downgrading of another through vicious words and cruel acts (Randle, 2003). It is manifested through overt behaviors such as withholding pertinent information, criticism and failure to respect confidences, and covert behaviors such as "eyebrow raising", snide remarks and turning away (Griffin, 2004).

1. Using the above definition, please state whether you have experienced this type of behavior.

Yes

No

2. If Yes:

When?

How

Frequently?

3. Have you seen others subjected to this type of behavior?

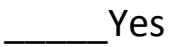

NO

4. If Yes:

When?

How

frequently

5. If you have witnessed this type of behavior, what was the response of the victim?

Silence

Crying

Responded to perpetrator in a very emotional way, i.e. speaking through a very tight larynx

Walk away

Other

(Griffin, 2004) 
6. What do you view as helpful in reducing horizontal violence in the workplace? Check all that apply:

Workplace policy Manager awareness and support Education in the workplace Education in nursing programs Staff support Nothing helps Other

7. If you have experienced horizontal violence or have seen others who have been treated poorly, who is most likely to exhibit this negative behavior? Check all that apply.

Peer or fellow nurse

Patient Patient's family Manager/Administrator Physician Other health care worker Other

(Farrell, 1997; Wilson, Diedrich, Phelps \& Choi, 2011)

8. What factors do you view as increasing horizontal violence in the workplace?

Accepted practice on the unit Increase in work load/stress Patient acuity Manager attitude Lack of implementation of policies Other 
APPENDIX F

WHEN EXPERIENCED AND FREQUENCY

\begin{tabular}{|l|l|}
\hline \multicolumn{1}{|c|}{ WHEN } & HOW FREQUENTLY \\
\hline Today & Every hour \\
\hline Many times & Very frequently \\
\hline Every shift & Every shift \\
\hline In our work environment & Daily \\
\hline This week & Almost daily \\
\hline Daily & Daily \\
\hline Previous employment & Almost daily \\
\hline $2-3$ weeks ago & $1-2$ times per week \\
\hline Early in my career and when I went to graduate \\
school & Weekly \\
\hline Getting/giving report & \\
\hline Recently & 3 or more times per week \\
\hline Years ago & Few times a week \\
\hline Over most of my experience as an RN & Weekly \\
\hline Receiving patients from RR & At least once a week \\
\hline As a new nurse & Weekly \\
\hline Three weeks ago & Once a week \\
\hline Work & At least once a week \\
\hline Yes, while working at Rhode Island Hospital & Maybe once a week \\
\hline Two weeks ago & Several times \\
\hline Varies in time and place & At least once a month \\
\hline Recovery Room & Monthly \\
\hline Three weeks ago & Several times a month \\
\hline During meetings & Every other month \\
\hline Various times & Once a month \\
\hline More than once in the past month & Every few months \\
\hline $3-11$ shift & At least 3 times \\
\hline Over past several months & Varies \\
\hline Throughout my 30 year career in nursing & Personally, infrequent \\
\hline Within the past year & Observed, frequently \\
\hline In previous jobs & Can't say for sure \\
\hline 2 days ago & Sporadic \\
\hline 8 years ago & $1-2$ times a month \\
\hline Not exactly sure of specific time frame & Varies \\
\hline & Not frequently \\
\hline & Infrequently \\
\hline
\end{tabular}




\begin{tabular}{|l|l|}
\hline When being blamed for actions that others have done & Every few years \\
\hline When I was a staff nurse years ago & $2-3$ times \\
\hline Sometimes when I give my opinion & Random \\
\hline 12 years ago & As a new employee \\
\hline When I started nursing/night shift & $1-2$ weeks \\
\hline 3 years ago & 2 weeks \\
\hline $2011 / 2012$ & Twice \\
\hline At work & Twice \\
\hline One month ago & Once \\
\hline August 2013 & Once \\
\hline Within this year & Once \\
\hline 3 months ago & Rarely \\
\hline Occasionally & \\
\hline
\end{tabular}


APPENDIX G

WHEN WITNESSED AND FREQUENCY

\begin{tabular}{|l|l|}
\hline \multicolumn{1}{|c|}{ WHEN WITNESSED } & \\
\hline Every day & Every hour \\
\hline Daily & Daily \\
\hline Yesterday & Daily \\
\hline Daily & Daily \\
\hline Usually after the person walks away & Daily \\
\hline Most of the months & All the time \\
\hline Recently & Almost daily \\
\hline $\begin{array}{l}\text { When others ask for help or ask } \\
\text { questions }\end{array}$ & Daily on specific units \\
\hline Every shift & Every shift \\
\hline Previous employment & Almost daily \\
\hline Getting/giving report & Often \\
\hline When doing job & $1-2$ times/week \\
\hline Various times & Weekly \\
\hline Over my years of experience as an RN & At least once/week \\
\hline Last week & Almost weekly \\
\hline At different times & Once a month \\
\hline In previous jobs & $1-2$ times per month \\
\hline Over the past several months & Over the past several months \\
\hline Various times & Every few months \\
\hline While working at Rhode Island Hospital & Several times \\
\hline $\begin{array}{l}\text { Surgeons towards charge nurse and also } \\
\text { surgeons toward nurses and techs during } \\
\text { surgery }\end{array}$ & Occasionally \\
\hline $3-11$ shift & \\
\hline Two weeks ago & Varies \\
\hline During conversations with superior & A couple times \\
\hline Same shift (night shift) over time & $3 x$ a year or more if perpetrator is MD \\
\hline When there are breeches of rules & Whenever someone new started \\
\hline Three months ago & Every few years \\
\hline Last week & Rarely \\
\hline A few years ago & One time \\
\hline $\begin{array}{l}\text { In the same clinical setting where it } \\
\text { happened to me }\end{array}$ & Once \\
\hline 2012 & Once or twice \\
\hline One month ago & Once \\
\hline & Once \\
\hline
\end{tabular}




\begin{tabular}{|l|l|}
\hline Not exactly sure when & Infrequent \\
\hline $\begin{array}{l}\text { When I worked as a nurse's aide on the } \\
\text { floor seven years ago }\end{array}$ & Not frequently \\
\hline $1-2$ weeks ago & \\
\hline Occasionally & Occasionally \\
\hline Occasionally & Occasionally \\
\hline
\end{tabular}




\section{APPENDIX H \\ QUALITATIVE QUESTIONS}

1. Have you personally experienced horizontal violence? If yes, describe the two most distressing incidents that you remember. Are there any other incidents that you would like to tell me about?

2. What was your response to these incidents?

3. What happened as a result to your response?

4. Did you try to stop the behavior?

5. What if any were the responses that were successful in stopping the behavior?

6. How did these incidents affect job performance?

7. Despite having experienced this behavior, what are the reasons you chose to stay in the position? 


\section{APPENDIX I}

\section{THEMES}

$\begin{array}{ll}\text { A - Stress } & \text { Cause } \\ \text { B - Patient acuity } & \text { Cause } \\ \text { C - Short staffing/increased responsibility } & \text { Cause } \\ \text { D - Not helping/ignoring/avoiding } & \text { Characteristics } \\ \text { E - New nurse } & \text { When } \\ \text { F - Personality (of both) } & \text { Cause } \\ \text { G - Managerial support } & \text { Cause, consequence } \\ \text { H - Communication (lack of) } & \text { Cause } \\ \text { I - Job performance } & \text { Consequence } \\ \text { J - Affect patients } & \text { Consequence } \\ \text { K- Who is the perpetrator } & \text { Who } \\ \text { L - Victims } & \text { Cause } \\ \text { M - How did it make you feel? } & \text { Characteristics } \\ \mathrm{N}-\text { Floating to another unit } & \text { Consequence } \\ \end{array}$


APPENDIX J

\begin{tabular}{|c|c|c|c|c|c|c|}
\hline Interview & Causes & $\begin{array}{c}\text { Characterist } \\
\text { ics }\end{array}$ & When & Who & $\begin{array}{c}\text { Consequenc } \\
\text { es }\end{array}$ & $\begin{array}{c}\text { Response } \\
\mathrm{s} \\
\end{array}$ \\
\hline$\# 1$ & $\begin{array}{l}\begin{array}{l}\text { Older and } \\
\text { younger } \\
\text { nurses } \\
\text { working } \\
\text { together }\end{array} \\
\text { Happens a } \\
\text { lot with } \\
\text { floating } \\
\text { New nurse } \\
\text { who is } \\
\text { insecure } \\
\text { Stress } \\
\text { High acuity } \\
\text { Nurses } \\
\text { doing more } \\
\text { and more } \\
\text { on the } \\
\text { floor } \\
\text { Culture of } \\
\text { the unit } \\
\text { Long hours, } \\
\text { being tired }\end{array}$ & $\begin{array}{l}\text { Avoid } \\
\text { Ignore } \\
\text { Facial } \\
\text { expressions } \\
\text { Yelling, } \\
\text { screaming } \\
\text { They snap at } \\
\text { you } \\
\text { Not helping } \\
\text { out } \\
\text { Silent abuse } \\
\text { Not always } \\
\text { aware of } \\
\text { how they } \\
\text { are acting }\end{array}$ & $\begin{array}{l}\text { As a new } \\
\text { nurse } \\
\text { During my } \\
\text { orientation } \\
\text { When the } \\
\text { perpetrator } \\
\text { is having a } \\
\text { bad day } \\
\text { Floating to } \\
\text { another unit }\end{array}$ & $\begin{array}{l}\text { Younger RNs } \\
\text { were the } \\
\text { perpetrators } \\
\text { That's how } \\
\text { the person } \\
\text { usually is } \\
\text { Physician } \\
\text { Physician's } \\
\text { Assistant } \\
\text { New recruits }\end{array}$ & $\begin{array}{l}\text { Just chalked } \\
\text { it up to } \\
\text { experience } \\
\text { and went on } \\
\text { Patients are } \\
\text { affected, } \\
\text { when I am } \\
\text { given the } \\
\text { worst } \\
\text { assignment } \\
\text { and I can't } \\
\text { answer the } \\
\text { call lights in } \\
\text { a timely } \\
\text { manner } \\
\text { It does } \\
\text { affect } \\
\text { patients } \\
\text { because } \\
\text { they can } \\
\text { sense you } \\
\text { are having a } \\
\text { bad day and } \\
\text { they don't } \\
\text { want to } \\
\text { that you can } \\
\text { get away } \\
\text { from it } \\
\text { 100\% } \\
\text { even though } \\
\text { they may } \\
\text { need } \\
\text { something } \\
\text { I think the } \\
\text { patients are } \\
\text { so attune to } \\
\text { what's going } \\
\text { on and the } \\
\text { nurses don't } \\
\text { realize it } \\
\text { and think } \\
\text { that }\end{array}$ & 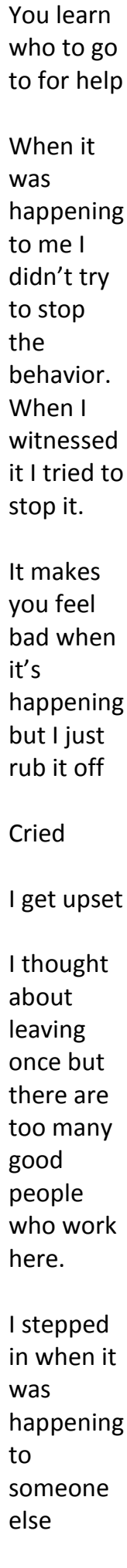 \\
\hline
\end{tabular}




\begin{tabular}{|c|c|c|c|c|c|c|}
\hline & & & & & $\begin{array}{l}\text { patient } \\
\text { suffering }\end{array}$ & \\
\hline \#2 & $\begin{array}{l}\text { Different } \\
\text { generation } \\
\text { s working } \\
\text { together } \\
\text { "They have } \\
\text { to go } \\
\text { through it } \\
\text { because } \\
\text { we went } \\
\text { through it" } \\
\text { Stress, } \\
\text { stressful } \\
\text { environme } \\
\text { nt } \\
\text { Personal } \\
\text { issues } \\
\text { Culture of } \\
\text { the unit } \\
\text { Poor } \\
\text { communica } \\
\text { tion }\end{array}$ & $\begin{array}{l}\text { Disrespectfu } \\
\text { I } \\
\text { communica- } \\
\text { tion } \\
\text { People } \\
\text { aren't } \\
\text { always } \\
\text { aware of } \\
\text { how they } \\
\text { are coming } \\
\text { across. }\end{array}$ & New nurse & $\begin{array}{l}\text { Head nurse } \\
\text { Physician }\end{array}$ & 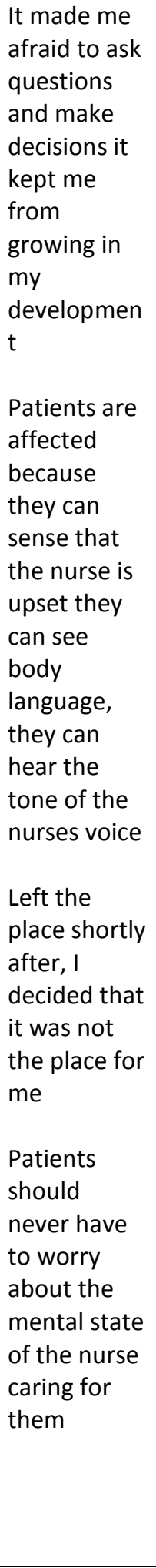 & 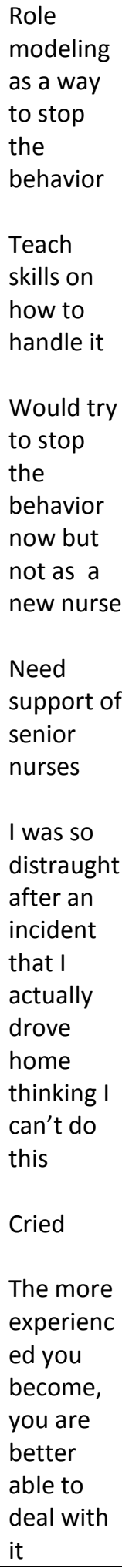 \\
\hline \#3 & Short staff & $\begin{array}{l}\text { A lot of } \\
\text { snapping }\end{array}$ & $\begin{array}{l}\text { HV happens } \\
\text { behind the }\end{array}$ & $\begin{array}{l}\text { Nurse } \\
\text { manager - I }\end{array}$ & $\begin{array}{l}\text { Would leave } \\
\text { job if it }\end{array}$ & $\begin{array}{l}\text { Didn't } \\
\text { report the }\end{array}$ \\
\hline
\end{tabular}




\begin{tabular}{|c|c|c|c|c|c|c|}
\hline & $\begin{array}{l}\text { High } \\
\text { patient } \\
\text { acuity } \\
\text { Stress }\end{array}$ & $\begin{array}{l}\text { between } \\
\text { nurses } \\
\text { Not willing } \\
\text { to help each } \\
\text { other } \\
\text { Talking } \\
\text { down to } \\
\text { aides } \\
\text { Yelling, } \\
\text { screaming }\end{array}$ & $\begin{array}{l}\text { scene, } \\
\text { people } \\
\text { watching } \\
\text { other } \\
\text { people and } \\
\text { reporting } \\
\text { back } \\
\text { Everyone is } \\
\text { a target }\end{array}$ & $\begin{array}{l}\text { call them } \\
\text { "clip board" } \\
\text { nurses } \\
\text { because all } \\
\text { they do is } \\
\text { walk around } \\
\text { with their } \\
\text { clip boards } \\
\text { and go to } \\
\text { meetings. I } \\
\text { think they } \\
\text { are very } \\
\text { insecure }\end{array}$ & $\begin{array}{l}\text { persisted } \\
\text { It could } \\
\text { affect both } \\
\text { the patient } \\
\text { and job } \\
\text { performanc } \\
\text { e depending } \\
\text { on the } \\
\text { person, if } \\
\text { they take } \\
\text { things to } \\
\text { heart }\end{array}$ & $\begin{array}{l}\text { episode } \\
\text { for fear of } \\
\text { retaliation } \\
\text { I was } \\
\text { upset } \\
\text { I felt } \\
\text { embarrass } \\
\text { ed for the } \\
\text { nurse } \\
\text { manager, } \\
\text { it was } \\
\text { horrible } \\
\text { behavior, } \\
\text { terrible } \\
\text { behavior }\end{array}$ \\
\hline$\# 4$ & $\begin{array}{l}\text { Attitude } \\
\text { problem } \\
\text { Accepted } \\
\text { practice on } \\
\text { the unit } \\
\text { Floating } \\
\text { Patient } \\
\text { acuity } \\
\text { Patient } \\
\text { demands } \\
\text { Poor } \\
\text { communica } \\
\text { tion } \\
\text { Working } \\
\text { the night } \\
\text { shift } \\
\text { Culture of } \\
\text { the unit } \\
\text { Ordering } \\
\text { other } \\
\text { nurses } \\
\text { around } \\
\text { Too much } \\
\text { work }\end{array}$ & $\begin{array}{l}\text { Not helping } \\
\text { out } \\
\text { Pawn off } \\
\text { duties to } \\
\text { newer } \\
\text { nurses and } \\
\text { justify by } \\
\text { saying it's a } \\
\text { learning } \\
\text { experience } \\
\text { They are } \\
\text { aware of } \\
\text { how they } \\
\text { are acting }\end{array}$ & $\begin{array}{l}\text { As a new } \\
\text { nurse } \\
\text { Excessive } \\
\text { abuse of our } \\
\text { CNAs }\end{array}$ & $\begin{array}{l}\text { Same nurse } \\
\text { Managemen } \\
\mathrm{t} \\
\text { Nurse } \\
\text { manager }\end{array}$ & $\begin{array}{l}\text { Floor is } \\
\text { falling apart } \\
\text { because we } \\
\text { have no } \\
\text { manager in } \\
\text { place } \\
\text { I see } \\
\text { patients } \\
\text { suffering } \\
\text { because of } \\
\text { this type of } \\
\text { behavior } \\
\text { Affects } \\
\text { nurse and } \\
\text { job } \\
\text { performanc } \\
\text { e especially } \\
\text { when they } \\
\text { are going to } \\
\text { do their best } \\
\text { not to show } \\
\text { something } \\
\text { in front of } \\
\text { others } \\
\text { Increase } \\
\text { patient } \\
\text { suffering }\end{array}$ & $\begin{array}{l}\text { Confront } \\
\text { in the } \\
\text { moment } \\
\text { Attack the } \\
\text { problem } \\
\text { head on } \\
\text { No } \\
\text { tolerance } \\
\text { policies } \\
\text { are not } \\
\text { enforced } \\
\text { Accepted } \\
\text { practice } \\
\text { on the } \\
\text { unit - falls } \\
\text { under } \\
\text { "well } \\
\text { that's just } \\
\text { how that } \\
\text { person } \\
\text { usually is" }\end{array}$ \\
\hline$\# 5$ & $\begin{array}{l}\text { Low } \\
\text { staffing }\end{array}$ & $\begin{array}{l}\text { Not helping, } \\
\text { sitting }\end{array}$ & $\begin{array}{l}\text { As a new } \\
\text { nurse }\end{array}$ & $\begin{array}{l}\text { Nurse } \\
\text { manager }\end{array}$ & $\begin{array}{l}\text { Know who } \\
\text { you can }\end{array}$ & $\begin{array}{l}\text { Fear of } \\
\text { retaliation }\end{array}$ \\
\hline
\end{tabular}




\begin{tabular}{|c|c|c|c|c|c|c|}
\hline & $\begin{array}{l}\text { Stress } \\
\text { Accepted } \\
\text { practice on } \\
\text { the unit, } \\
\text { culture of } \\
\text { the unit } \\
\text { Increased } \\
\text { responsibili } \\
\text { ty } \\
\text { Nice one } \\
\text { day, mean } \\
\text { the next } \\
\text { Too many } \\
\text { tasks, } \\
\text { increased } \\
\text { responsibili } \\
\text { ty }\end{array}$ & $\begin{array}{l}\text { around } \\
\text { Angry, } \\
\text { pushing you } \\
\text { around }\end{array}$ & CNAs & $\begin{array}{l}\text { Physician } \\
\text { Same nurses } \\
\text { who do it all } \\
\text { the time }\end{array}$ & $\begin{array}{l}\text { count on } \\
\text { and who } \\
\text { you can't } \\
\text { Patient's } \\
\text { and family } \\
\text { get angry } \\
\text { and it's the } \\
\text { patients in } \\
\text { the end who } \\
\text { suffer } \\
\text { Patient's see } \\
\text { the RNs } \\
\text { frustration } \\
\text { It's the } \\
\text { patients in } \\
\text { the end who } \\
\text { suffer for it }\end{array}$ & $\begin{array}{l}\text { Makes me } \\
\text { angry, } \\
\text { frustrated } \\
\text { Did not } \\
\text { confront } \\
\text { I find } \\
\text { people I } \\
\text { can work } \\
\text { with, you } \\
\text { know who } \\
\text { you can } \\
\text { count on } \\
\text { and who } \\
\text { you can't } \\
\text { Nurses } \\
\text { would be } \\
\text { in tears } \\
\text { I am not a } \\
\text { confronta } \\
\text { tional } \\
\text { person so } \\
\text { if anyone } \\
\text { confronts } \\
\text { me, I'll } \\
\text { back off }\end{array}$ \\
\hline \#6 & $\begin{array}{l}\text { Personal } \\
\text { stressors } \\
\text { Accepted } \\
\text { practice on } \\
\text { the unit } \\
\text { Stress } \\
\text { Acuity } \\
\text { New nurses } \\
\text { and } \\
\text { seasoned } \\
\text { nurses } \\
\text { working } \\
\text { together } \\
\text { Poor } \\
\text { communica } \\
\text { tion }\end{array}$ & $\begin{array}{l}\text { Attitude, } \\
\text { yelling, } \\
\text { facial } \\
\text { expressions, } \\
\text { body } \\
\text { language } \\
\text { Didn't } \\
\text { realize they } \\
\text { came across } \\
\text { that way }\end{array}$ & $\begin{array}{l}\text { I think it } \\
\text { happens to } \\
\text { you as long } \\
\text { as you allow } \\
\text { it to } \\
\text { New nurse } \\
\text { Nurse being } \\
\text { oriented } \\
\text { Problems } \\
\text { with new } \\
\text { nurses } \\
\text { thinking that } \\
\text { they know it } \\
\text { all } \\
\text { Newer more } \\
\text { timid nurses }\end{array}$ & $\begin{array}{l}\text { Nurses } \\
\text { Nurse } \\
\text { managers } \\
\text { Physicians } \\
\text { OR techs }\end{array}$ & $\begin{array}{l}\text { More } \\
\text { experience, } \\
\text { able to } \\
\text { handle it } \\
\text { Nurse on } \\
\text { receiving } \\
\text { end may } \\
\text { feel that } \\
\text { they are } \\
\text { never going } \\
\text { to be able to } \\
\text { move on } \\
\text { and will not } \\
\text { want to stay } \\
\text { in the job } \\
\text { It can affect } \\
\text { job } \\
\text { performanc } \\
\text { e, someone } \\
\text { bit my head }\end{array}$ & $\begin{array}{l}\text { I step in } \\
\text { when it's } \\
\text { happening } \\
\text { in a room. } \\
\text { If it } \\
\text { happens } \\
\text { to me I } \\
\text { have to } \\
\text { take a } \\
\text { minute to } \\
\text { compose } \\
\text { myself } \\
\text { and then I } \\
\text { will go } \\
\text { talk to the } \\
\text { person } \\
\text { sometime } \\
\text { s they } \\
\text { deny it } \\
\text { sometime } \\
\text { s they } \\
\text { become }\end{array}$ \\
\hline
\end{tabular}




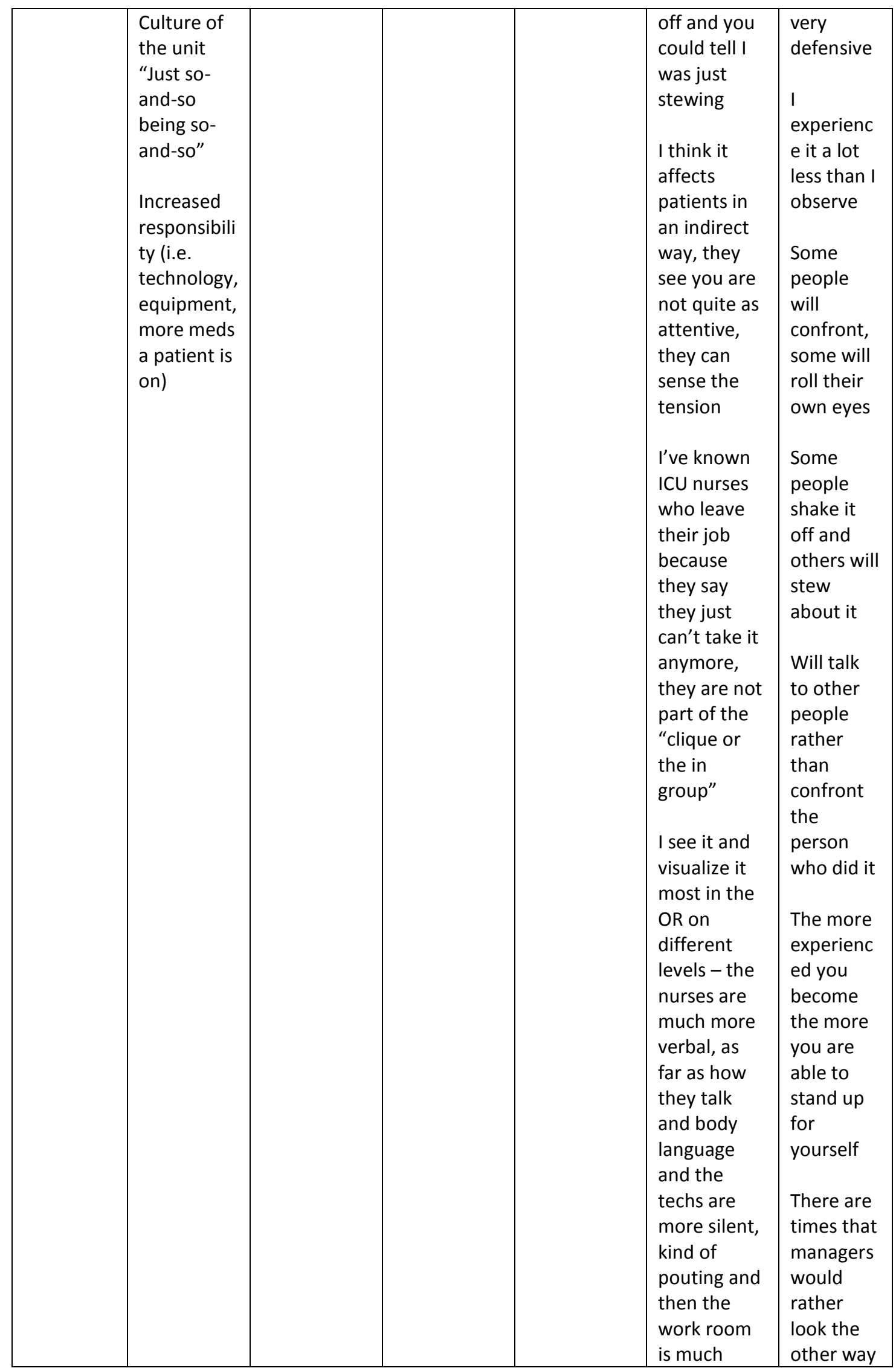




\begin{tabular}{|c|c|c|c|c|c|c|}
\hline & & & & & $\begin{array}{l}\text { more } \\
\text { emotional. } \\
\text { They yell, } \\
\text { they cry - } \\
\text { It's a } \\
\text { trickledown } \\
\text { effect } \\
\text { The feel } \\
\text { they are } \\
\text { never going } \\
\text { to move } \\
\text { forward, } \\
\text { you can't } \\
\text { intimidate } \\
\text { them cause } \\
\text { then they'll } \\
\text { want to } \\
\text { leave }\end{array}$ & $\begin{array}{l}\text { because if } \\
\text { he bully is } \\
\text { bullying } \\
\text { another } \\
\text { nurse, } \\
\text { they will } \\
\text { bully } \\
\text { them also }\end{array}$ \\
\hline \#7 & $\begin{array}{l}\begin{array}{l}\text { Generation } \\
\text { al } \\
\text { differences }\end{array} \\
\text { Stress } \\
\text { Too many } \\
\text { tasks not } \\
\text { enough } \\
\text { time } \\
\text { Short } \\
\text { staffing } \\
\text { Acuity } \\
\text { Results of } \\
\text { how a } \\
\text { person } \\
\text { reacts to } \\
\text { conflict } \\
\text { Personality } \\
\text { Outside } \\
\text { stressors } \\
\text { Floating }\end{array}$ & $\begin{array}{l}\text { Snapping at } \\
\text { each other } \\
\text { Yelling } \\
\text { Eye rolling, } \\
\text { making } \\
\text { faces, } \\
\text { disrespectfu } \\
\text { I behavior } \\
\text { Actions are } \\
\text { more subtle } \\
\text { between } \\
\text { nurses it's } \\
\text { more like } \\
\text { well } \\
\text { someone } \\
\text { didn't do } \\
\text { such and } \\
\text { such and } \\
\text { now I have } \\
\text { to fix it }\end{array}$ & $\begin{array}{l}\text { New nurses, } \\
\text { nurses eat } \\
\text { their young } \\
\text { we are not } \\
\text { kind to each } \\
\text { other }\end{array}$ & $\begin{array}{l}\text { Nurses } \\
\text { Physicians }\end{array}$ & $\begin{array}{l}\text { Knew } \\
\text { someone } \\
\text { who left the } \\
\text { job because } \\
\text { of it } \\
\text { It does } \\
\text { affect } \\
\text { patients } \\
\text { because } \\
\text { sometimes } \\
\text { you get } \\
\text { yelled at } \\
\text { and you feel } \\
\text { bad and the } \\
\text { patient can } \\
\text { sense that, } \\
\text { it comes } \\
\text { right } \\
\text { through }\end{array}$ & $\begin{array}{l}\text { Not worth } \\
\text { it to } \\
\text { address it } \\
\text { Stand } \\
\text { there, be } \\
\text { silent, } \\
\text { walk away } \\
\text { (this } \\
\text { sometime } \\
\text { s prompts } \\
\text { more } \\
\text { abuse) } \\
\text { Walk off } \\
\text { the job } \\
\text { Person } \\
\text { would } \\
\text { cower } \\
\text { As you get } \\
\text { older you } \\
\text { learn that } \\
\text { people } \\
\text { are not } \\
\text { always } \\
\text { attacking } \\
\text { you } \\
\text { personally } \\
\text { it comes } \\
\text { from } \\
\text { other }\end{array}$ \\
\hline
\end{tabular}




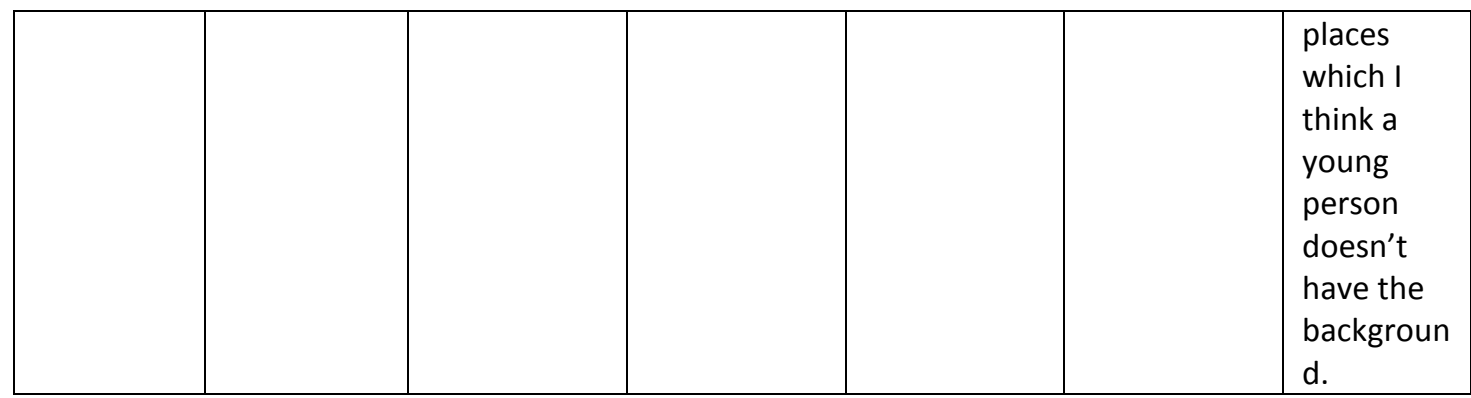




\section{APPENDIX K}

Stage Four of Analysis

\begin{tabular}{|c|c|c|c|c|c|}
\hline Who & When & $\begin{array}{c}\text { Characteristic } \\
\mathrm{s} \\
\end{array}$ & Causes & $\begin{array}{c}\text { Consequence } \\
\mathrm{s} \\
\end{array}$ & $\begin{array}{c}\text { Response } \\
\mathrm{s} \\
\end{array}$ \\
\hline $\begin{array}{l}\text { Younger } \\
\text { nurses were } \\
\text { the } \\
\text { perpetrator } \\
\text { s- } \\
\text { interview } \\
\# 1\end{array}$ & $\begin{array}{l}\text { As a new } \\
\text { nurse - } \\
\text { intervie } \\
\text { ws \#1, } \\
\# 2, \# 3 \text {, } \\
\# 4, \# 5 \text {, } \\
\# 6, \# 7\end{array}$ & $\begin{array}{l}\text { Avoid - } \\
\text { interview \#1 }\end{array}$ & $\begin{array}{l}\text { Older } \\
\text { nurses and } \\
\text { younger } \\
\text { nurses } \\
\text { working } \\
\text { together - } \\
\text { interviews } \\
\# 1, \# 2, \# 6 \text {, } \\
\# 7\end{array}$ & $\begin{array}{l}\text { Yes, affects } \\
\text { patients - } \\
\text { interviews \#1, } \\
\# 2, \# 3, \# 4, \# 5 \text {, } \\
\# 6, \# 7\end{array}$ & $\begin{array}{l}\text { You learn } \\
\text { who to go } \\
\text { to for help } \\
\text { - } \\
\text { interview } \\
\# 1 \text {, \#5 }\end{array}$ \\
\hline $\begin{array}{l}\text { Physician - } \\
\text { interviews } \\
\# 1, \# 2, \# 5 \text {, } \\
\# 6, \# 7\end{array}$ & $\begin{array}{l}\text { Floating } \\
\text { to } \\
\text { another } \\
\text { unit - } \\
\text { intervie } \\
\text { ws \#1, } \\
\# 4 \text {, \#7 }\end{array}$ & $\begin{array}{l}\text { Ignore - } \\
\text { interview \#1 }\end{array}$ & $\begin{array}{l}\text { Floating - } \\
\text { interviews } \\
\# 1, \# 4, \# 7\end{array}$ & $\begin{array}{l}\text { Yes, affects } \\
\text { job } \\
\text { performance } \\
\text { - interviews } \\
\# 1, \# 2, \# 3, \# 4, \\
\# 5, \# 6, \# 7\end{array}$ & $\begin{array}{l}\text { Did not } \\
\text { stop the } \\
\text { behavior } \\
\text { when } \\
\text { happening } \\
\text { to me - } \\
\text { interviews } \\
\# 1, \# 2 \text {, \#3, } \\
\# 5, \# 7\end{array}$ \\
\hline $\begin{array}{l}\text { Physician } \\
\text { Assistant - } \\
\text { interview } \\
\# 1\end{array}$ & $\begin{array}{l}\text { During } \\
\text { orienta- } \\
\text { tion } \\
\text { intervie } \\
\text { ws \#1, } \\
\# 6 \text {, \#7 }\end{array}$ & $\begin{array}{l}\text { Certain facial } \\
\text { expressions / } \\
\text { body } \\
\text { language - } \\
\text { interviews \#1, } \\
\# 6, \# 7\end{array}$ & $\begin{array}{l}\text { Stress, } \\
\text { stressful } \\
\text { environme } \\
\text { nt } \\
\text { interviews } \\
\# 1, \# 2, \# 3 \text {, } \\
\# 4, \# 5, \# 6, \\
\# 7\end{array}$ & $\begin{array}{l}\text { Patient's } \\
\text { know what's } \\
\text { going on - } \\
\text { interviews \#1, } \\
\# 2, \# 5, \# 6, \# 7\end{array}$ & $\begin{array}{l}\text { Cried, } \\
\text { became } \\
\text { upset - } \\
\text { interviews } \\
\# 1, \# 2, \# 3 \text {, } \\
\# 5, \# 7\end{array}$ \\
\hline $\begin{array}{l}\text { Nurse } \\
\text { Manager - } \\
\text { interviews } \\
\# 2 \text {, \#3, \#4, } \\
\# 5, \# 6\end{array}$ & $\begin{array}{l}\text { Happens } \\
\text { behind } \\
\text { the } \\
\text { scenes - } \\
\text { intervie } \\
\text { w \#3 }\end{array}$ & $\begin{array}{l}\text { Yelling, } \\
\text { screaming - } \\
\text { interviews \#1, } \\
\# 3, \# 6, \# 7\end{array}$ & $\begin{array}{l}\text { High } \\
\text { Patient } \\
\text { acuity - } \\
\text { interviews } \\
\# 1, \# 3 \text {, \#4, } \\
\# 6 \text {, \#7 }\end{array}$ & $\begin{array}{l}\text { Leaving } \\
\text { job/knew } \\
\text { someone who } \\
\text { left job - } \\
\text { interviews \#2, } \\
\# 6, \# 7\end{array}$ & $\begin{array}{l}\text { Step in } \\
\text { when it is } \\
\text { happen- } \\
\text { ing to } \\
\text { others - } \\
\text { interviews } \\
\# 1, \# 2 \text {, \#6 }\end{array}$ \\
\hline $\begin{array}{l}\text { Fellow } \\
\text { nurse - } \\
\text { interviews } \\
\# 1, \# 2 \text {, \#3, } \\
\# 4, \# 5 \text {, \#6, }\end{array}$ & & $\begin{array}{l}\text { They snap at } \\
\text { you - } \\
\text { interviews \#1, } \\
\# 3, \# 7\end{array}$ & $\begin{array}{l}\text { Increase } \\
\text { responsibili } \\
\text { ty } \\
\text { interviews } \\
\# 1, \# 4, \# 5 \text {, }\end{array}$ & $\begin{array}{l}\text { Patients } \\
\text { suffer - } \\
\text { interviews \#1, } \\
\# 4 \text {, \#5 }\end{array}$ & $\begin{array}{l}\text { Address } \\
\text { the } \\
\text { behavior } \\
\text { in the } \\
\text { moment }\end{array}$ \\
\hline
\end{tabular}




\begin{tabular}{|c|c|c|c|c|}
\hline$\# 7$ & & \#6, \#7 & & $\begin{array}{l}\text { (when } \\
\text { happen- } \\
\text { Ing to me } \\
\text { interviews } \\
\# 2, \# 4, \# 6\end{array}$ \\
\hline \multirow[t]{5}{*}{$\begin{array}{l}\text { Preceptor - } \\
\text { interviews } \\
\# 1, \# 7\end{array}$} & $\begin{array}{l}\text { Not helping } \\
\text { out - } \\
\text { interviews \#1, } \\
\# 3 \text {, \#4, \#5 }\end{array}$ & $\begin{array}{l}\text { Culture of } \\
\text { the unit / } \\
\text { accepted } \\
\text { practice - } \\
\text { interviews } \\
\# 1, \text {, \#2, \#4, } \\
\# 5, \# 6\end{array}$ & $\begin{array}{l}\text { Afraid to ask } \\
\text { questions, } \\
\text { make } \\
\text { decisions, } \\
\text { affected } \\
\text { developing as } \\
\text { a nurse - } \\
\text { interviews \#2, } \\
\# 4\end{array}$ & $\begin{array}{l}\text { Didn't } \\
\text { report } \\
\text { episode } \\
\text { for fear of } \\
\text { retaliation } \\
\text { interviews } \\
\# 3 \text {, \#5 }\end{array}$ \\
\hline & $\begin{array}{l}\text { Silent abuse } \\
\text { interview \#1 }\end{array}$ & $\begin{array}{l}\text { Long hours } \\
\text { / being } \\
\text { tired } \\
\text { interviews } \\
\# 1 \text {, \#4, \#7 }\end{array}$ & $\begin{array}{l}\text { Patient's } \\
\text { family gets } \\
\text { angry } \\
\text { interview \#5 }\end{array}$ & $\begin{array}{l}\text { Felt } \\
\text { embarrass } \\
\text { ed for the } \\
\text { perpetrat } \\
\text { or - } \\
\text { interview } \\
\# 3\end{array}$ \\
\hline & $\begin{array}{l}\text { Not always } \\
\text { aware of how } \\
\text { they are } \\
\text { acting - } \\
\text { interviews \#1, } \\
\# 2 \text {, \#6 }\end{array}$ & $\begin{array}{l}\text { Personal } \\
\text { issues / } \\
\text { personality } \\
\text { - } \\
\text { interviews } \\
\# 1, \# 2, \# 4, \\
\# 5, \# 6, \# \&\end{array}$ & & $\begin{array}{l}\text { Backing } \\
\text { off - } \\
\text { interviews } \\
\# 5, \# 7\end{array}$ \\
\hline & $\begin{array}{l}\text { Disrespectful } \\
\text { communica- } \\
\text { tion - } \\
\text { interviews \#1, } \\
\# 2, \# 3, \# 4, \# 5 \text {, } \\
\# 6, \# 7\end{array}$ & $\begin{array}{l}\text { Poor } \\
\text { communic } \\
\text { a-tion - } \\
\text { interviews } \\
\# 2, \# 4\end{array}$ & & $\begin{array}{l}\text { The more } \\
\text { experienc } \\
\text { e you are } \\
\text { the better } \\
\text { able you } \\
\text { are to } \\
\text { handle it } \\
\text { interviews } \\
\# 2, \# 6, \# 7\end{array}$ \\
\hline & $\begin{array}{l}\text { Pawn off } \\
\text { duties to } \\
\text { newer nurses } \\
\text { interviews \#1, } \\
\# 4\end{array}$ & $\begin{array}{l}\text { Short } \\
\text { staffing } \\
\text { interviews } \\
\# 3, \# 5, \# 7\end{array}$ & & $\begin{array}{l}\text { Silence / } \\
\text { walked } \\
\text { away } \\
\text { interviews } \\
\# 1, \# 5 \text {, } \\
\# 6, \# 7\end{array}$ \\
\hline
\end{tabular}




\begin{tabular}{|l|l|l|l|l|l|}
\hline & $\begin{array}{l}\text { Angry, } \\
\text { pushing you } \\
\text { around - } \\
\text { interviews \#5, } \\
\# 6, \# 7\end{array}$ & & & \\
\hline & $\begin{array}{l}\text { Subtle } \\
\text { behaviors - } \\
\text { interview \#7 }\end{array}$ & & & \\
\hline
\end{tabular}




\section{BIBLIOGRAPHY}

Aiken, L., Clarke, S., Sloane, D., Sochaliski, J., Busse, R., Clarke, H., \& Shamian, J. (2001). Nurses' report on hospital care in five countries. Health Affairs, $20(3), 43-53$

Almost, J. (2006). Conflict within nursing work environments: Concept analysis. Journal of Advanced Nursing, 53(4), 444-453.

Alspach, G. (2007). Critical care nurses as coworkers: Are our intentions nice or nasty? Critical Care Nurse, 27(3), 10-14.

Anderson, L.L. (2011). Communication in nursing. Retrieved May 18, 2012 from: http://nursetogether.com/Career/Career-Article/itemid/906/ Communication-in-nursing,aspx

Bally, J.M (2007). The role of nursing leadership in creating a mentoring culture in acute care environments. Nursing Economics, 25(3), 143-148.

Baltimore, J.J. (2006). Nurse collegiality: Fact or fiction. Nursing Management, 37(5), 28-36.

Bartholomew, K. (2006). Ending Nurse-to-Nurse Hostility: Why Nurses Eat Their Young and Each Other. Marblehead, MA: HCPro inc.

Becher, J. \& Visovsky, C. (2012). Horizontal violence in nursing. Medsurg Nursing, 21(4), 210-213.

Bigony, L., Lipke, T., Lundberg, A., McGraw, C.A., Pagac, G.L. \& Rogers, A. (2009). Lateral violence in the perioperative setting. AORN Journal, 89(4), 688-696.

Bitsch, V. (2005). Qualitative research: A grounded theory example and evaluation. 
Journal of Argibusiness, 23(1), 75-91.

Blumer, H. (1969). Symbolic interactionism: Perspective and method. Prentice-Hall: Englewood Cliffs, NJ.

Bowles, C. \& Candela, L. (2005). First job experiences of recent RN graduates. Journal Of Nursing Administration, 35(3), 130-137.

Budin, W.C., Brewer, C.S., Chao, Y.Y., \& Kovner, C. (2013). Verbal abuse from nurse colleagues and work environment of early career registered nurses. Journal of Nursing Scholarship, 45(3), 308-316.

Center for American Nurses. (2008). Bullying and lateral violence in the workplace. Retrieved January 21, 2010 from: http://centerforamericannurses.org/ associations/9102/files/Position\%20StatementLateral\%20Violence\%20and Bullying.pdf

Chipps, E.M., \& McRury, M. (2012). The development of an educational intervention to address workplace bullying. Journal for Nurses in Staff Development, 28(3), 94-98.

Corbin, J. \& Morse, J.M. (2003). The unstructured interactive interview: Issues of reciprocity and risks when dealing with sensitive topics. Qualitative Inquiry, 9(3), 335-354.

Corney, B. (2008). Aggression in the workplace - A study of horizontal violence utilizing Heideggerian hermeneutic phenomenology. Journal of Health Organization and Management, 22(2), 164-177.

Cox, H.C. (1987). Verbal abuse in nursing: Report of a study. Nursing Management, 
18(11), 47-50.

Cox, K. (2001). The effects of unit morale and interpersonal relations on conflict in the nursing unit. Journal of Advanced Nursing, 35(1), 17-25.

Craig, C. (2008). Horizontal hostility: Another Look. Oklahoma Nurse

Croft, R.K. \& Cash, P.A. (2012). Deconstructing contributing factors to bullying and lateral violence in nursing using a postcolonial feminist lens. Contemporary Nurse, 42(2), 226-242.

Curtis, J., Bowen, I., \& Reid, A. (2007). You have no credibility: Nursing students' experiences of horizontal violence. Nurse Education in Practice, 7(3), 156-163.

Dehue, F., Bolman, C., Vollink, T., \& Pouwelse, M. (2012). Coping with bullying at work and health related problems. International Journal of Stress Management, 19(3), 175-197.

Dellasega, C. (2009). Bullying among nurses. American Journal of Nursing, 109(1), $52-58$

Dendas, N. (2004). The scholarship related to nursing work environments: Where do we go from here? Advances in Nursing Science, 27(1), 12-20.

DeMarco, R., \& Roberts, S. (2003). Negative behaviors in nursing. The American Journal of Nursing, 103(3), 113-116.

Dimarino, T.J. (2011). Eliminating lateral violence in the ambulatory setting: One center's strategies. AORN J. 93(5), 583-588.

Ditmer, D. (2010). A safe environment for nurses and patients: Halting horizontal violence. Journal of Nursing Regulation, 1(3), 9-14. 
Duffy, E. (1995). Horizontal violence: A conundrum for nursing. Collegian, 2(2), 5-17.

Dunn, H. (2003). Horizontal violence among nurses in the operating room. AORN J. 78(6), 977-988.

Edwards, S.L. \& O’Connell, C.F. (2007). Exploring bullying: implications for nurse educators. Nurse Education in Practice, 7(1), 26-35.

Embree, J.L. \& White, A.H. (2010). Concept analysis: Nurse-to-nurse lateral violence. Nursing Forum, 45(3), 166-173.

Farrell, G.A. (1997). Aggression in clinical settings: Nurses' views. Journal of Advanced Nursing, 25(3), 501-508.

Farrell, G.A. (1999). Aggression in clinical settings: Nurses' views - A follow up study. Journal of Advanced Nursing, 29(2), 532-541.

Farrell, G.A. (2001). From tall poppies to squashed weeds: Why don't nurses pull together more? Journal of Advanced Nursing, 35(1), 26-33.

Farrell, G.A., Bobrowski, C., \& Bobrowski, P. (2006). Scoping workplace aggression in nursing: Findings from an Australian study. Journal of Advanced Nursing, 55(6) 778-787.

Finlayson, J.G. (2004). Habermas: A very short introduction. Oxford University Press. Fletcher, K. (2006). Beyond dualism: leading out of oppression. Nursing Forum, 42(2), 50-59.

Freire, P. (1968). Pedagogy of the Oppressed. New York: Seabury Press.

Freshwater, D. (2000). Crosscurrents: against cultural narration in nursing. Journal of 
Advanced Nursing, 32(2), 481-484.

Gaddis, S. (2006). The power of positive nursing. Alabama Nurse, 33(4), 22.

Gerardi, D. (2004). Using mediation techniques to manage conflict and create healthy work environments. AACN Clinical Issues: Advanced Practice in Acute and Critical Care, 15(2), 182-195.

Griffin, M. (2004). Teaching cognitive rehearsal as a shield for lateral violence: An intervention for newly licensed nurses. The Journal of Continuing Education in Nursing, 25(6), 257-263.

Hastie, C. (2007). Horizontal violence in the workplace. Retrieved November 14, 2007. From: http:/www.birthinternational.com/articles/hastie02.html Healthcare Risk Control Supplement A: Disruptive practitioner behavior. ERCI: March 2009. Retrieved October 15, 2013 from: https:/www.ecri.org/Documents/PSA/May_2009/Disruptive-practitioner_ behavior.pdf

Holmes, C. (2006). Violence, zero tolerance and the subversion of professional practice. Contemporary Nurse, 21(2), 212-227.

Hughes, A. (2003). Being bullied what an insight. British Journal of Perioperative Nursing, 13(4), 166-168, 171.

Hutchinson, M. (2009). Restorative approaches to workplace bullying: educating nurses towards shared responsibility. Contemporary Nurse, 32(1-2), 147-155. Hutchinson, M., Jackson, D., Vickers, M., \& Wilkes, L. (2006). They stand you in a corner; you are not to speak: nurses tell of abusive indoctrination in work 
teams dominated by bullies. Contemporary Nurse, 21(2), 228-238.

Hutchinson, M., Jackson, D., Vickers, M., \& Wilkes, L. (2008). The development and validation of a bullying inventory for the nursing workplace. Nursing Researcher,15(2), 19-29.

Hutchinson, M., Wilson, M.E., \& Wilson, H.S. (1994). Benefits of participating in research interviews. Image: The Journal of Nursing Scholarship, 26(2), $161-164$

Hutchinson, M., Vickers, M., Jackson, D., \& Wilkes, L. (2006). Workplace bullying in nursing: Towards a more critical organizational perspective. Nursing Inquiry, 13(2), 118-126.

Hutchinson, M., Vickers, M., Jackson, D., \& Wilkes, L. (2005). “I’m gonna do what I wanna do." Organizational change as a legitimized vehicle for bullies. Health Care Management Review, 30(4), 331-336.

Hutchinson, M., Vickers, M., Wilkes, L., \& Jackson, D. (2010). A typology of bullying behaviors: The experience of Australian nurses. Journal of Clinical Nursing, 19, 2319-2328.

Jackson, D., Clare, J., \& Mannix, J. (2002). Would you want to be a nurse? Violence in The workplace - a factor in recruitment and retention. Journal of Nursing Management, 10(1), 13-20.

Jackson, D., Firtko, A., \& Edenborough, M. (2007). Personal resilience as a strategy for surviving and thriving in the face of workplace adversity: A literature review. Journal of Advanced Nursing, 60(1), 1-9. 
Johnson, S.L., \& Rea, R.E. (2009). Workplace bullying: Concerns for nurse leaders. The Journal of Nursing Administration, 39(2), 84-90.

Joint Commission (2008, July). Sentinel Event Alert. Behaviors that undermine a Culture of safety. Retrieved September 6, 2008 from:

http://www.jointcommission.org/org/SentinelEvents/SentinelEventAlert/Sea -40.htm

Jones, C.B. (2005). The costs of nursing turnover, part 2: Application of the nursing turnover cost calculation methodology. Journal of Nursing Administration, 35(1), 41-49.

Kim, H.S. (2010). The nature of theoretical thinking in nursing. $\left(3^{\text {rd }}\right.$ ed.). Springer Publishing Company: New York.

Kupperschmidt, B., Kientz, E., Ward, J., \& Reinholz, B. (2010). A health work environment: It begins with you. The Online Journal of Issues in Nursing 15(1), 1-10.

Lambert, V.A., Lambert, C.E., \& Ito, M. (2004). Workplace stressors, ways of coping and demographic characteristics as predictors of physical and mental health of Japanese hospital nurses. International Journal of Nursing Studies, 41, 85-97.

Laschinger, H.K.S., Grau, A.L., Finegan, J., \& Wilk, P. (2010). New graduate nurses' experiences of bullying and burnout in hospital settings. Journal of Advanced Nursing, 66(12), 2732-2742. 
Laschinger, H.K.S., Leiter, M.P., Day, A., \& Gilin, D. (2009b). Workplace

empowerment, Incivility, and burnout: Impact on staff nurse recruitment and retention outcomes. Journal of Nursing Management, 17(3), 302-311.

Lee, M.B., \& Saeed, I. (2001). Oppression and horizontal violence: The case of nurses in Pakistan. Nursing Forum, 36(1), 15-24.

Lewis, L.A. (2006). Nurse bullying: Organizational considerations in the maintenance and perpetration of health care bullying cultures. Journal of Nursing Management, 14(1), 52-58.

Longo, J., \& Sherman, R. (2007). Leveling horizontal violence. Nursing Management, $38(3), 34-37,50-51$.

Longo, J., \& Smith, M.C. (2011). A prescription for disruptions in care: community building among nurses to address horizontal violence. Advances in Nursing Science, 34(4), 345-356.

Maddelena, V., Kearney, S., \& Adams, L. (2012). Quality of work life of novice nurses. Journal for Nurses in Staff Development, 28(2), 74-94.

Martin, W. (2008). Is your hospital safe? Disruptive behavior and workplace bullying. Hospital Topics, 86(3), 21-28.

McKenna, B.G., Smith, N.A., Poole, S.J., \& Coverdale, J.H. (2003). Horizontal violence: experiences of registered nurses in their first year of practice. Journal of Advanced Nursing, 42(1), 90-96.

McAllister, M., \& Lowe, J.B. (2011). The resilient nurse: Empowering your practice. Springer/New York. 
McNamara, S.A. (2010). Workplace violence and its effects on patient safety. AORN J, 92(6), 677-682.

McNamara, S.A. (2012). Incivility in nursing: unsafe nurse, unsafe patients. AORN J, 95(4), 535-540.

Mendez, T.M. (2011). Horizontal violence in nursing work environment: Beyond oppressed group behavior. University of New Orleans Theses and Dissertations. Paper 1377.

Morrow, S. (2008). New graduate transition: Leaving the nest, joining the flight. Journal of Nursing Management, 17(3), 278-287.

Moye, M. (2010). Nursing Hostility: What is causing horizontal violence between nurses and what steps can individuals take to bring it to an end? Retrieved September, 62011 from: http://nursing.advanceweb.com/Features/Articles2/Nursing-Hostility.aspx

Nabb, D. (2000). Visitors' violence: the serious effects of aggression on nurses and others. Nursing Standard, 14(23), 36-38.

O'Connell, B., Young, J., Brooks, J., Hutchings, J., \& Lofthouse, J. (2000). Nurses' perceptions of the nature and frequency of aggression in general ward settings and high dependency areas. Journal of clinical Nursing, 9(4), 602-610.

O’Brien-Pallas, L., Griffin, P., Shamian, J., Buchan, J., Diffield, C., Hughes, F., Spence-Laschinger, H.K., North, N., \& Stone, P.W. (2006). The impact of nurse turnover on patient, nurse, and system outcomes: A pilot study and focus for 
a multicenter international study. Policy Political Nurse Practice, 7(3), 169179.

Parse, R. (2010). Respect! Nursing Science Quarterly, 23(3), 193.

Patton, M.Q. (1987). Depth Interviewing. In P. Munhall (Ed.), Nursing research a qualitative perspective ( $4^{\text {th }}$ ed., pp.108-143). Boston, MA: Jones and Bartlett Publishers.

Polit, D.F., \& Beck, C.T. (2008). Nursing research: Generating and assessing evidence for nursing practice. ( $8^{\text {th }}$ ed.). Philadelphia: Lippincott, Williams \& Wilkins.

Porto, G., \& Lauve, R. (2006). Disruptive clinical behavior: A persistent threat to safety. Retrieved June 10, 2009 from: http://www.psqh.com/julaug06/disruptive.html

Privitera, R.M. (2010). Workplace violence in mental and general health settings. Jones \& Bartlett Publishers: Canada.

Purpora, C., \& Blegen, M.A. (2012). Horizontal violence and the quality and safety of patient care: A conceptual model. Nursing Research and Practice, Volume 2012, Article ID 306948, doi:10.1155/2012/306984

Quine, L. (2001). Workplace bullying in nurses. Journal of Health Psychology, 6(1), 73-84.

Randle, J. (2003). Bullying in the nursing profession. Journal of Advanced Nursing, 43(4), 395-401.

Ritzer, G. \& Goodman, D.J. (2003). Sociological Theory: $6^{\text {th }}$ Edition. McGraw-Hill, Boston,MA. 
Roberts, S.J. (1983). Oppressed group behavior: Implications for nursing. Advances in Nursing Science, 5(3), 21-30.

Roberts, S.J., DeMarco, R., \& Griffin, M. (2009). The effects of oppressed group behaviors on the culture of the nursing workplace: a review of the evidence and interventions for change. Journal of Nursing Management, 17(3), 288-293.

Rocker, C.F. (2008). Addressing nurse-to-nurse bullying to promote nurse retention. Online Journal of Issues in Nursing, 13(3). (11p)

Rosenstein, A., \& O’Daniel, M. (2005). Disruptive behavior and clinical outcomes: Perceptions of nurses and physicians. American Journal of Nursing, 105(1), 54-64.

Rosenstein, A., \& O’Daniel, M. (2006). Impact and implications of disruptive behavior in the peri-operative arena. Journal of American College of Surgeons, 203(1), 96-105.

Rowell, P. (2006). Being a "target" at work: Or William Tell and how the apple felt. Journal of Nursing Administration, 35(9), 377-379.

Rubin, H.J., \& Rubin, I.S. (2012). Qualitative interviewing: The art of hearing data. ( $3^{\text {rd }}$ ed.). Sage/Los Angeles.

Sellers, K., Millenbach, L., Kovach, N., \& Yingling, J.K. (2010). The prevalence of horizontal violence in New York State registered nurses. Journal of New York State Nurses Association, 40(2), 20-25.

Sheridan-Leos, N. (2008). Understanding lateral violence in nursing. Clinical Journal of 
Oncology Nursing, 12(3), 399-403.

Shader, K., Broome, M.E., Broome, C.D., West, M.E. \& Nash, M. (2001). Factors influencing satisfaction and anticipated turnover for nurses in an academic medical center. Journal of Nursing Administration, 31(4), 210-216.

Simons, S. (2008). Workplace bullying experienced by Massachusetts registered nurses and the relationship to intent to leave the organization. Advances in Nursing Science, 31(2), E48-E59.

Simons, S., \& Mawn, B. (2010). Bullying in the workplace - A qualitative study of newly licensed registered nurses. AOHN Journal, 58(305-311.

Smith, L.M., Andrusyszyn, M.A., \& Laschinger, H.K.S. (2010). Effects of workplace incivility and empowerment on newly-graduated nurses' organizational commitment. Journal of Nursing Management, 18(8), 1004-1015.

Sofield, L., \& Salmond, S. (2003). Workplace violence: A focus on verbal abuse and intent to leave the organization. Orthopaedic Nurses, 22(4), 274-283.

Speedy, S. (2006). Workplace violence: the dark side of organizational life. Contemporary Nurse, 21(2), 239-250.

Stagg, S.J., Sheridan, D., Jones, R.A., \& Speroni, K.G. (2011). Evaluation of a workplace bullying cognitive rehearsal program in a hospital setting. The Journal of Continuing Education in Nursing, 42(9), 395-401.

Stanley, K.M., Dulaney, P., \& Martin, M. (2007). Nurses' eating our young - It has a name: Lateral violence. The South Carolina Nurse, Jan-Mar.

Stanley, K.M., Martin, M.M., Michel, Y., Welton, J.M., \& Nemeth, L.S. (2007). 
Examining lateral violence in the nursing workforce. Issues in Mental Health Nursing, 28(11), 1247-1265.

Taylor, B. (2001). Identifying and transforming dysfunctional nurse-nurse relationships through reflective practice and action research. International Journal of Practice, 7, 406-413.

Thobaben, M. (2007). Horizontal workplace violence. Home Health Care Management and Practice, 20(1), 82-83.

Thomas, S.P. (2003). Horizontal hostility - nurses against themselves: How to resolve this threat to retention. American Journal of Nursing, 103(10), 87-88, 90-91.

Thomas, S.P. (2004). Transforming nurses' stress and anger: Steps towards healing. New York: Springer.

Thomas, S.P., \& Burke, R. (2009). Junior nursing students' experiences of vertical violence during clinical rotations. Nursing Outlook, 57, 226-231.

Thomas, C.M. (2010). Teaching nursing students and newly registered nurses strategies to deal with violent behaviors in the professional practice environment. The Journal of Continuing Education in Nursing, 41(7), 299-308.

Townsend, T. (2012). Break the bullying cycle. American Nurse Today, 7(1), 12-15.

Tunajek, S. (2007). Workplace incivility - Part 1: Anger, harassment, and horizontal violence. AANA NewsBulletin, 30-31.

Valentine, P. (1995). Management of conflict: do nurses/women handle it differently? Journal of Advanced Nursing, 22(1), 142-149.

Vessey, J.A., DeMarco, R.F., \& DiFazio, R. (2011). Bullying, harassment, and horizontal 
violence in the nursing workforce in The Workplace. Springer Publishing Company.

Vessey, J.A., DeMarco, R.F., Gaffney, D.A., \& Budin, W.C. (2009). Bullying of staff registered nurses in the workplace: A preliminary study for developing personal and organizational strategies for the transformation of hostile to

healthy workplace environments. Journal of Professional Nursing, 25(5), 299-306.

Vickers, M. (2006). Writing what's relevant: workplace incivility in public administration- A wolf in sheep's clothing. Administrative Theory \& Praxis, 28(1), 69-88.

Waldman, J. D., Kelly, F., Aurora, S., \& Smith, H.L. (2004). The shocking cost of turnover in health care. Health Care Management Review, 29(1), 2-7.

Walrafen, N., Brewer, K., \& Mulvenon, C. (2012). Sadly caught up in the moment: An exploration of horizontal violence. Nurse Economist, 30(1), 6-12.

Weinard, M.R. (2010). Horizontal violence in nursing: History, impact, and solution. JOCEPS: The Journal of Chi Eta Phi sorority, 55(1), 23-26.

Wilson-Thomas, L. (1995). Applying critical social theory in nursing education to bridge the gap between theory, research and practice. Journal of Advanced Nursing, 21(3), 568-575.

Wilson, B.L., Diedrich, A., Phelps, C.L. \& Choi, M. (2011). Bullies at work: The impact of horizontal hostility in the hospital setting and intent to leave. The Journal of Nursing Administration, 41(11), 453-458. 
Woelfe, C.Y., \& McCaffrey, R. (2007). Nurse on nurse. Nursing Forum, 42(3), 123-131.

Wolf, Z. R. (1987). Ethnography: the method. In P. Munhall (Ed.), Nursing research a Qualitative perspective ( $4^{\text {th }}$ ed., pp. 293-330). Boston, MA: Jones and Bartlett Publishers.

Yildirim, D. (2009). Bullying among nurses and its effects. International Nursing Review, 56(4), 504-511.

Young, S. (2011). Does nursing school facilitate lateral and horizontal violence? Tennesse Nurse, 74(3), 1, 4. 